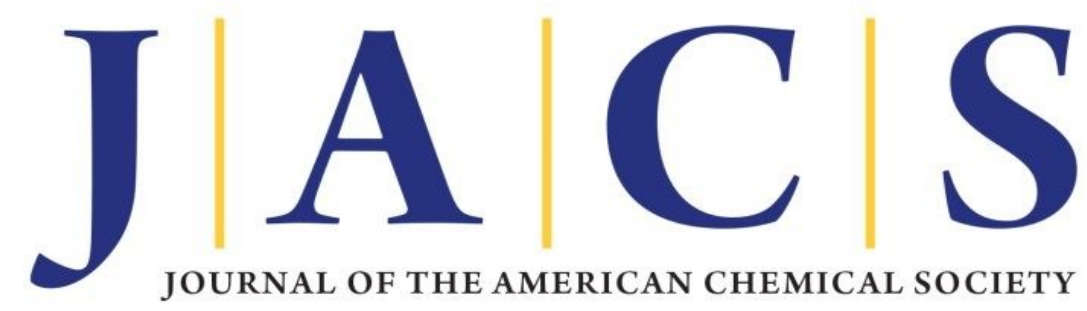

\title{
A Redox-Switchable Molecular Zipper
}

Melissa Dumartin, ${ }^{\dagger}$ Mark C. Lipke ${ }^{*}, \|$ and J. Fraser Stoddart ${ }^{*}, \dagger, \S,+$

'Department of Chemistry, Northwestern University, 2145 Sheridan Road, Evanston, Illinois 60208, United States

"Department of Chemistry and Chemical Biology, Rutgers, The State University of New Jersey, 610 Taylor Road, Piscataway, New Jersey 08854, United States

SInstitute of Molecular Design and Synthesis, Tianjin University, 92 Weijin Road, Nankai District, Tianjin, 300072, P. R. China

${ }^{7}$ School of Chemistry, University of New South Wales, Sydney, NSW 2052, Australia

*E-mail: stoddart@northwestern.edu $\quad *$ E-mail: ml1353@,chem.rutgers.edu

\section{Supporting Information}

Table of Contents

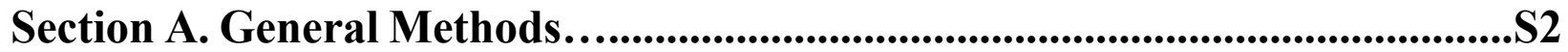

Section B. Synthetic Protocols...............................................S3

Section C. Crystallographic Characterization................................S16

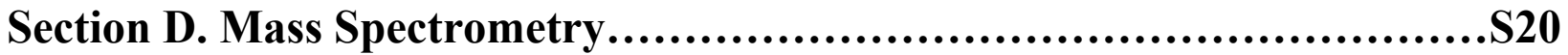

Section E. UV-Vis-NIR Absorption Spectroscopy..........................S21

Section F. NMR Spectroscopy............................................S23

Section G. Cyclic Voltammetry..............................................S34

Section H. References......................................................S40 


\section{Section A. General Methods}

The reagents were purchased from commercial suppliers (Sigma-Aldrich or TCI America) and used without further purification. Cyclobis(paraquat-p-biphenylene)tetrakis(hexafluorophosphate) ${ }^{1}$ (MS·4PF 6 ), 4,6-dibromo-m-xylene ${ }^{2}$ (1), 1-azido-3,5-bis(bromomethyl)benzene ${ }^{3}$ (5), 4-tris(4-tertbutylphenyl)phenol $^{4}$ (6) and 1,3-bis(bromomethyl)-5-(propargyloxy)benzene ${ }^{5}$ (11) were synthesized as described in the literature. Thin layer chromatography (TLC) was performed on silica gel 60 F254 (E. Merck), column chromatography was executed on silica gel 60F (Merck $9385,0.040-0.063 \mathrm{~mm}$ ) or by using an automatic companion of purification (Combiflash Rf200, Teledyne Isco) with pre-packed columns (silica and C-18) RediSep Rf. For all reactions using $\mathrm{MeCN}$, THF and $\mathrm{CH}_{2} \mathrm{Cl}_{2}$, the solvents were dried using solvent purification columns supplied by Pure Process Technologies. Anhydrous DMF was purchased from Sigma-Aldrich. Deuterated solvents $\left(\mathrm{CD}_{3} \mathrm{CN}, \mathrm{CDCl}_{3}\right.$ and $\left.\mathrm{CD}_{3} \mathrm{COCD}_{3}\right)$ were purchased from Cambridge Isotopes. Routine nuclear magnetic resonance (NMR) spectra were recorded at $298 \mathrm{~K}$ on Bruker Avance 600 or 500 spectrometers, with working frequencies of 600 or $500 \mathrm{MHz}$ for ${ }^{1} \mathrm{H}$ nuclei and 150 or $125 \mathrm{MHz}$ for ${ }^{13} \mathrm{C}$ nuclei, respectively. Chemical shifts are reported in ppm relative to the signals corresponding to the residual non-deuterated solvents $\left(\mathrm{CDCl}_{3}: \delta=7.26 \mathrm{ppm}, \mathrm{CD}_{3} \mathrm{CN}: \delta=1.94\right.$ ppm, $\left.\mathrm{CD}_{3} \mathrm{COCD}_{3}: \delta=2.05 \mathrm{ppm}\right)$. Variable temperature ${ }^{1} \mathrm{H}$ NMR spectra were recorded using a Bruker Avance III $600 \mathrm{MHz}$ spectrometer. Diffusion ordered NMR spectrum (DOSY) was recorded using an Agilent DD2 spectrometer with a $600 \mathrm{MHz}$ working frequency for ${ }^{1} \mathrm{H}$ nuclei. High resolution mass spectra (HRMS) were measured on an Agilent 6210 Time of Flight (TOF) Liquid Chromatography-Mass Spectrometry (LC-MS), employing an ElectroSpray Ionization (ESI) source, coupled with an Agilent 1100 HPLC stack using direct infusion $(0.6 \mathrm{~mL} / \mathrm{min})$. All 
UV-Vis-NIR spectra were recorded using a Shimadzu UV-3600 spectrophotometer. A Gamry Reference 600 potentiostat was used to record cyclic voltammograms (CVs) with a glassy carbon working electrode, platinum coil counter electrode, an $\mathrm{AgNO}_{3} / \mathrm{Ag}$ reference electrode, and potentials were referenced to the $\mathrm{Fc} / \mathrm{Fc}^{+}$redox couple of an internal ferrocene standard. Simulation and fitting of $\mathrm{CV}$ data was carried out using $\mathrm{CH}$ Instruments $\mathrm{CHI} 630 \mathrm{E}$ software.

\section{Section B. Synthetic Protocols}

1. Synthesis of the derivative of the meta-CBPQT Box $\left(\boldsymbol{m}-\mathbf{N}_{3}-\mathbf{A r}_{2}-\mathbf{C B P Q T} \cdot 4 \mathrm{PF}_{6}\right)$
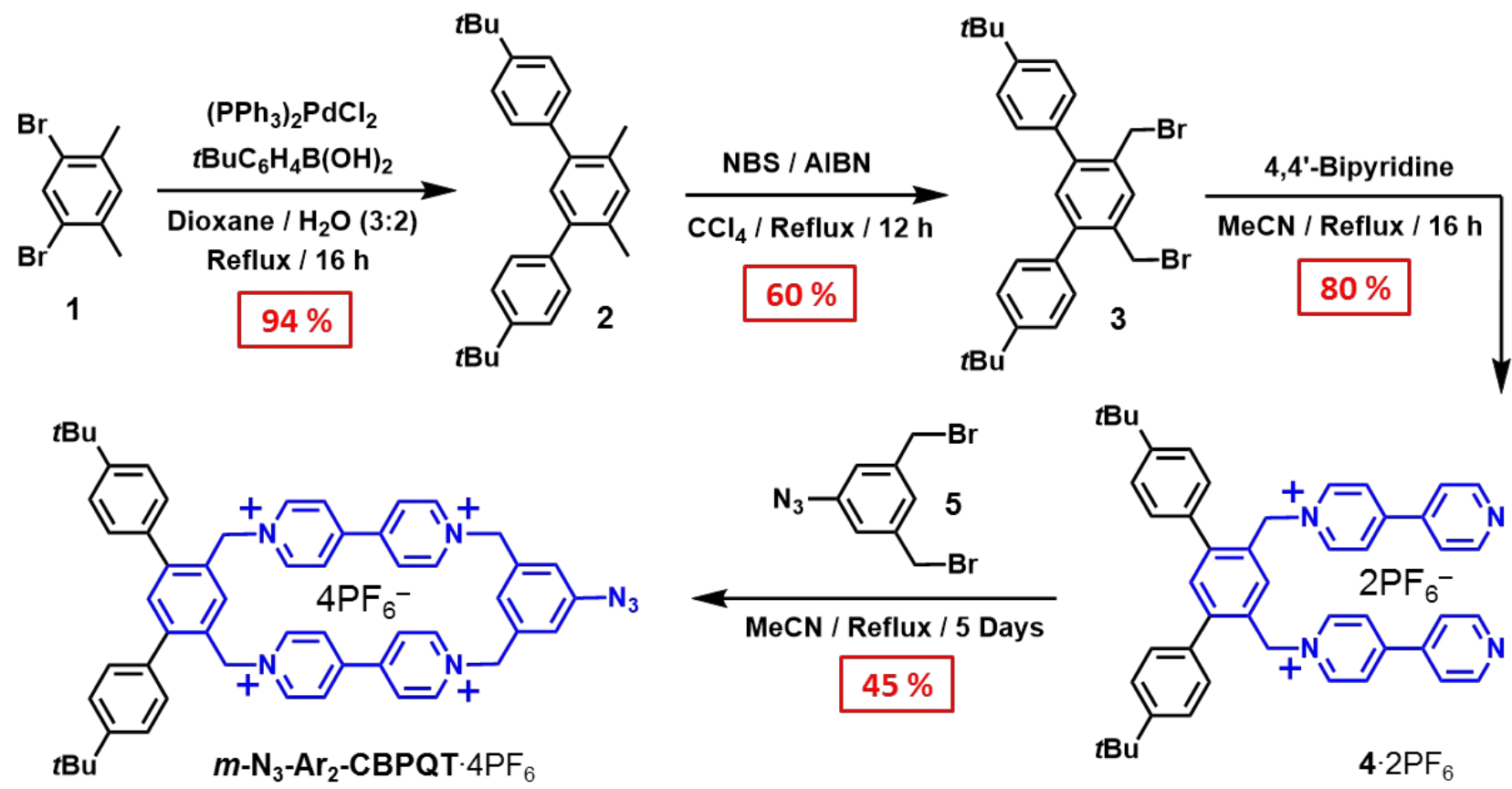

Scheme S1. Synthesis of the $\boldsymbol{m}-\mathbf{N}_{3}-\mathrm{Ar}_{2}-\mathrm{CBPQT} \cdot 4 \mathrm{PF}_{6}$ derivative. 


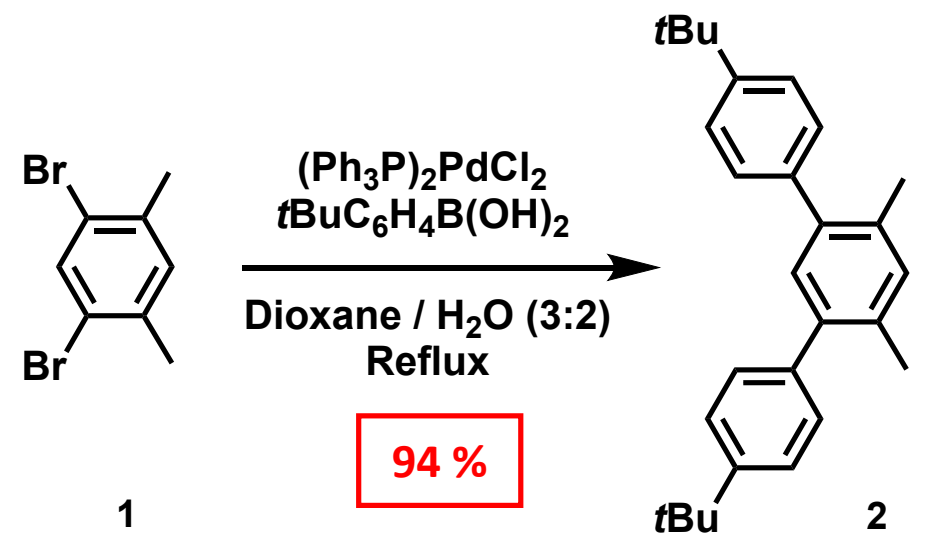

a) 4,6-Dibromo-m-xylene (1) (19.5 mmol, $5.15 \mathrm{~g})$, 4-tert-butylphenylboronic acid (10.11 g, 56.8 mmol), bis(triphenylphosphine)palladium(II) dichloride $(0.660 \mathrm{~g}, 0.94 \mathrm{mmol})$ and $\mathrm{K}_{2} \mathrm{CO}_{3}(8 \mathrm{~g}$, $57.9 \mathrm{mmol}$ ) were introduced in a round-bottomed flask and dissolved in a mixture of 1,4-dioxane (150 mL) and $\mathrm{H}_{2} \mathrm{O}(100 \mathrm{~mL})$ that had been sparged for $\geq 20$ min with $\mathrm{N}_{2}$. The reaction mixture was heated under reflux overnight in a $\mathrm{N}_{2}$ atmosphere and then allowed to cool to room temperature. $\mathrm{CH}_{2} \mathrm{Cl}_{2}(150 \mathrm{~mL})$ was added to the reaction mixture, the organic layer separated, dried $\left(\mathrm{MgSO}_{4}\right)$ and the solvent evaporated. The resulting crude compound was then purified by chromatography on silica gel (hexanes) to provide the pure compound 2 as a white solid. $(6.78 \mathrm{~g}, 94 \%){ }^{1} \mathrm{H} \mathrm{NMR}$ $\left(\mathrm{CDCl}_{3}, 500 \mathrm{MHz}\right): \delta_{\mathrm{ppm}}=7.43(\mathrm{~d}, J=8.4 \mathrm{~Hz}, 4 \mathrm{H}), 7.32(\mathrm{~d}, J=8.4 \mathrm{~Hz}, 4 \mathrm{H}), 7.20(\mathrm{~s}, 2 \mathrm{H}), 2.35(\mathrm{~s}$, $6 \mathrm{H}), 1.38(\mathrm{~s}, 18 \mathrm{H}) .{ }^{13} \mathrm{C} \mathrm{NMR}\left(\mathrm{CDCl}_{3}, 125 \mathrm{MHz}\right): \delta_{\mathrm{ppm}}=149.6,139.5,138.7,134.2,132.5,131.7$, 129.1, 125.1, 34.7, 31.6, 20.3. HRMS (ESI) for 2; Calcd for $\mathrm{C}_{28} \mathrm{H}_{35}: m / z=371.2733[M+\mathrm{H}]^{+}$, found: $371.2739[M+\mathrm{H}]^{+}$ 

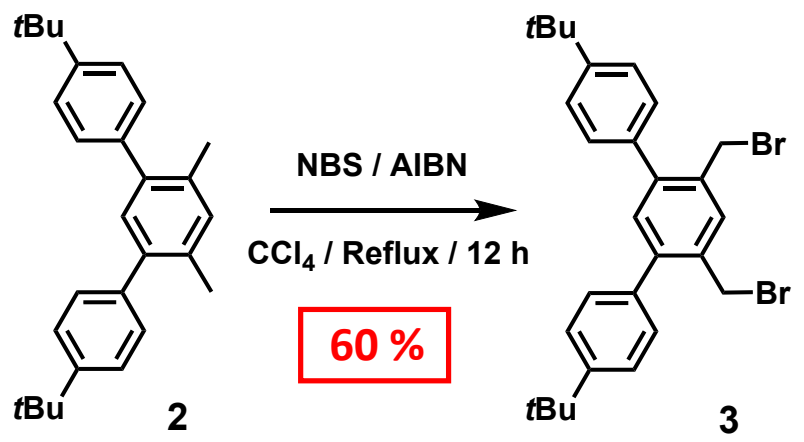

b) In a round-bottomed flask compound $2(1 \mathrm{~g}, 2.7 \mathrm{mmol}), N$-bromosuccinimide $(1.06 \mathrm{~g}, 6 \mathrm{mmol})$ and azobisisobutyronitrile $(0.090 \mathrm{~g}, 0.55 \mathrm{mmol})$ were introduced and dissolved in $\mathrm{CCl}_{4}(80 \mathrm{~mL})$ under $\mathrm{N}_{2}$. The mixture was heated for $12 \mathrm{~h}$ under reflux. The solvent was then removed under reduced pressure and the resulting crude compound purified by chromatography on silica gel (hexanes) to provide the desired product 3 as a white powder. $(0.850 \mathrm{~g}, 60 \%){ }^{1} \mathrm{H}$ NMR $\left(\mathrm{CDCl}_{3}\right.$, $500 \mathrm{MHz}): \delta_{\mathrm{ppm}}=7.73(\mathrm{~s}, 1 \mathrm{H}), 7.47(\mathrm{~d}, J=8.4 \mathrm{~Hz}, 4 \mathrm{H}), 7.42(\mathrm{~d}, J=8.4 \mathrm{~Hz}, 4 \mathrm{H}), 7.21(\mathrm{~s}, 1 \mathrm{H}), 4.54$ (s, 4H), $1.38(\mathrm{~s}, 18 \mathrm{H}) \cdot{ }^{13} \mathrm{C} \mathrm{NMR}\left(\mathrm{CDCl}_{3}, 125 \mathrm{MHz}\right): \delta_{\mathrm{ppm}}=150.8,142.3,136.6,134.9,133.9,132.9$, 128.8, 125.5, 34.8, 32.0, 31.5. HRMS (ESI) for 3; Calcd for $\mathrm{C}_{38} \mathrm{H}_{22} \mathrm{Br}_{2}: m / z=546.1196[M+$ $\left.\mathrm{NH}_{4}\right]^{+}$, found: $546.1182\left[M+\mathrm{NH}_{4}\right]^{+}$
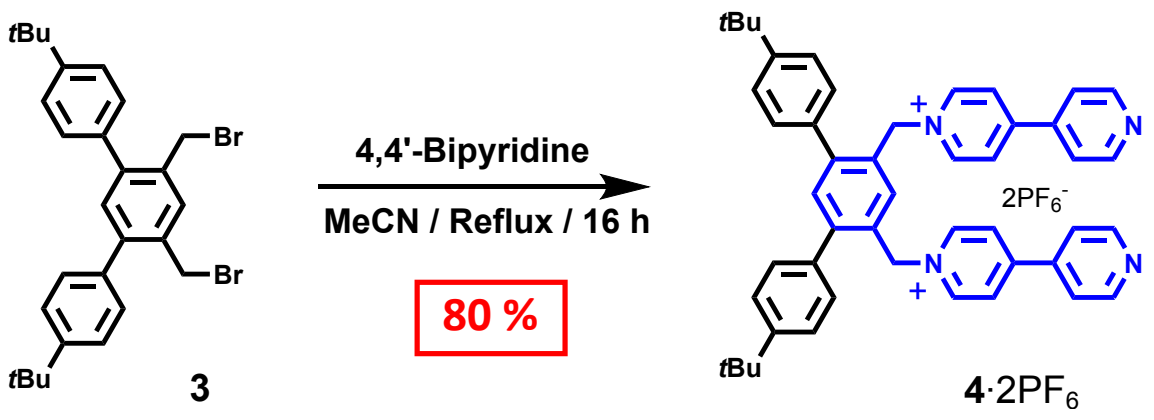

c) Compound $3(0.351 \mathrm{~g}, 0.67 \mathrm{mmol})$ was dissolved in $\mathrm{MeCN}(20 \mathrm{~mL})$ and added slowly to a refluxing solution of 4,4'-bipyridine $(1.01 \mathrm{~g}, 6.5 \mathrm{mmol})$ in $\mathrm{MeCN}(25 \mathrm{~mL})$ using a syringe pump $(3 \mathrm{~mL} / \mathrm{h})$. The mixture was then heated under reflux overnight and allowed to cool at room temperature. The solvent was evaporated and the resulting crude solid dissolved in $\mathrm{H}_{2} \mathrm{O}$. The 
precipitate was filtered off and $\mathrm{NH}_{4} \mathrm{PF}_{6}(1.5 \mathrm{~g} / 50 \mathrm{~mL}$ of water $)$ added to the filtrate to precipitate the desired product. The product $4 \cdot 2 \mathrm{PF}_{6}$ was collected by filtration, washed with $\mathrm{H}_{2} \mathrm{O}$, washed with $\mathrm{Et}_{2} \mathrm{O}$ and dried to afford a pure white solid. $(0.514 \mathrm{~g}, 80 \%){ }^{1} \mathrm{H} \mathrm{NMR}\left(\mathrm{CD}_{3} \mathrm{CN}, 500 \mathrm{MHz}\right)$ : $\delta_{\mathrm{ppm}}=8.85(\mathrm{~d}, J=6.1 \mathrm{~Hz}, 4 \mathrm{H}), 8.30(\mathrm{~d}, J=6.8 \mathrm{~Hz}, 4 \mathrm{H}), 8.05(\mathrm{~d}, J=6.9 \mathrm{~Hz}, 4 \mathrm{H}), 7.72(\mathrm{~m}, 5 \mathrm{H})$, $7.40(\mathrm{~d}, J=8.3 \mathrm{~Hz}, 4 \mathrm{H}), 7.32(\mathrm{~s}, 1 \mathrm{H}), 7.12(\mathrm{~d}, J=8.3 \mathrm{~Hz}, 4 \mathrm{H}), 5.85(\mathrm{~s}, 4 \mathrm{H}), 1.37$ (s, 18H). ${ }^{13} \mathrm{C}$ $\operatorname{NMR}\left(\mathrm{CD}_{3} \mathrm{CN}, 125 \mathrm{MHz}\right): \delta_{\mathrm{ppm}}=155.2,152.6,152.2,146.0,145.4,141.9,136.3,134.9,134.4$ 131.7, 129.1, 127.0, 126.3, 122.7, 63.6, 35.3, 31.5. HRMS (ESI) for 4.2PF ; Calcd for $\left[\mathrm{C}_{48} \mathrm{H}_{48} \mathrm{~F}_{6} \mathrm{~N}_{4} \mathrm{P}\right]^{+}: m / z=825.3515\left[M-\mathrm{PF}_{6}\right]^{+}$, found: $825.3505\left[M-\mathrm{PF}_{6}\right]^{+} /$Calcd for $\left[\mathrm{C}_{48} \mathrm{H}_{48} \mathrm{~N}_{4}\right]^{2+}$ : $m / z=340.1918\left[M-2 \mathrm{PF}_{6}\right]^{2+}$, found: $340.1944\left[M-2 \mathrm{PF}_{6}\right]^{2+}$
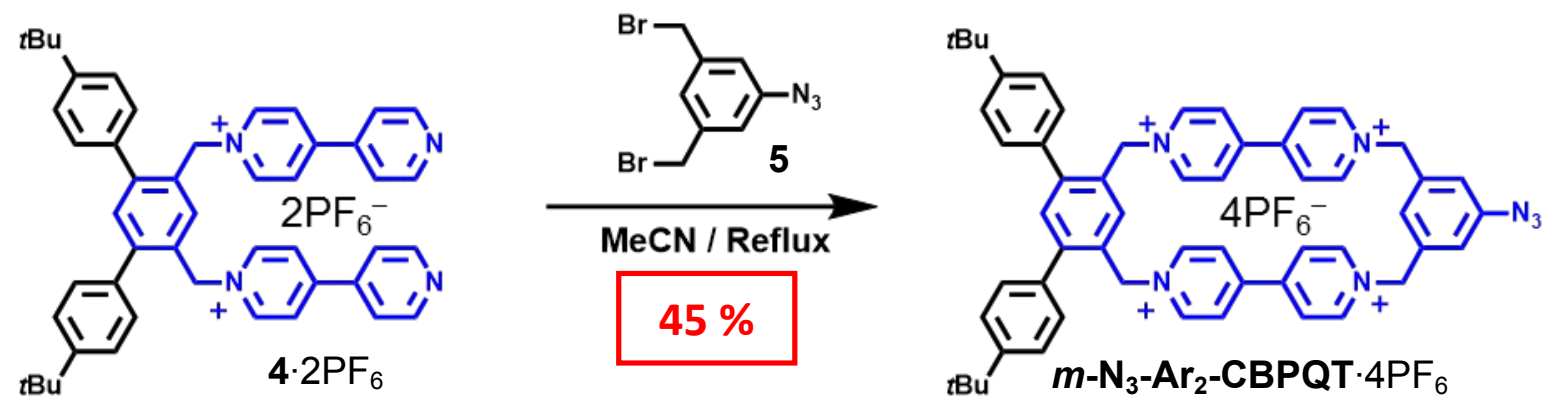

d) $\boldsymbol{m}-\mathrm{N}_{3}-\mathrm{Ar}_{2}-\mathbf{C B P Q T} \cdot \mathbf{4} \mathbf{P F}_{6}$. Compound $4 \cdot 2 \mathrm{PF}_{6}(0.441 \mathrm{~g}, 0.45 \mathrm{mmol})$ and 1-azido-3,5bis(bromomethyl)benzene (5) (0.134 g, $0.44 \mathrm{mmol})$ were dissolved separately in $\mathrm{MeCN}$ (20 mL each) and then added very slowly (3.5 days) to a refluxing solution of $\mathrm{MeCN}(80 \mathrm{~mL})$ using a double syringe pump. After completing the addition, the mixture was heated under reflux one additional day before it was allowed to cool to room temperature. The yellow solution containing a white solid was then filtered and the precipitate collected. The white powder was suspended in $\mathrm{MeCN}(20 \mathrm{~mL})$ and treated with conc. $\mathrm{HCl}$, stirred for $10 \mathrm{~min}$ and collected by filtration. The solid was then dissolved in $\mathrm{H}_{2} \mathrm{O}$ and an aqueous solution of $\mathrm{NH}_{4} \mathrm{PF}_{6}$ was added to precipitate the pure product $\left(\boldsymbol{m}-\mathbf{N}_{3}-\mathbf{A r}_{2}-\mathbf{C B P Q T} \cdot 4 \mathrm{PF}_{6}\right)$ as a white solid. $(0.281 \mathrm{~g}, 45 \%)$ 
${ }^{1} \mathrm{H} \mathrm{NMR}\left(\mathrm{CD}_{3} \mathrm{CN}, 500 \mathrm{MHz}\right): \delta_{\mathrm{ppm}}=8.74(\mathrm{~d}, J=6.9 \mathrm{~Hz}, 4 \mathrm{H}), 8.58(\mathrm{~d}, J=6.9 \mathrm{~Hz}, 4 \mathrm{H}), 8.08(\mathrm{dd}$, $J=14.1-6.9 \mathrm{~Hz}, 8 \mathrm{H}), 7.62(\mathrm{~m}, 5 \mathrm{H}), 7.48(\mathrm{~m}, 6 \mathrm{H}), 6.89(\mathrm{~s}, 1 \mathrm{H}), 6.56(\mathrm{~s}, 1 \mathrm{H}), 5.85(\mathrm{~s}, 4 \mathrm{H}), 5.77$ (s, 4H), $1.37(\mathrm{~s}, 18 \mathrm{H}) .{ }^{13} \mathrm{C}$ NMR $\left(\mathrm{CD}_{3} \mathrm{CN}, 125 \mathrm{MHz}\right): \delta_{\mathrm{ppm}}=152.8,151.0,150.8,146.8,145.6$, $143.5,137.8,136.0,134.3,131.6,130.3,130.2,128.2,127.9,126.9,123.9,122.7,64.7,62.2,35.4$, 31.5. HRMS (ESI) for $\boldsymbol{m}-\mathbf{N}_{3}-\mathbf{A r}_{2}-\mathbf{C B P Q T} \cdot 4 \mathrm{PF}_{6}$; Calcd for $\mathrm{C}_{56} \mathrm{H}_{55} \mathrm{~F}_{18} \mathrm{~N}_{7} \mathrm{P}_{3}: m / z=1260.3439[M-$ $\left.\mathrm{PF}_{6}\right]^{+}$, found: $1260.3448\left[M-\mathrm{PF}_{6}\right]^{+}$

\section{Synthesis of the Half-Dumbbell (HD-Alkyne)}

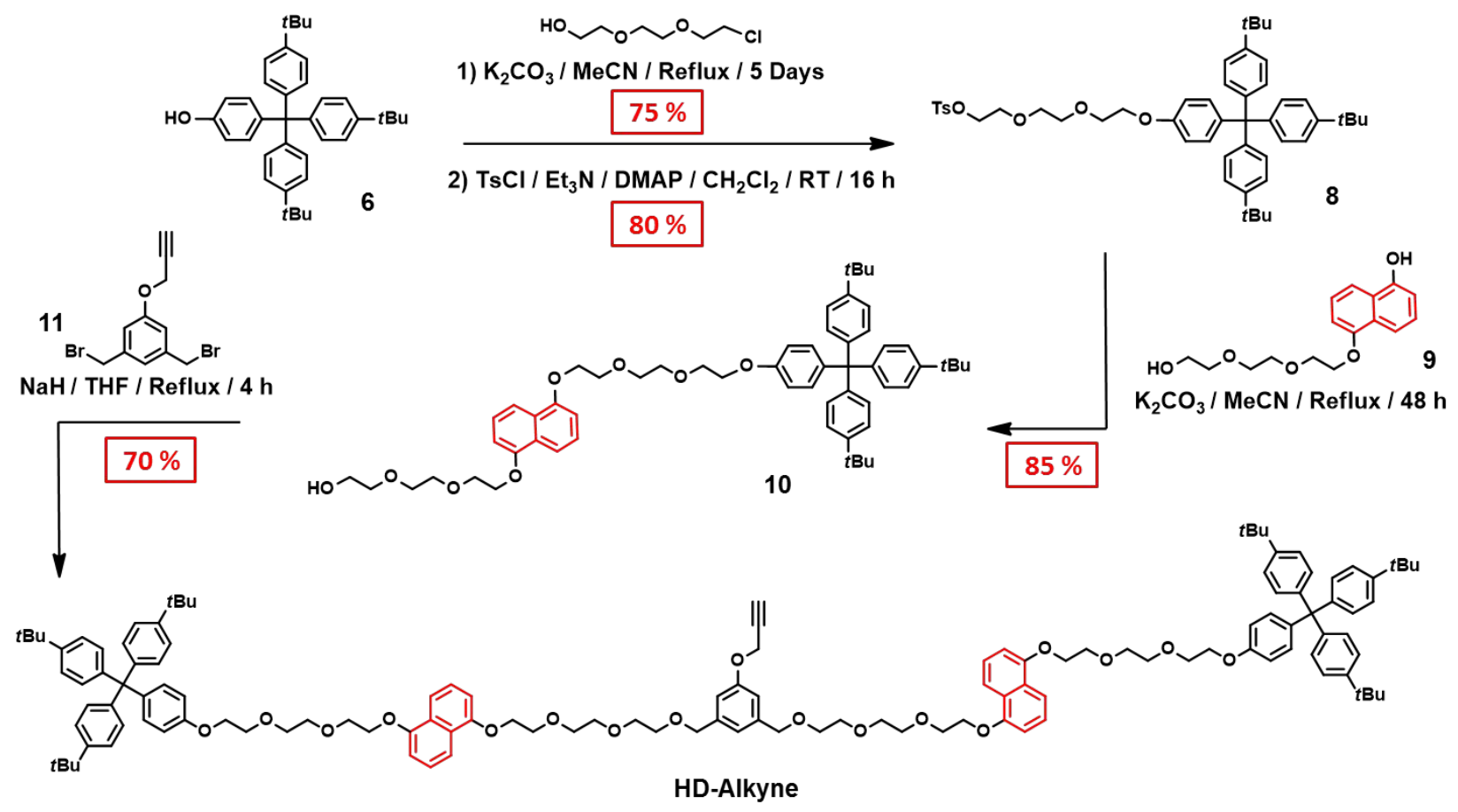

Scheme S2. Synthesis of the half-dumbbell (HD-Alkyne) 

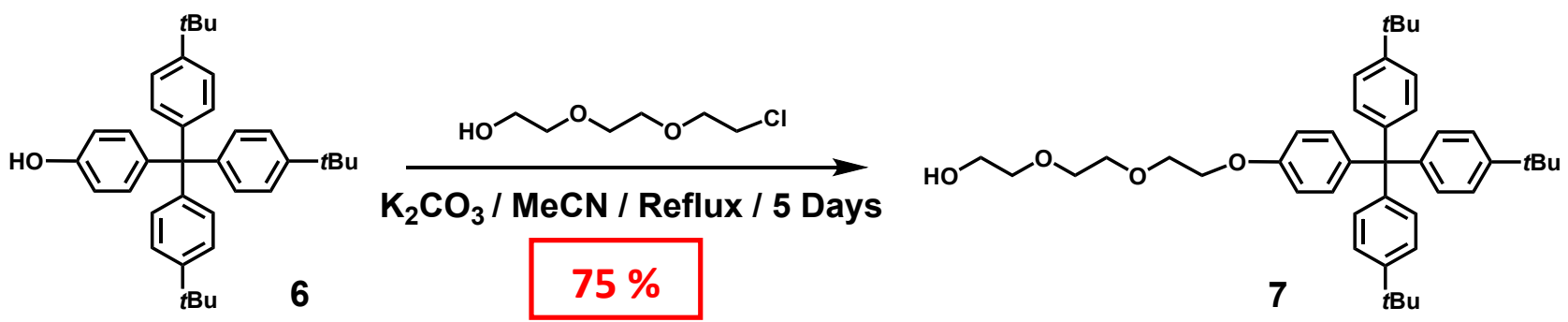

a) 4-Tris(4-tert-butylphenyl)phenol (6) (0.800 g, $1.58 \mathrm{mmol})$ was added to a mixture of dry $\mathrm{MeCN}$ (100 mL), $\mathrm{K}_{2} \mathrm{CO}_{3}(0.655 \mathrm{~g}, 4.74 \mathrm{mmol})$ and 2-[2'-(2"-chloroethoxy)ethoxy]ethanol (0.533 g, 3.16 mmol) under an inert atmosphere. The reaction mixture was heated under reflux for 5 days and the completion of the reaction monitored by TLC $\left(\mathrm{SiO}_{2}\right): 60 \%$ hexanes $/ 40 \%$ EtOAc $\left(R_{\mathrm{f}}=0.2\right)$. The precipitate formed was filtered off and rinsed with MeCN $(200 \mathrm{~mL})$. The resulting filtrate was collected, and the solvent removed under reduced pressure. The pure compound 7 was obtained after silica gel chromatography (hexanes / EtOAc) as a beige solid $(0.760 \mathrm{~g}, 1.19 \mathrm{mmol}, 75 \%) .{ }^{1} \mathrm{H}$ $\operatorname{NMR}\left(\mathrm{CDCl}_{3}, 500 \mathrm{MHz}\right): \delta_{\mathrm{ppm}}=7.23(\mathrm{~d}, J=8.5 \mathrm{~Hz}, 6 \mathrm{H}), 7.08(\mathrm{~m}, 8 \mathrm{H}), 6.78(\mathrm{~d}, J=8.8 \mathrm{~Hz}, 2 \mathrm{H})$, $4.11(\mathrm{~m}, 2 \mathrm{H}), 3.85(\mathrm{~m}, 2 \mathrm{H}), 3.71(\mathrm{~m}, 6 \mathrm{H}), 3.62(\mathrm{~m}, 2 \mathrm{H}), 2.32(\mathrm{~s}, 1 \mathrm{H}), 1.30(\mathrm{~s}, 27 \mathrm{H}) .{ }^{13} \mathrm{C}$ NMR $\left(\mathrm{CDCl}_{3}, 125 \mathrm{MHz}\right): \delta_{\mathrm{ppm}}=156.6,148.4,144.3,140.0,132.4,130.9,124.2,113.2,72.6,70.9,70.5$ 69.9, 67.3, 63.2, 61.9, 34.4, 31.5. HRMS (ESI) for 7; Calcd for $\mathrm{C}_{43} \mathrm{H}_{56} \mathrm{NaO}_{4}: m / z=659.4071[M$ $+\mathrm{Na}]^{+}$, found: $659.4092[M+\mathrm{Na}]^{+} /$Calcd for $\mathrm{C}_{43} \mathrm{H}_{60} \mathrm{NO}_{4}: m / z=654.4517\left[M+\mathrm{NH}_{4}\right]^{+}$, found: $654.4536\left[M+\mathrm{NH}_{4}\right]^{+}$

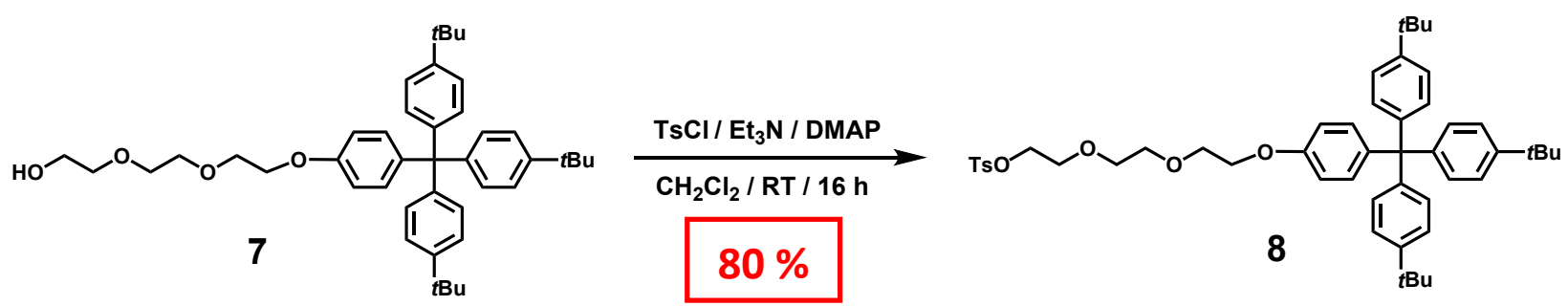

b) $p$-Toluenesulfonyl chloride $(0.149 \mathrm{~g}, 0.78 \mathrm{mmol})$ was added in several portions under vigorous stirring to an iced-cooled mixture of 2-[2-[2-[4-[tris[4-(tert-butyl)phenyl]methyl]phenoxy]ethoxy] 
ethoxy]-ethanol (7) (0.250 g, $0.39 \mathrm{mmol})$, 4-dimethylaminopyridine $(0.050 \mathrm{~g}, 0.39 \mathrm{mmol})$ and $\mathrm{Et}_{3} \mathrm{~N}(0.394 \mathrm{~g}, 3.9 \mathrm{mmol})$ in $\mathrm{CH}_{2} \mathrm{Cl}_{2}(20 \mathrm{~mL})$ under an inert atmosphere. The reaction mixture was then allowed to warm to room temperature and was stirred overnight. Completion of the reaction was monitored by TLC $\left(\mathrm{SiO}_{2}\right): 60 \%$ hexanes / 40\% EtOAc $\left(R_{\mathrm{f}}=0.5\right)$. Distilled $\mathrm{H}_{2} \mathrm{O}(20 \mathrm{~mL})$ was added to the reaction mixture and the organic phase separated. The aqueous phase was washed with $\mathrm{CH}_{2} \mathrm{Cl}_{2}(2 \times 50 \mathrm{~mL})$, the organic phases combined, dried $\left(\mathrm{MgSO}_{4}\right)$ and evaporated. The crude compound was purified by silica gel chromatography (hexanes / EtOAc) to afford the pure compound 8 as a white powder in $80 \%$ yield. $(0.245 \mathrm{~g}, 0.31 \mathrm{mmol}){ }^{1} \mathrm{H} \mathrm{NMR}\left(\mathrm{CDCl}_{3}, 500 \mathrm{MHz}\right)$ : $\delta_{\mathrm{ppm}}=7.79(\mathrm{~d}, J=8.2 \mathrm{~Hz}, 2 \mathrm{H}), 7.31(\mathrm{~d}, J=8.0 \mathrm{~Hz}, 2 \mathrm{H}), 7.23(\mathrm{~d}, J=8.5 \mathrm{~Hz}, 6 \mathrm{H}), 7.08(\mathrm{~m}, 8 \mathrm{H})$, $6.76(\mathrm{~d}, J=8.9 \mathrm{~Hz}, 2 \mathrm{H}), 4.16(\mathrm{~m}, 2 \mathrm{H}), 4.08(\mathrm{~m}, 2 \mathrm{H}), 3.80(\mathrm{~m}, 2 \mathrm{H}), 3.69(\mathrm{~m}, 2 \mathrm{H}), 3.65(\mathrm{~m}, 2 \mathrm{H})$, $3.61(\mathrm{~m}, 2 \mathrm{H}), 2.41(\mathrm{~s}, 3 \mathrm{H}), 1.30(\mathrm{~s}, 27 \mathrm{H}) .{ }^{13} \mathrm{C} \mathrm{NMR}\left(\mathrm{CDCl}_{3}, 125 \mathrm{MHz}\right): \delta_{\mathrm{ppm}}=156.6,148.5,144.9$, 144.3, 140.0, 133.2, 132.4, 130.9, 130.0, 128.1, 124.2, 113.2, 71.0, 70.9, 70.0, 69.4, 68.9, 67.3, 63.2, 34.4, 31.5, 21.8. HRMS (ESI) for 8; Calcd for $\mathrm{C}_{50} \mathrm{H}_{62} \mathrm{NaO}_{6} \mathrm{~S}: m / z=813.4159[M+\mathrm{Na}]^{+}$, found: $813.4106[M+\mathrm{Na}]^{+} /$Calcd for $\mathrm{C}_{50} \mathrm{H}_{66} \mathrm{NO}_{6} \mathrm{~S}: m / z=808.4605\left[M+\mathrm{NH}_{4}\right]^{+}$, found: 808.4544 $\left[M+\mathrm{NH}_{4}\right]^{+}$

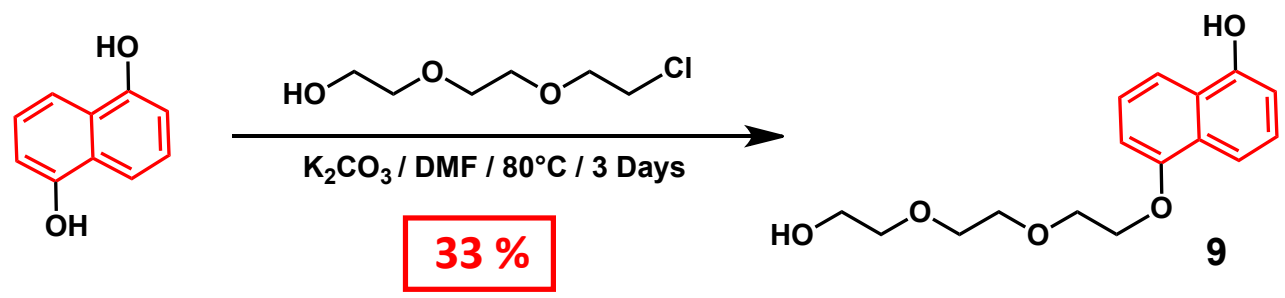

c) 1,5-Dihydroxynaphthalene ( $5 \mathrm{~g}, 31.2 \mathrm{mmol})$ and $\mathrm{K}_{2} \mathrm{CO}_{3}(8.62 \mathrm{~g}, 62.4 \mathrm{mmol})$ were dissolved in DMF $(150 \mathrm{~mL})$ in a round-bottomed flask under an inert atmosphere. A solution of the 2-[2-(2chloroethoxy)ethoxy]-ethanol $(5.04 \mathrm{~g}, 29.9 \mathrm{mmol})$ in DMF $(50 \mathrm{~mL})$ was added dropwise and the 
reaction mixture heated at $80^{\circ} \mathrm{C}$ for 3 days. Completion of the reaction was monitored by TLC $\left(\mathrm{SiO}_{2}\right): 50 \%$ hexanes $/ 50 \%$ EtOAc $\left(R_{\mathrm{f}}=0.1\right)$. The solvent was removed under reduce pressure and the crude compound dissolved in EtOAc $(100 \mathrm{~mL})$. The organic phase was washed successively with an aqueous solution of $\mathrm{NH}_{4} \mathrm{Cl}(2 \times 30 \mathrm{~mL})$ and $\mathrm{H}_{2} \mathrm{O}(30 \mathrm{~mL})$ and was separated, dried $\left(\mathrm{MgSO}_{4}\right)$ and evaporated. The crude compound was purified by silica gel chromatography (hexanes / EtOAc) to afford the pure compound 9 as a dark red oil in $33 \%$ yield. $(2.912 \mathrm{~g}, 9.96$ mmol) ${ }^{1} \mathrm{H} \mathrm{NMR}\left(\mathrm{CDCl}_{3}, 500 \mathrm{MHz}\right): \delta_{\mathrm{ppm}}=7.75(\mathrm{dd}, J=11.4-8.6 \mathrm{~Hz}, 2 \mathrm{H}), 7.28(\mathrm{t}, J=8.00 \mathrm{~Hz}$, 1H), $7.17(\mathrm{t}, J=7.9 \mathrm{~Hz}, 1 \mathrm{H}), 6.87(\mathrm{br}, 1 \mathrm{H}), 6.80(\mathrm{~d}, J=7.4 \mathrm{~Hz}, 1 \mathrm{H}), 6.73(\mathrm{~d}, J=7.6 \mathrm{~Hz}, 1 \mathrm{H}), 4.24$ $(\mathrm{m}, 2 \mathrm{H}), 3.96(\mathrm{~m}, 2 \mathrm{H}), 3.80(\mathrm{~m}, 2 \mathrm{H}), 3.70(\mathrm{~m}, 4 \mathrm{H}), 3.60(\mathrm{~m}, 2 \mathrm{H}), 2.90(\mathrm{br}, 1 \mathrm{H}) .{ }^{13} \mathrm{C} \mathrm{NMR}\left(\mathrm{CDCl}_{3}\right.$, $125 \mathrm{MHz}): \delta_{\mathrm{ppm}}=154.2,151.9,126.9,125.7,125.3,124.9,114.5,114.0,109.4,105.5,72.5,70.9$, 70.3, 69.8, 67.7, 61.8. HRMS (ESI) for 9; Calcd for $\mathrm{C}_{16} \mathrm{H}_{21} \mathrm{O}_{5}: m / z=293.1384[M+\mathrm{H}]^{+}$, found: 293.1385 $[M+\mathrm{H}]^{+} /$Calcd for $\mathrm{C}_{16} \mathrm{H}_{20} \mathrm{NaO}_{5}: m / z=315.1203[M+\mathrm{Na}]^{+}$, found: $315.1205[M+$ $\mathrm{Na}]^{+}$

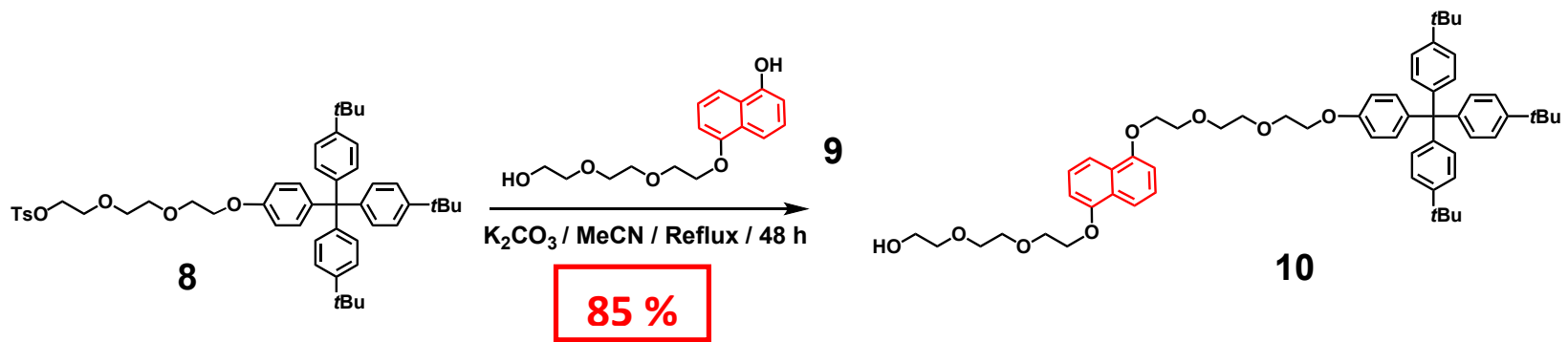

d) Compound $9(0.107 \mathrm{~g}, 0.366 \mathrm{mmol})$ was added to a solution of $\mathrm{K}_{2} \mathrm{CO}_{3}(0.152 \mathrm{~g}, 1.098 \mathrm{mmol})$ in $\mathrm{MeCN}(20 \mathrm{~mL})$ under an inert atmosphere. The tosylate $8(0.290 \mathrm{~g}, 0.366 \mathrm{mmol})$ in $\mathrm{MeCN}(10$ $\mathrm{mL}$ ) was added to this solution and the reaction mixture heated under reflux for 2 days. Completion of the reaction was monitored by TLC $\left(\mathrm{SiO}_{2}\right)$ : 50\% hexanes / 50\% EtOAc $\left(R_{\mathrm{f}}=0.2\right)$. The reaction mixture was then allowed to cool to room temperature and a saturated aqueous solution of $\mathrm{NH}_{4} \mathrm{Cl}$ added to reach $\mathrm{pH}=7$. The $\mathrm{MeCN}$ was removed under reduce pressure and EtOAc $(150 \mathrm{~mL})$ added to the mixture. The organic layer was then separated, washed with $\mathrm{H}_{2} \mathrm{O}(2 \times 50 \mathrm{~mL})$, isolated, dried 
$\left(\mathrm{MgSO}_{4}\right)$ and evaporated. The pure compound $\mathbf{1 0}$ was obtained after silica gel chromatography (hexanes / EtOAc) as a white powder in $85 \%$ yield. $(0.282 \mathrm{~g}, 0.310 \mathrm{mmol}){ }^{1} \mathrm{H} \mathrm{NMR}\left(\mathrm{CDCl}_{3}, 500\right.$ MHz): $\delta_{\mathrm{ppm}}=7.86(\mathrm{t}, J=8.0 \mathrm{~Hz}, 2 \mathrm{H}), 7.33(\mathrm{td}, J=8.2-4.9 \mathrm{~Hz}, 2 \mathrm{H}), 7.22(\mathrm{~d}, J=8.6 \mathrm{~Hz}, 6 \mathrm{H})$, $7.07(\mathrm{~m}, 8 \mathrm{H}), 6.83(\mathrm{dd}, J=7.6-2.9 \mathrm{~Hz}, 2 \mathrm{H}), 6.77(\mathrm{~d}, J=8.9 \mathrm{~Hz}, 2 \mathrm{H}), 4.29(\mathrm{t}, J=4.7 \mathrm{~Hz}, 4 \mathrm{H})$, $4.09(\mathrm{~m}, 2 \mathrm{H}), 4.00(\mathrm{t}, J=4.7 \mathrm{~Hz}, 4 \mathrm{H}), 3.86(\mathrm{~m}, 2 \mathrm{H}), 3.81(\mathrm{~m}, 4 \mathrm{H}), 3.76(\mathrm{~m}, 2 \mathrm{H}), 3.72(\mathrm{~m}, 4 \mathrm{H})$, $3.62(\mathrm{~m}, 2 \mathrm{H}), 1.32(\mathrm{~s}, 27 \mathrm{H}) .{ }^{13} \mathrm{C} \mathrm{NMR}\left(\mathrm{CDCl}_{3}, 125 \mathrm{MHz}\right): \delta_{\mathrm{ppm}}=156.7,154.5,154.4,148.4,144.3$, $139.9,132.4,130.9,126.9,126.9,125.3,125.2,124.2,114.9,114.7,113.2,105.9,72.6,71.2,71.2$ 71.1, 70.7, 70.1, 70.0, 68.1, 68.1, 67.4, 63.2, 62.0, 34.4, 31.5. HRMS (ESI) for 10; Calcd for $\left[\mathrm{C}_{59} \mathrm{H}_{78} \mathrm{NO}_{8}\right]^{+}: m / z=928.5722\left[M+\mathrm{NH}_{4}\right]^{+}$, found: $928.5725\left[M+\mathrm{NH}_{4}\right]^{+} /$Calcd for $\left[\mathrm{C}_{59} \mathrm{H}_{74} \mathrm{NaO}_{8}\right]^{+}: m / z=933.5276[M+\mathrm{Na}]^{+}$, found: $933.5285[M+\mathrm{Na}]^{+}$

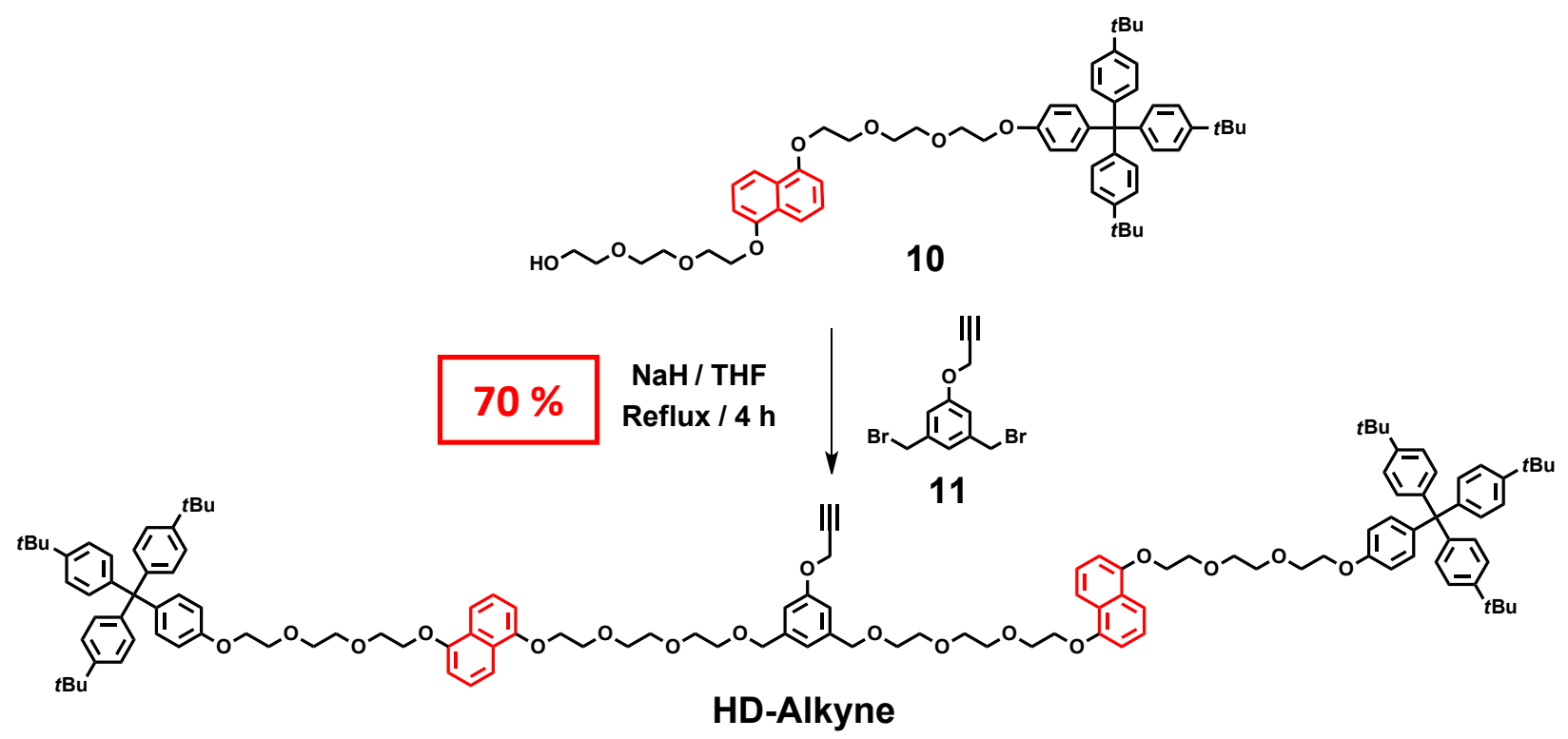

e) HD-Alkyne. In a round-bottomed flask were introduced under an inter atmosphere $\mathrm{NaH}(60 \%$ in mineral oil, $15 \mathrm{mg})$ and a solution of the alcohol $10(0.112 \mathrm{~g}, 0.123 \mathrm{mmol})$ in dry THF $(2 \mathrm{~mL})$. The mixture was stirred and heated under reflux for $30 \mathrm{~min}$ before a solution of 1,3bis(bromomethyl)-5-(propargyloxy)benzene (11) $(0.016 \mathrm{~g}, 0.051 \mathrm{mmol})$ in dry THF $(2 \mathrm{~mL})$ was 
added. The reaction mixture was then stirred while heating under reflux for $4 \mathrm{~h}$ and the completion of the reaction monitored by TLC $\left(\mathrm{SiO}_{2}\right): 50 \%$ hexanes / 50\% EtOAc $\left(R_{\mathrm{f}}=0.4\right)$. Once the reaction was complete, the mixture was cooled to room temperature and a saturated aqueous solution of $\mathrm{NH}_{4} \mathrm{Cl}(15 \mathrm{~mL})$ was added in order to quench the excess of $\mathrm{NaH}$. The crude product was then extracted with EtOAc $(60 \mathrm{~mL})$ and the organic phase washed with $\mathrm{H}_{2} \mathrm{O}(3 \times 20 \mathrm{~mL})$. The organic phase was isolated and dried $\left(\mathrm{MgSO}_{4}\right)$ and finally evaporated to give the crude compound which was then further purified by silica gel chromatography (hexanes / EtOAc). The HD-Alkyne was obtained as a beige powder in $70 \%$ yield. $(0.071 \mathrm{~g}, 0.036 \mathrm{mmol}){ }^{1} \mathrm{H} \mathrm{NMR}\left(\mathrm{CDCl}_{3}, 500 \mathrm{MHz}\right)$ : $\delta_{\text {ppm }}=7.85(\mathrm{dd}, J=8.4-4.8 \mathrm{~Hz}, 4 \mathrm{H}), 7.31(\mathrm{td}, J=8.3-2.3 \mathrm{~Hz}, 4 \mathrm{H}), 7.22(\mathrm{~d}, J=8.5 \mathrm{~Hz}, 12 \mathrm{H})$, $7.07(\mathrm{~m}, 16 \mathrm{H}), 6.90(\mathrm{~s}, 1 \mathrm{H}), 6.88(\mathrm{~s}, 2 \mathrm{H}), 6.81(\mathrm{dd}, J=7.5-3.6 \mathrm{~Hz}, 4 \mathrm{H}), 6.77(\mathrm{~d}, J=8.9 \mathrm{~Hz}, 4 \mathrm{H})$ $4.65(\mathrm{~d}, J=2.4 \mathrm{~Hz}, 2 \mathrm{H}), 4.51(\mathrm{~s}, 4 \mathrm{H}), 4.27(\mathrm{q}, J=5.7 \mathrm{~Hz}, 8 \mathrm{H}), 4.09(\mathrm{~m}, 4 \mathrm{H}), 3.99(\mathrm{~m}, 8 \mathrm{H}), 3.85$ (m, 4H), $3.80(\mathrm{~m}, 8 \mathrm{H}), 3.76(\mathrm{~m}, 4 \mathrm{H}), 3.69(\mathrm{~m}, 8 \mathrm{H}), 3.61(\mathrm{~m}, 4 \mathrm{H}), 2.48(\mathrm{t}, J=2.3 \mathrm{~Hz}, 1 \mathrm{H}), 1.29(\mathrm{~s}$, 54H). ${ }^{13} \mathrm{C} \mathrm{NMR}\left(\mathrm{CDCl}_{3}, 125 \mathrm{MHz}\right): \delta_{\mathrm{ppm}}=158.0,156.7,154.5,148.4,144.3,140.2,139.9,132.4$ $130.9,126.9,125.2,124.2,120.1,114.8,113.3,113.2,105.8,75.7,73.0,71.2,71.1,70.9,70.0$ 69.7, 68.1, 67.4, 63.2, 55.9, 34.4, 31.5. HRMS (ESI) for HD-Alkyne; Calcd for $\left[\mathrm{C}_{129} \mathrm{H}_{160} \mathrm{NO}_{17}\right]^{+}$: $m / z=1996.1715\left[M+\mathrm{NH}_{4}\right]^{+}$, found: $1996.1693\left[M+\mathrm{NH}_{4}\right]^{+} /$Calcd for $\left[\mathrm{C}_{129} \mathrm{H}_{156} \mathrm{NaO}_{17}\right]^{+}: m / z=$ $2001.1269[M+\mathrm{Na}]^{+}$, found: $2001.1267[M+\mathrm{Na}]^{+}$ 


\section{Rotaxane Assembly $\left(\right.$ Zip-R $\left.\cdot 8 \mathrm{PF}_{6}\right)$}

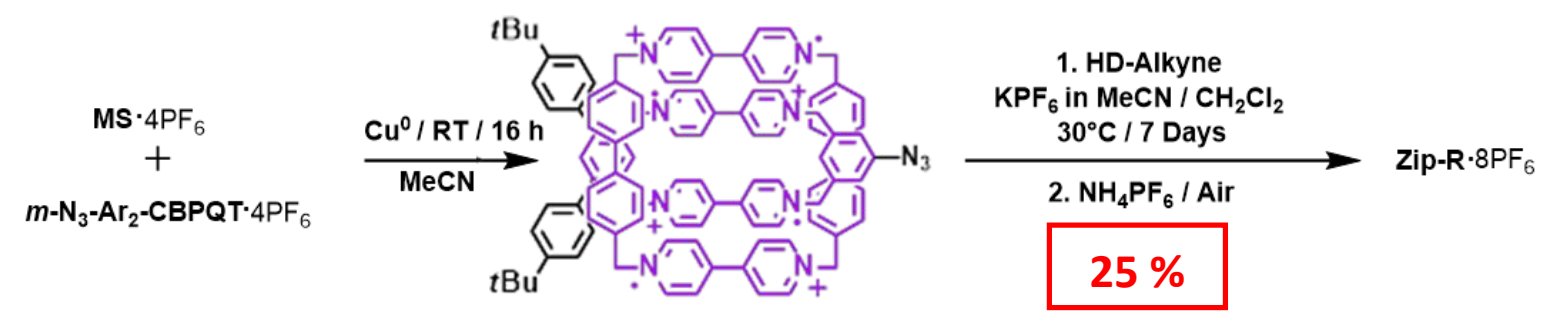

a) Zip-R·8PF ${ }_{6}$ Under an inert atmosphere (glove-box), $\mathbf{M S}^{-} 4 \mathrm{PF}_{6}(15 \mathrm{mg}, 0.012 \mathrm{mmol})$ and the $\boldsymbol{m}-\mathbf{N}_{3}-\mathbf{A r}_{2}-\mathbf{C B P Q T} \cdot 4 \mathrm{PF}_{6}(16.8 \mathrm{mg}, 0.012 \mathrm{mmol})$ were dissolved in dry and de-oxygenated deuterated $\mathrm{MeCN}(1.5 \mathrm{~mL}) . \mathrm{Cu}(0)$ dust was then added in large excess and the reaction mixture was stirred at room temperature overnight. A solution of $\mathrm{KPF}_{6}(-15 \mathrm{mg})$ in $\mathrm{MeCN}(0.5 \mathrm{~mL})$ was added to the reaction mixture followed by a solution of the half-dumbbell (HD-Alkyne) $(21.3 \mathrm{mg}$, $0.011 \mathrm{mmol})$ previously dissolved in $\mathrm{CH}_{2} \mathrm{Cl}_{2}(1 \mathrm{~mL})$. The resulting mixture was heated to $30^{\circ} \mathrm{C}$ and stirred at this temperature for 7 days. The reaction progress was followed by ${ }^{1} \mathrm{H}$ NMR spectroscopy using a J-Young NMR tube. The mixture was then diluted with MeCN (10 mL) and the $\mathrm{Cu}$ removed by filtration of the solution through a syringe filter. $\mathrm{NH}_{4} \mathrm{PF}_{6}$ was added in excess and air was introduced very slowly into the mixture outside of the glovebox. After stirring overnight, the completion of the oxidation was evident from the loss of the purple color associated with the reduced state of the rotaxane. The solvent was removed under vacuum and $\mathrm{H}_{2} \mathrm{O}(20 \mathrm{~mL})$ was added to the crude solid. The undissolved solids were collected by filtration and washed with $\mathrm{H}_{2} \mathrm{O}(2 \times 10 \mathrm{~mL})$. The crude compound was then dried under vacuum and taken up in $\mathrm{MeCN}(3$ $\mathrm{mL}$ ). The precipitate formed was filtered off and the filtrate evaporated to dryness. The crude solid was then purified by reverse phase chromatography $(\mathrm{C}-18)$ : $\mathrm{MeCN}+0.1 \%$ TFA / $\mathrm{H}_{2} \mathrm{O}+0.1 \%$ 
TFA, with the desired compound eluting at $90 \% \mathrm{MeCN}+0.1 \%$ TFA / $10 \% \mathrm{H}_{2} \mathrm{O}+0.1 \%$ TFA. The fractions containing the desired product were evaporated and the resulting solid was dissolved in a minimum amount of $\mathrm{MeCN}(1 \mathrm{~mL})$. An aqueous solution of $\mathrm{NH}_{4} \mathrm{PF}_{6}(20 \mathrm{~mL})$ was then added and the precipitate collected by filtration, washed with $\mathrm{H}_{2} \mathrm{O}(2 \times 10 \mathrm{~mL})$ and dried under vacuum. The pure rotaxane $\mathbf{Z i p}-\mathbf{R} \cdot 8 \mathrm{PF}_{6}$ was obtained as a pale purple solid (12.5 $\left.\mathrm{mg}, 0.0027 \mathrm{mmol}, 25 \%\right)$ ${ }^{1} \mathrm{H}$ NMR $\left(\mathrm{CD}_{3} \mathrm{CN}, 500 \mathrm{MHz}\right): \delta_{\mathrm{ppm}}=8.80(\mathrm{~d}, J=6.6 \mathrm{~Hz}, 4 \mathrm{H}), 8.68(\mathrm{~d}, J=6.5 \mathrm{~Hz}, 8 \mathrm{H}), 8.59(\mathrm{~d}, J$ $=6.6 \mathrm{~Hz}, 4 \mathrm{H}), 8.50(\mathrm{~s}, 1 \mathrm{H}), 8.24(\mathrm{~s}, 2 \mathrm{H}), 8.13(\mathrm{~d}, J=6.5 \mathrm{~Hz}, 4 \mathrm{H}), 8.08(\mathrm{~d}, J=6.6 \mathrm{~Hz}, 4 \mathrm{H}), 8.02$ $(\mathrm{d}, J=8.3 \mathrm{~Hz}, 8 \mathrm{H}), 7.81(\mathrm{~d}, J=8.3 \mathrm{~Hz}, 8 \mathrm{H}), 7.62(\mathrm{~m}, 5 \mathrm{H}), 7.48(\mathrm{~d}, J=8.2 \mathrm{~Hz}, 4 \mathrm{H}), 7.27(\mathrm{~d}, J=$ $8.4 \mathrm{~Hz}, 12 \mathrm{H}), 7.09(\mathrm{~m}, 20 \mathrm{H}), 7.00(\mathrm{~d}, J=8.7 \mathrm{~Hz}, 4 \mathrm{H}), 6.91(\mathrm{~s}, 1 \mathrm{H}), 6.87(\mathrm{~s}, 1 \mathrm{H}), 6.71(\mathrm{~s}, 1 \mathrm{H}), 6.60$ (s, 2H), $6.50(\mathrm{~d}, J=8.7 \mathrm{~Hz}, 4 \mathrm{H}), 5.90(\mathrm{~s}, 4 \mathrm{H}), 5.85(\mathrm{~s}, 4 \mathrm{H}), 5.70-5.56(\mathrm{~m}, 16 \mathrm{H}), 5.10(\mathrm{~s}, 2 \mathrm{H}), 4.52$ $(\mathrm{d}, J=8.2 \mathrm{~Hz}, 2 \mathrm{H}), 4.45(\mathrm{~d}, J=8.2 \mathrm{~Hz}, 2 \mathrm{H}), 4.22(\mathrm{~s}, 4 \mathrm{H}), 4.00-3.80(\mathrm{~m}, 32 \mathrm{H}), 3.76-3.62(\mathrm{~m}, 16 \mathrm{H})$ $1.37(\mathrm{~s}, 18 \mathrm{H}), 1.27(\mathrm{~s}, 54 \mathrm{H}) .{ }^{13} \mathrm{C} \mathrm{NMR}\left(\mathrm{CD}_{3} \mathrm{CN}, 125 \mathrm{MHz}\right): \delta_{\mathrm{ppm}}=157.1,152.8,152.5,152.3$ $151.1,150.8,149.5,146.9,146.8,146.6,145.6,145.5,145.1,141.6,141.4,140.8,139.0,137.7$ 136.0, 134.3, 132.6, 131.6, 131.3, 131.1, 130.3, 130.1, 128.9, 128.2, 127.9, 126.9, 126.4, 125.4, 125.0, 124.9, 123.9, 119.7, 114.1, 113.8, 113.0, 112.8, 104.3, 104.2, 73.1, 71.8, 71.8, 71.4, 71.1, 71.0, 70.9, 70.6, 70.3, 68.3, 68.1, 68.1, 65.8, 64.5, 63.9, 62.2, 35.4, 34.9, 31.6. HRMS (ESI) for Zip-R-8PF 6 ; Calcd for $\mathrm{C}_{233} \mathrm{H}_{251} \mathrm{~F}_{36} \mathrm{~N}_{11} \mathrm{O}_{17} \mathrm{P}_{6}: m / z=2173.3511\left[M-2 \mathrm{PF}_{6}\right]^{2+}$, found: $2173.3459[M$ $\left.-2 \mathrm{PF}_{6}\right]^{2+} /$ Calcd for $\left[\mathrm{C}_{233} \mathrm{H}_{251} \mathrm{~F}_{30} \mathrm{~N}_{11} \mathrm{O}_{17} \mathrm{P}_{5}\right]^{3+}: m / z=1400.5789\left[M-3 \mathrm{PF}_{6}\right]^{3+}$, found: 1400.5788 $\left[M-3 \mathrm{PF}_{6}\right]^{3+} /$ Calcd for $\left[\mathrm{C}_{233} \mathrm{H}_{251} \mathrm{~F}_{18} \mathrm{~N}_{11} \mathrm{O}_{17} \mathrm{P}_{3}\right]^{5+}: m / z=782.3616\left[M-5 \mathrm{PF}_{6}\right]^{5+}$, found: 782.3614 $\left[M-5 \mathrm{PF}_{6}\right]^{5+}$ 


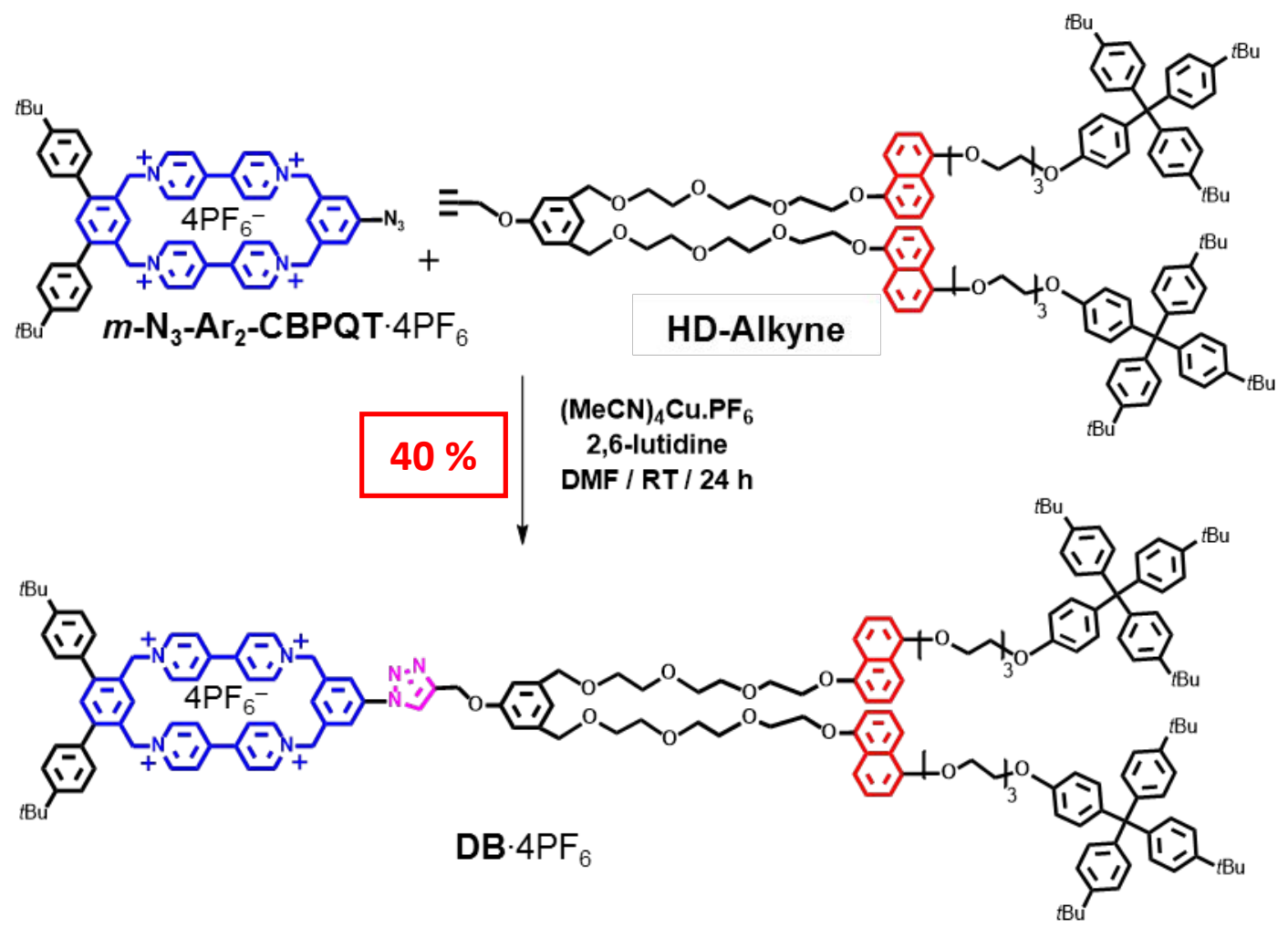

b) $\mathbf{D B} \cdot 4 \mathrm{PF}_{6} \cdot \boldsymbol{m}-\mathrm{N}_{\mathbf{3}}-\mathrm{Ar}_{2}-\mathrm{CBPQT} \cdot 4 \mathrm{PF}_{6}(28 \mathrm{mg}, 0.020 \mathrm{mmol})$, HD-Alkyne (40 mg, $\left.0.020 \mathrm{mmol}\right)$, tetrakis(acetonitrile)copper(I) hexafluorophosphate $(3 \mathrm{mg}, 0.008 \mathrm{mmol})$ and 2,6-lutidine $(1 \mathrm{mg}$, $0.010 \mathrm{mmol})$ were dissolved in dry, deoxygenated DMF (2 $\mathrm{mL})$ under inert atmosphere. The resulting solution was stirred at room temperature for $24 \mathrm{~h}$. The mixture was then evaporated, and the resulting crude solid taken up in $\mathrm{Et}_{2} \mathrm{O}$. The solid was triturated, collected by filtration and washed with $\mathrm{Et}_{2} \mathrm{O}$. The solid was then dissolved in $\mathrm{MeCN}$ and the remaining precipitate filtered off. The crude solid was then purified by reverse phase chromatography $(\mathrm{C}-18)$ : $\mathrm{MeCN}+0.1 \%$ TFA $/ \mathrm{H}_{2} \mathrm{O}+0.1 \%$ TFA. After the chromatography the fractions containing the desired compound were combined and evaporated. The resulting solid was dissolved in a minimum of $\mathrm{MeCN}(1 \mathrm{~mL})$ and an aqueous solution of $\mathrm{NH}_{4} \mathrm{PF}_{6}(20 \mathrm{~mL})$ added. The precipitate was collected by filtration, washed with $\mathrm{H}_{2} \mathrm{O}(2 \times 10 \mathrm{~mL})$ and dried under vacuum. The final pure compound $\mathbf{D B} \cdot 4 \mathrm{PF}_{6}$ was obtained as a pale pink solid (27 mg, $0.008 \mathrm{mmol}, 40 \%){ }^{1} \mathrm{H} \mathrm{NMR}\left(\mathrm{CD}_{3} \mathrm{CN}, 500 \mathrm{MHz}\right): \delta_{\mathrm{ppm}}=8.69$ $(\mathrm{d}, J=6.9 \mathrm{~Hz}, 4 \mathrm{H}), 8.48(\mathrm{~d}, J=6.9 \mathrm{~Hz}, 4 \mathrm{H}), 8.42(\mathrm{~s}, 1 \mathrm{H}), 8.13(\mathrm{~s}, 2 \mathrm{H}), 7.97(\mathrm{~d}, J=6.9 \mathrm{~Hz}, 4 \mathrm{H})$, 
$7.93(\mathrm{~d}, J=6.9 \mathrm{~Hz}, 4 \mathrm{H}), 7.66(\mathrm{~m}, 4 \mathrm{H}), 7.61(\mathrm{~d}, J=8.4 \mathrm{~Hz}, 4 \mathrm{H}), 7.53(\mathrm{~s}, 1 \mathrm{H}), 7.43(\mathrm{~d}, J=8.4 \mathrm{~Hz}$, 4H), $7.26(\mathrm{~d}, J=8.6 \mathrm{~Hz}, 12 \mathrm{H}), 7.22(\mathrm{~m}, 4 \mathrm{H}), 7.10(\mathrm{~d}, J=8.6 \mathrm{~Hz}, 12 \mathrm{H}), 7.05(\mathrm{~d}, J=8.9 \mathrm{~Hz}, 4 \mathrm{H})$, $6.97(\mathrm{~s}, 2 \mathrm{H}), 6.87(\mathrm{~s}, 1 \mathrm{H}), 6.83(\mathrm{~s}, 1 \mathrm{H}), 6.79(\mathrm{~d}, J=7.6 \mathrm{~Hz}, 4 \mathrm{H}), 6.76(\mathrm{~s}, 1 \mathrm{H}), 6.70(\mathrm{~d}, J=8.9 \mathrm{~Hz}$, 4H), $5.81(\mathrm{~s}, 4 \mathrm{H}), 5.80(\mathrm{~s}, 4 \mathrm{H}), 5.31(\mathrm{~s}, 2 \mathrm{H}), 4.46(\mathrm{~s}, 4 \mathrm{H}), 4.17(\mathrm{~m}, 8 \mathrm{H}), 3.99(\mathrm{~m}, 4 \mathrm{H}), 3.88(\mathrm{~m}$, 8H), $3.74(\mathrm{~m}, 4 \mathrm{H}), 3.70(\mathrm{~m}, 8 \mathrm{H}), 3.66(\mathrm{~m}, 4 \mathrm{H}), 3.60(\mathrm{~m}, 8 \mathrm{H}), 3.57(\mathrm{~m}, 4 \mathrm{H}), 1.36(\mathrm{~s}, 18 \mathrm{H}), 1.26(\mathrm{~s}$ 54H). ${ }^{13} \mathrm{C}$ NMR $\left(\mathrm{CD}_{3} \mathrm{CN}, 125 \mathrm{MHz}\right): \delta_{\mathrm{ppm}}=157.6,155.2,152.8,150.7,150.4,149.4,146.7,146.6$, $145.5,141.7,140.6,139.9,137.6,136.6,135.9,134.4,132.6,131.5,131.2,130.2,128.0,127.6$, $127.3,127.3,126.9,126.7,126.4,126.4,123.7,123.0,122.5,120.5,120.0,117.0,115.0,115.0$ $114.3,113.9,106.9,73.2,71.5,71.5,71.2,70.5,70.4,70.3,70.2,69.0,68.3,64.5,63.9,62.3,62.1$, 35.4, 34.9, 31.5. HRMS (ESI) for DB·4PF 6 ; Calcd for $\left[\mathrm{C}_{185} \mathrm{H}_{211} \mathrm{~F}_{12} \mathrm{~N}_{7} \mathrm{O}_{17} \mathrm{P}_{2}\right]^{2+}: m / z=1547.2598$ $\left[M-2 \mathrm{PF}_{6}\right]^{2+}$, found: $1547.2601\left[M-2 \mathrm{PF}_{6}\right]^{2+}$

\section{Section C. Crystallographic Characterization}

General procedure used to grow single crystals and collect diffraction data on $\left[m-\mathrm{N}_{3}-\mathrm{Ar}_{2^{-}}\right.$ CBPQT $\subset$ MS $]^{4(+\bullet)}$. Under a $\mathrm{N}_{2}$ atmosphere in a glovebox, the tetracationic cyclophanes $\left(\boldsymbol{m}-\mathbf{N}_{3^{-}}\right.$ $\mathrm{Ar}_{2}-\mathrm{CBPQT} \cdot 4 \mathrm{PF}_{6}$ and $\left.\mathrm{MS} \cdot 4 \mathrm{PF}_{6}\right)$ were dissolved in $\mathrm{MeCN}$ and mixed (1:1) to obtain a solution containing $1 \mathrm{mM}$ of each cyclophane. This mixture was stirred over an excess of $\mathrm{Zn}$ dust for $1 \mathrm{~h}$ to provide a dark purple solution of the tetraradical tetracationic ring-in-ring complex $\left[\boldsymbol{m}-\mathbf{N}_{3}-\mathbf{A r}_{2}{ }^{-}\right.$ CBPQT $\subset$ MS $]^{4(+\bullet)}$. This solution was filtered, and dark purple crystals were grown over the course of 7-10 days by vapor diffusion of ${ }^{i} \mathrm{Pr}_{2} \mathrm{O}$ into the $\left[\boldsymbol{m}-\mathbf{N}_{3}-\mathbf{A r} \mathbf{r}_{2}-\mathbf{C B P Q T} \subset \mathbf{M S}\right]^{4(+\bullet)}$ solution at ambient temperature inside of the glovebox. 
Experimental. A suitable crystal was selected, and the crystal was mounted on a MITIGEN holder paratone on a Bruker APEX-II CCD diffractometer. The crystal was kept at $100 \mathrm{~K}$ during data collection. Using Olex $2,{ }^{6}$ the structure was solved with the ShelXT ${ }^{7}$ structure solution program using intrinsic phasing and refined with the $\mathrm{ShelXL}^{8}$ refinement package using least squares minimization.

Refinement Details. Distance restraints were imposed on the disordered $\mathrm{PF}_{6}{ }^{-}$anions. The enhanced rigid-bond restraint (SHELX keyword RIGU) was applied on the disordered atoms. ${ }^{9}$ ISOR restraints were imposed on C61, C61a, C58 and C58a restrained esd (0.01) that its Uij components approximate to isotropic. Restraints on similar amplitudes separated by less than 1.7 $\AA ̊$ on a disordered $\mathrm{PF}_{6}{ }^{-}$anions and the bridging $\mathrm{C} 58, \mathrm{C} 61$ carbon atoms.

Solvent Treatment Details. The solvent masking procedure as implemented in Olex2 was used to remove the electronic contribution of solvent molecules from the refinement. As the exact solvent content is not known, only the atoms used in the refinement model are reported in the formula here. Total solvent accessible volume / cell $=442.4 \AA^{3}[7.7 \%]$ Total electron count / cell $=108.2$. 


\section{Crystal Data Table}

\begin{tabular}{|c|c|}
\hline Empirical formula & $\mathrm{C}_{112} \mathrm{H}_{107} \mathrm{~F}_{24} \mathrm{~N}_{15} \mathrm{P}_{4}$ \\
\hline Formula weight & 2243.00 \\
\hline Temperature / K & 100.0 \\
\hline Crystal system & triclinic \\
\hline Space group & $P \overline{1}$ \\
\hline$a / \AA, b / \AA, c / \AA$ & $14.2048(10), 16.4078(10), 25.0897(16)$ \\
\hline$\alpha{ }^{\circ}, \beta /^{\circ}, \gamma /{ }^{\circ}$ & $96.289(4), 94.009(4), 98.065(4)$ \\
\hline Volume / $\AA^{3}$ & $5733.3(7)$ \\
\hline$Z$ & 2 \\
\hline$\rho_{\text {calc }} / \mathrm{mg} \mathrm{mm}^{-3}$ & 1.299 \\
\hline$\mu / \mathrm{mm}^{-1}$ & 1.403 \\
\hline$F(000)$ & 2320 \\
\hline Crystal size $/ \mathrm{mm}^{3}$ & $0.581 \times 0.092 \times 0.066$ \\
\hline \multicolumn{2}{|c|}{$2 \Theta$ range for data collection $/{ }^{\circ} 3.556$ to 133.498} \\
\hline Index ranges & $-15 \leq h \leq 16,-19 \leq k \leq 19,-29 \leq l \leq 29$ \\
\hline Reflections collected & 77467 \\
\hline Independent reflections & $20251\left[R_{\mathrm{int}}=0.0500\right]$ \\
\hline Data/restraints/parameters & $20251 / 879 / 1731$ \\
\hline Goodness-of-fit on $F^{2}$ & 1.035 \\
\hline Final $R$ indexes $[I>2 \sigma(I)]$ & $R_{1}=0.0718, w R_{2}=0.1845$ \\
\hline Final $R$ indexes [all data] & $R_{1}=0.0839, w R_{2}=0.1943$ \\
\hline
\end{tabular}



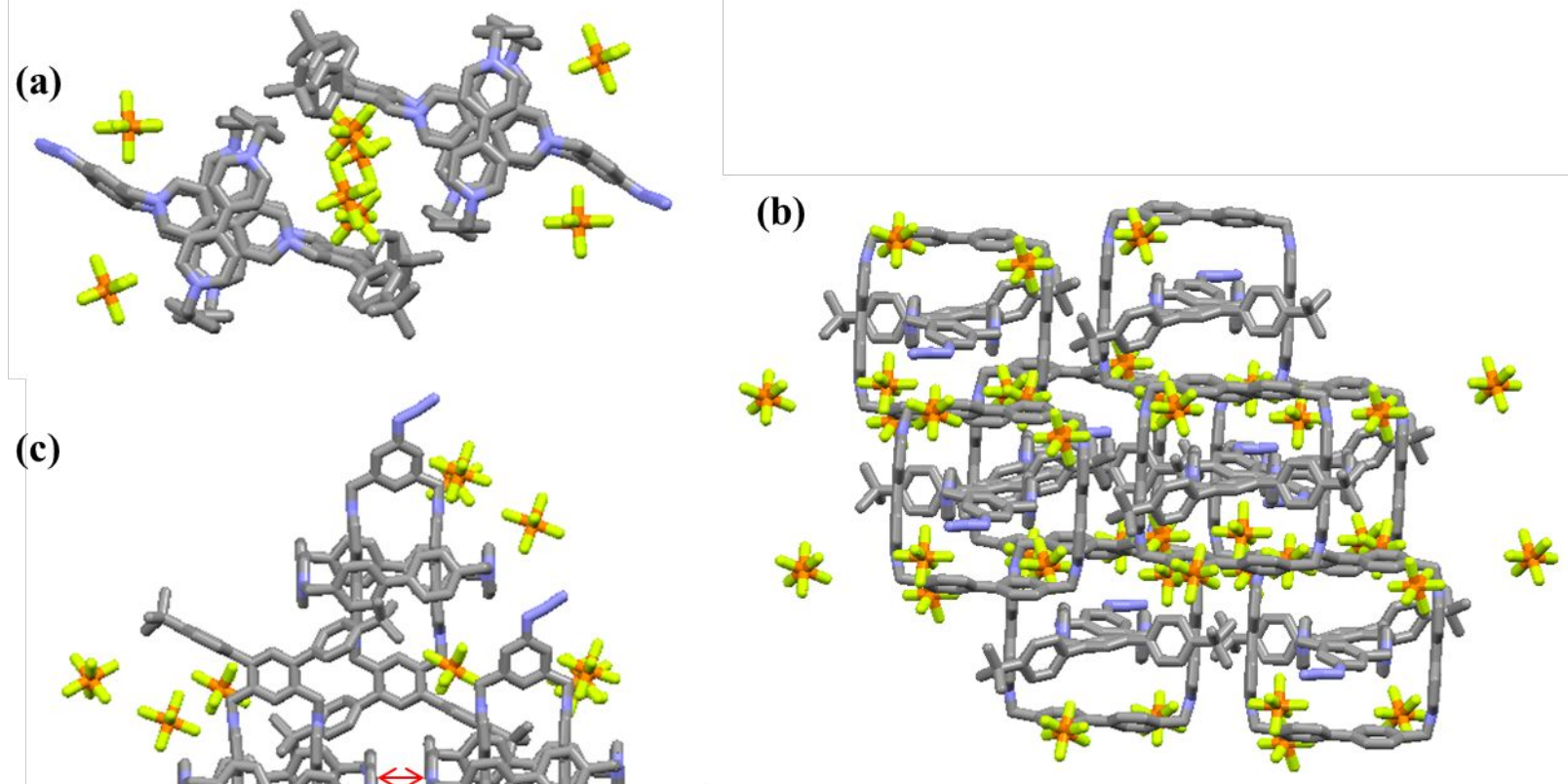

(c)

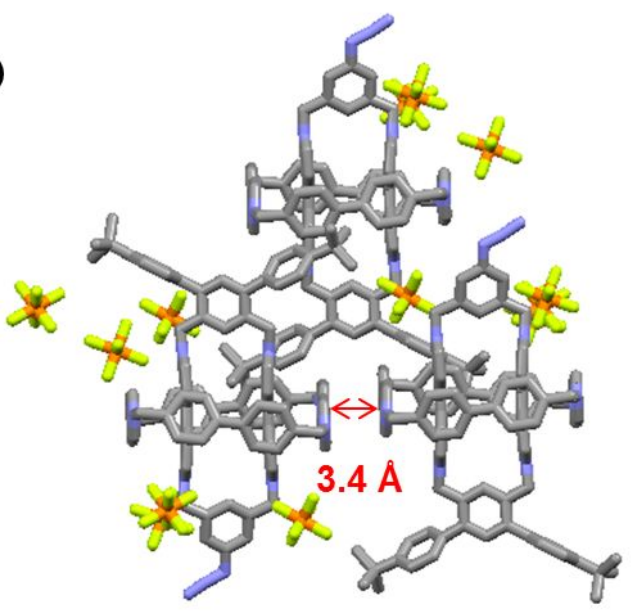

Figure S1. Solid-state superstructure of $\left[\boldsymbol{m}-\mathbf{N}_{3}-\mathbf{A r}_{2}-\mathbf{C B P Q T} \subset \mathbf{M S}\right]^{4(+\bullet)}$ with the $\mathrm{PF}_{6}{ }^{-}$counterions included. Hydrogen atoms have been omitted for the sake of clarity. a) Spatial arrangement, view with the viologen planes aligned parallel with the page. b) Molecular packing of the $\left[\boldsymbol{m}-\mathbf{N}_{3}-\mathbf{A r}_{\mathbf{2}^{-}}\right.$ CBPQT $\subset \mathbf{M S}]^{4(+\bullet)}$ complex with the $\mathbf{M S}^{2(+\bullet)}$ macrocyclic rings aligned parallel to the plane of the page, with the viologen units of $\mathbf{M S}^{2(+\bullet)}$ positioned on the left and right and the biphenyl units on the top and bottom. c) Spatial arrangement with the $\boldsymbol{m}-\mathbf{N}_{3}-\mathbf{A r}_{2}-\mathbf{C B P Q T}{ }^{2(+\bullet)}$ macrocyclic rings aligned parallel to the plane of the page. 


\section{Section D. Mass Spectrometry}

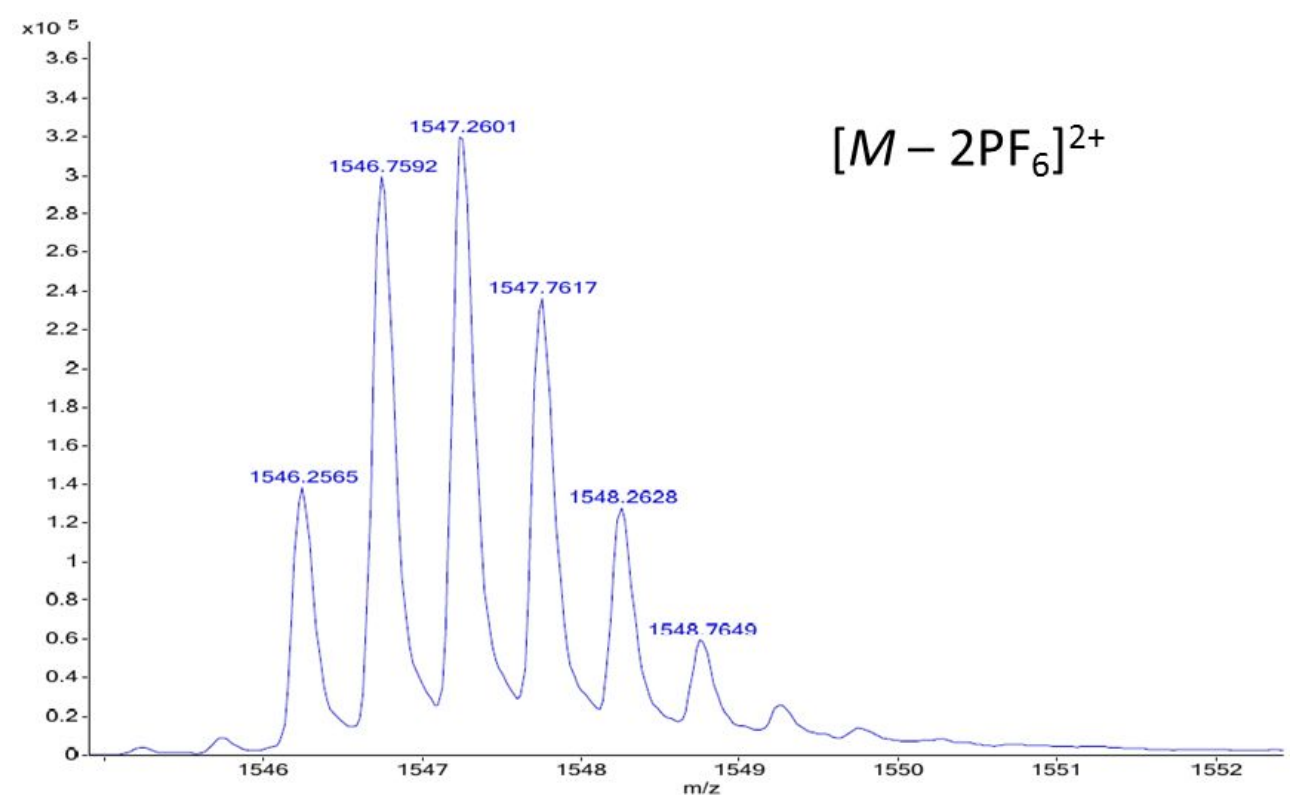

Figure S2. High-Resolution ESI-MS of DB·4PF 6 . Zoom of $\left[M-2 \mathrm{PF}_{6}\right]^{2+}$. Calculated peaks $m / z=$ $1546.2566 ; 1546.7583 ; 1547.2599 ; 1547.7615 ; 1548.2632 ; 1548.7648$

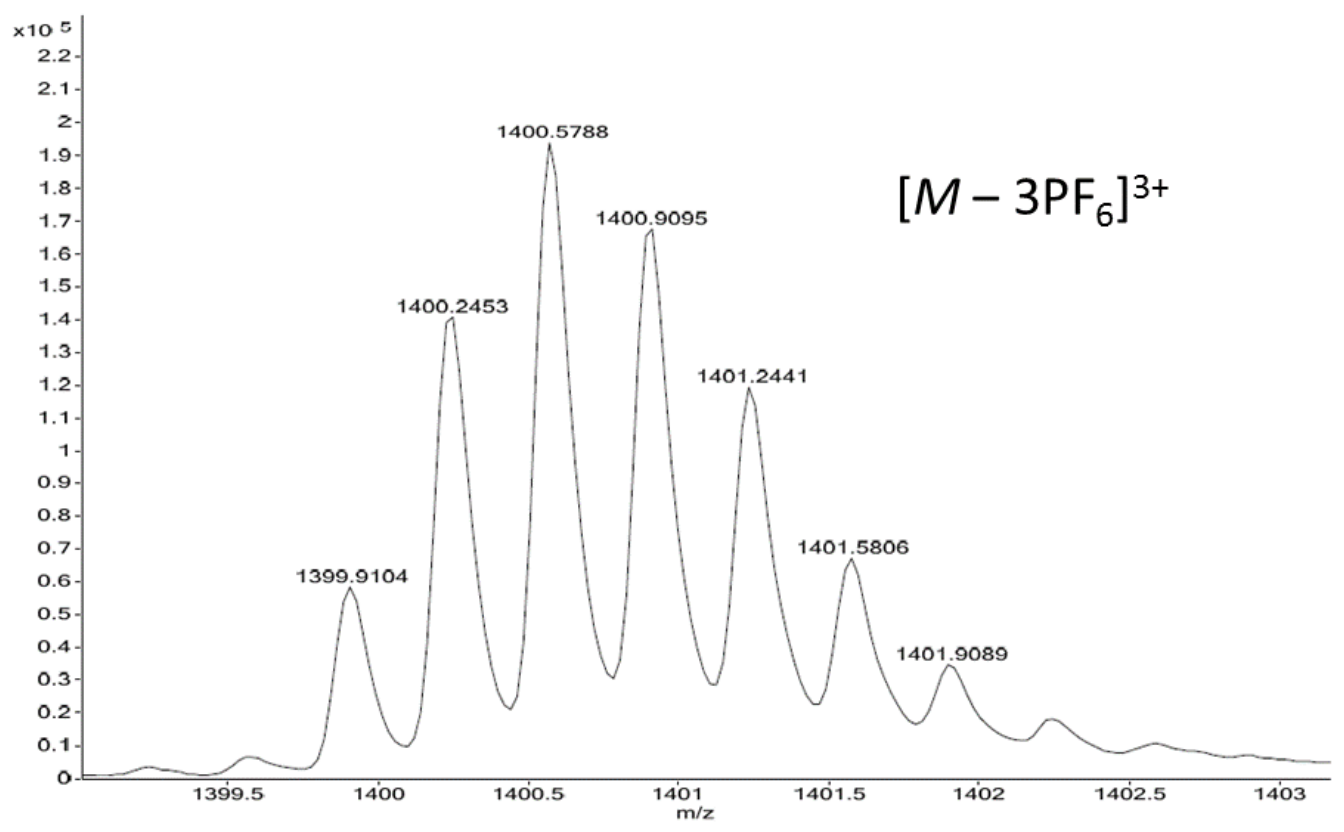

Figure S3. High-Resolution ESI-MS of Zip-R·8PF 6 . Zoom of $\left[M-3 \mathrm{PF}_{6}\right]^{3+}$. Calculated peaks $m / z$ $=1399.9102 ; 1400.2446 ; 1400.5790 ; 1400.9134 ; 1401.2478 ; 1401.5823 ; 1401.9166$ 


\section{Section E. UV-Vis-NIR Spectroscopy}

Stock solutions of Zip-R $\cdot 8 \mathrm{PF}_{6}(1.4 \mathrm{mM}), \mathbf{M S} \cdot 4 \mathrm{PF}_{6}(1 \mathrm{mM})$ and $\boldsymbol{m}-\mathbf{N}_{\mathbf{3}}-\mathbf{A r}_{\mathbf{2}}-\mathbf{C B P Q T} \cdot 4 \mathrm{PF}_{6}(1 \mathrm{mM})$ were prepared in air-free $\mathrm{MeCN}$ under a $\mathrm{N}_{2}$ atmosphere of a glove-box. Activated $\mathrm{Zn}$ dust was added to those stock solutions and the mixtures stirred for $15 \mathrm{~min}$ to form dark blue solutions of the individual macrocycles $\left(\mathbf{M S}^{\mathbf{2 ( + \bullet})}\right.$ and $\boldsymbol{m}-\mathbf{N}_{\mathbf{3}}-\mathbf{A r}_{2}-\mathbf{C B P Q T}^{\mathbf{2 ( + \bullet})}$ ) and a dark magenta-purple solution of the tetraradical tetracation $\mathbf{Z i p}-\mathbf{R}^{\mathbf{4 ( + \bullet}}$. These solutions were filtered and diluted with air-free $\mathrm{MeCN}$ using precision syringes prior to being transferred to a $1.0 \mathrm{~cm}$ quartz cuvette. The complex $\left[\boldsymbol{m}-\mathbf{N}_{\mathbf{3}}-\mathbf{A r}_{\mathbf{2}}-\mathbf{C B P Q T} \subset \mathbf{M S}\right]^{\mathbf{4 ( + \bullet )}}(3.33 \mathrm{mM})$ was obtained in similar fashion by reduction with $\mathrm{Zn}$ dust of a stock solution containing 1 equiv. each of $\mathbf{M S} \cdot 4 \mathrm{PF}_{6}$ and $\boldsymbol{m}-\mathbf{N}_{\mathbf{3}}-\mathbf{A r}_{\mathbf{2}}-\mathbf{C B P Q T} \cdot 4 \mathrm{PF}_{6}$ in air-free MeCN. After 15 min the $\mathrm{Zn}$ was filtered off and the dark magenta-purple solution of $\left[\boldsymbol{m}-\mathbf{N}_{3}-\mathrm{Ar}_{2}-\mathbf{C B P Q T} \subset \mathrm{MS}\right]^{\mathbf{4 ( + )}}$ diluted with air-free $\mathrm{MeCN}$ to reach the desired concentration.

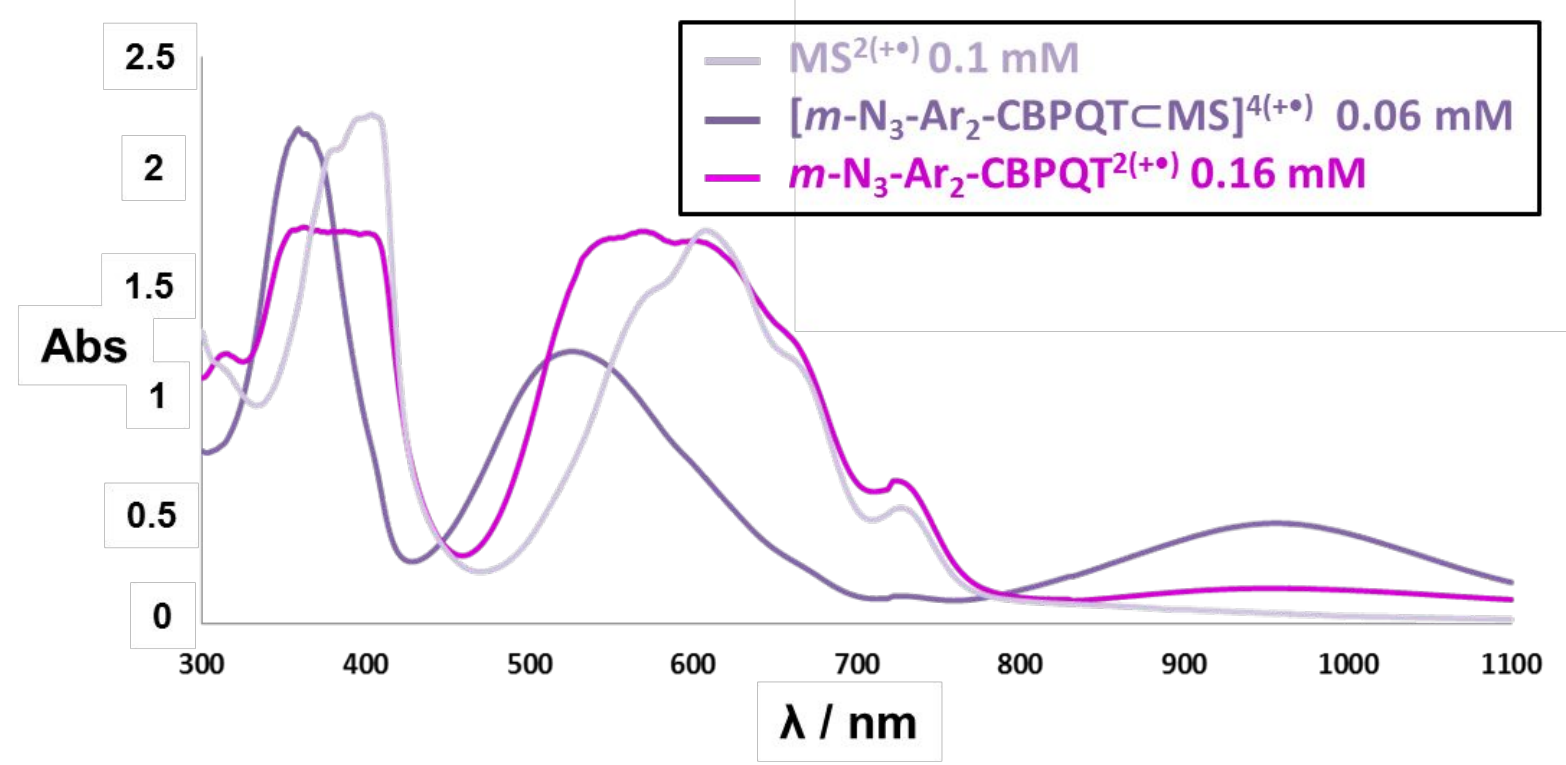

Figure S4. UV-Vis-NIR spectra of $\left[\boldsymbol{m}-\mathbf{N}_{3}-\mathbf{A r}_{2}-\mathbf{C B P Q T} \subset \mathbf{M S}\right]^{4(+\bullet)}$ complex $(0.06 \mathrm{mM}), \mathbf{M S}^{2(+\bullet)}$ $(0.1 \mathrm{mM})$ and $\boldsymbol{m}-\mathbf{N}_{\mathbf{3}}-\mathbf{A r}_{\mathbf{2}}-\mathbf{C B P Q T}^{\mathbf{2}(+\bullet)}(0.16 \mathrm{mM})$ in $\mathrm{MeCN}$ at $298 \mathrm{~K}$ 


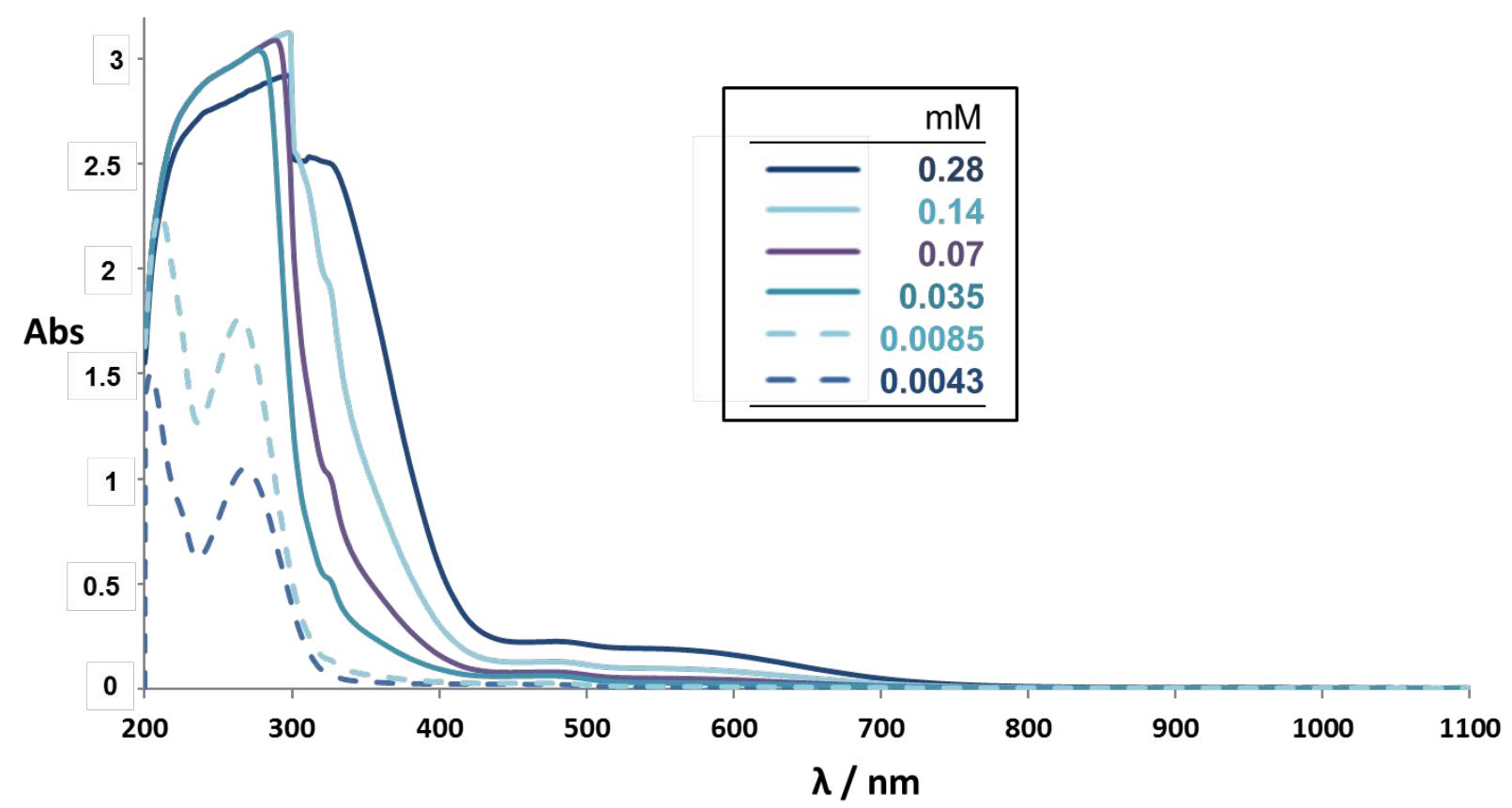

Figure S5. UV-Vis-NIR spectra of the rotaxane Zip-R $8 \mathrm{PF}_{6}$ in $\mathrm{MeCN}$ at $0.28 \mathrm{mM}, 0.14 \mathrm{mM}$, $0.07 \mathrm{mM}, 0.035 \mathrm{mM}, 0.0085 \mathrm{mM}$ and $0.0043 \mathrm{mM}(298 \mathrm{~K})$

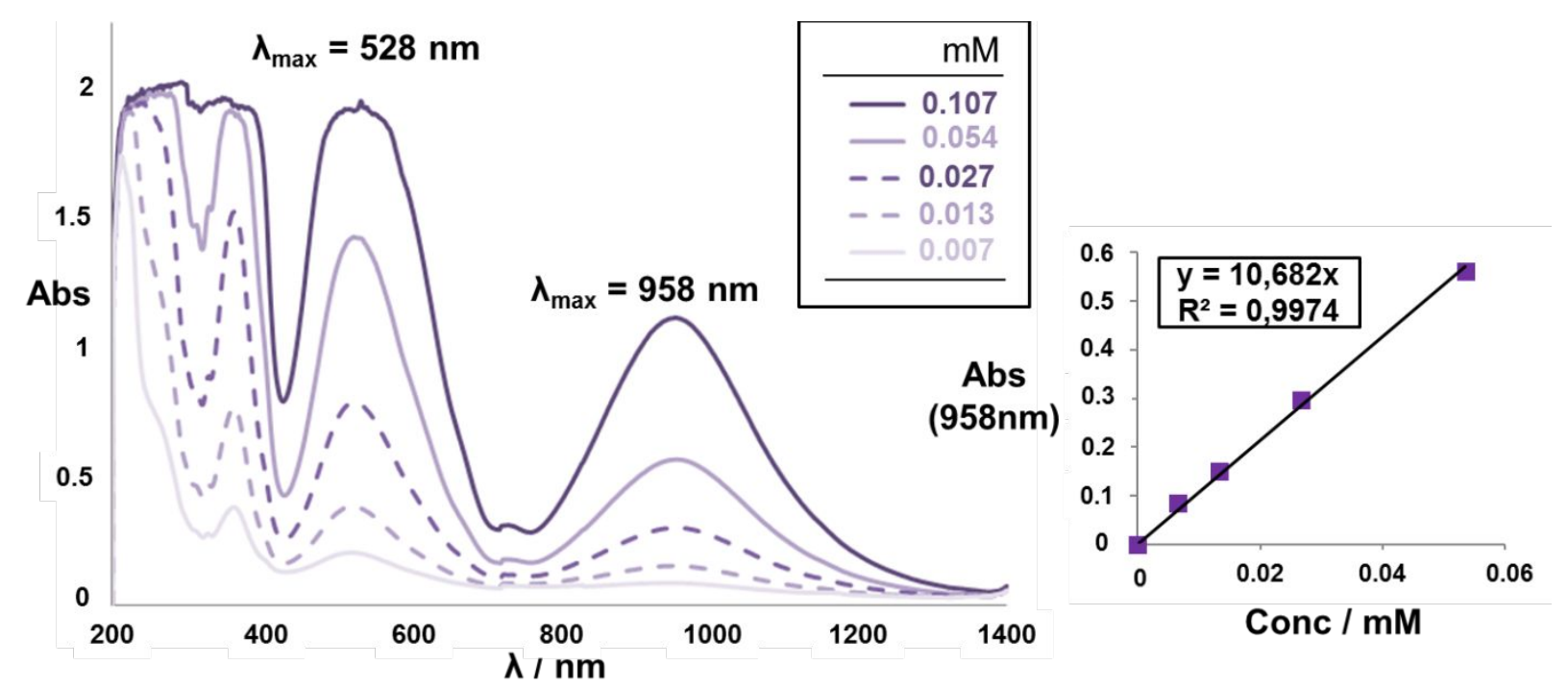

Figure S6. UV-Vis-NIR spectra of the Zip-R· $4 \mathrm{PF}_{6}$ in $\mathrm{MeCN}$ at $0.107 \mathrm{mM}, 0.054 \mathrm{mM}, 0.027$ $\mathrm{mM}, 0.013 \mathrm{mM}$ and $0.007 \mathrm{mM}(298 \mathrm{~K})$ and plot of the absorbance in function of the concentration at $958 \mathrm{~nm}$ 


\section{Section F. NMR Spectroscopy}

All NMR spectra of the radical compounds were recorded in a J-Young tube under an atmosphere of $\mathrm{N}_{2}$ after preparing the samples in a glove-box to prevent oxidation of these samples by air.

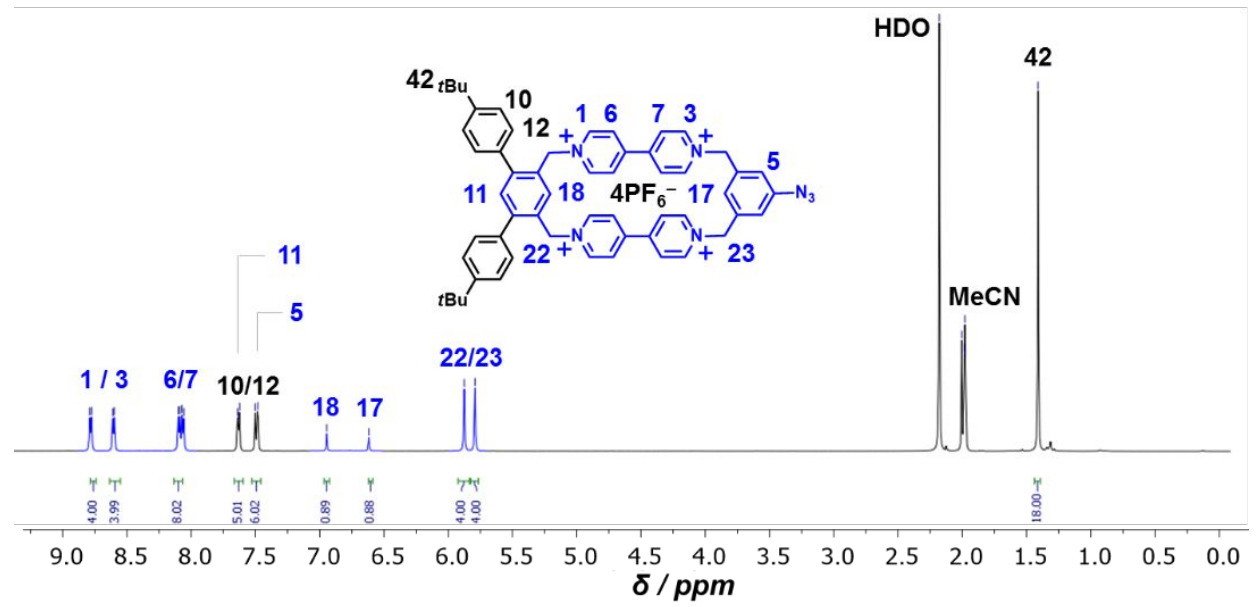

Figure S7. Full ${ }^{1} \mathrm{H}$ NMR spectrum of $\boldsymbol{m}-\mathbf{N}_{\mathbf{3}}-\mathbf{A r}_{\mathbf{2}}-\mathbf{C B P Q T} \cdot 4 \mathrm{PF}_{6}$ in $\mathrm{CD}_{3} \mathrm{CN}(10 \mathrm{mM})$ at $298 \mathrm{~K}(500$ $\mathrm{MHz})$

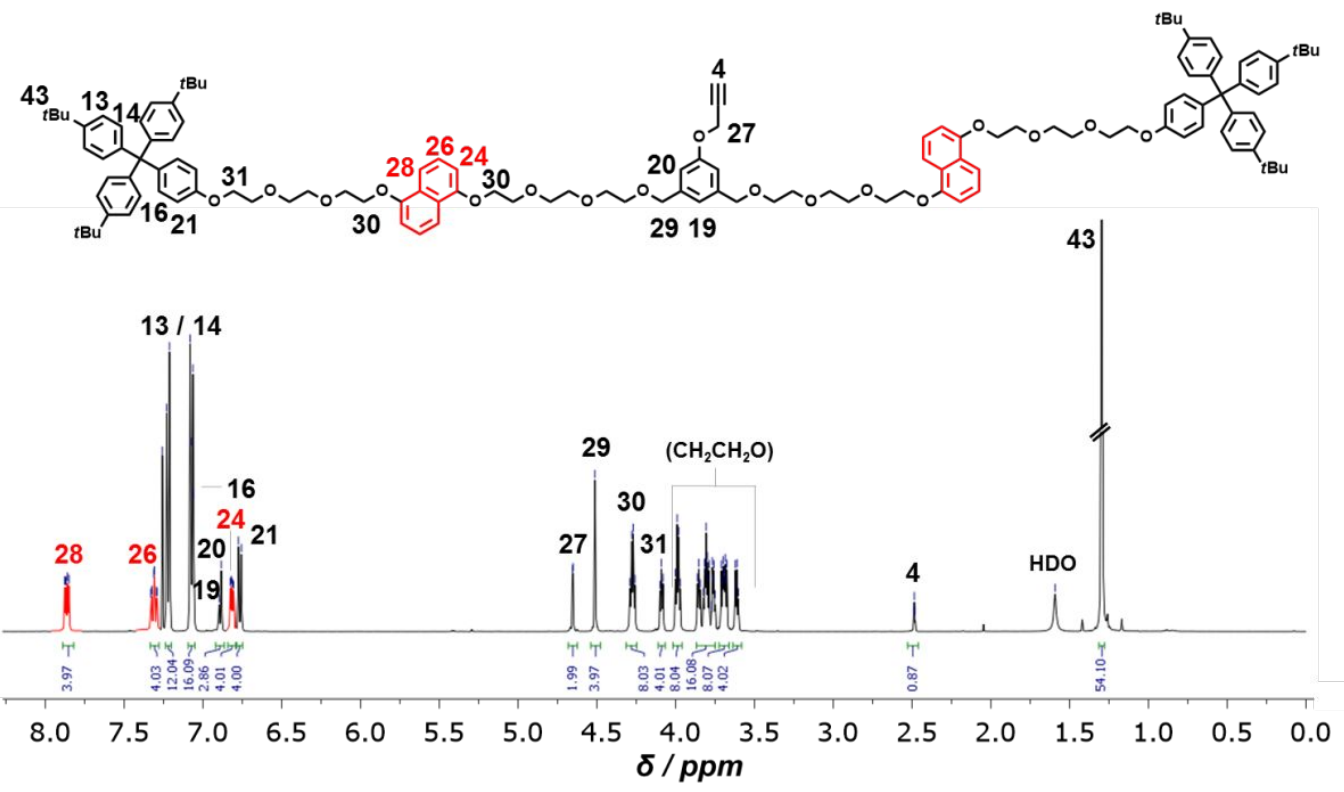

Figure S8. Full ${ }^{1} \mathrm{H}$ NMR spectrum of half-dumbbell alkyne derivative (HD-Alkyne) in $\mathrm{CDCl}_{3}(12$ $\mathrm{mM})$ at $298 \mathrm{~K}(500 \mathrm{MHz})$ 


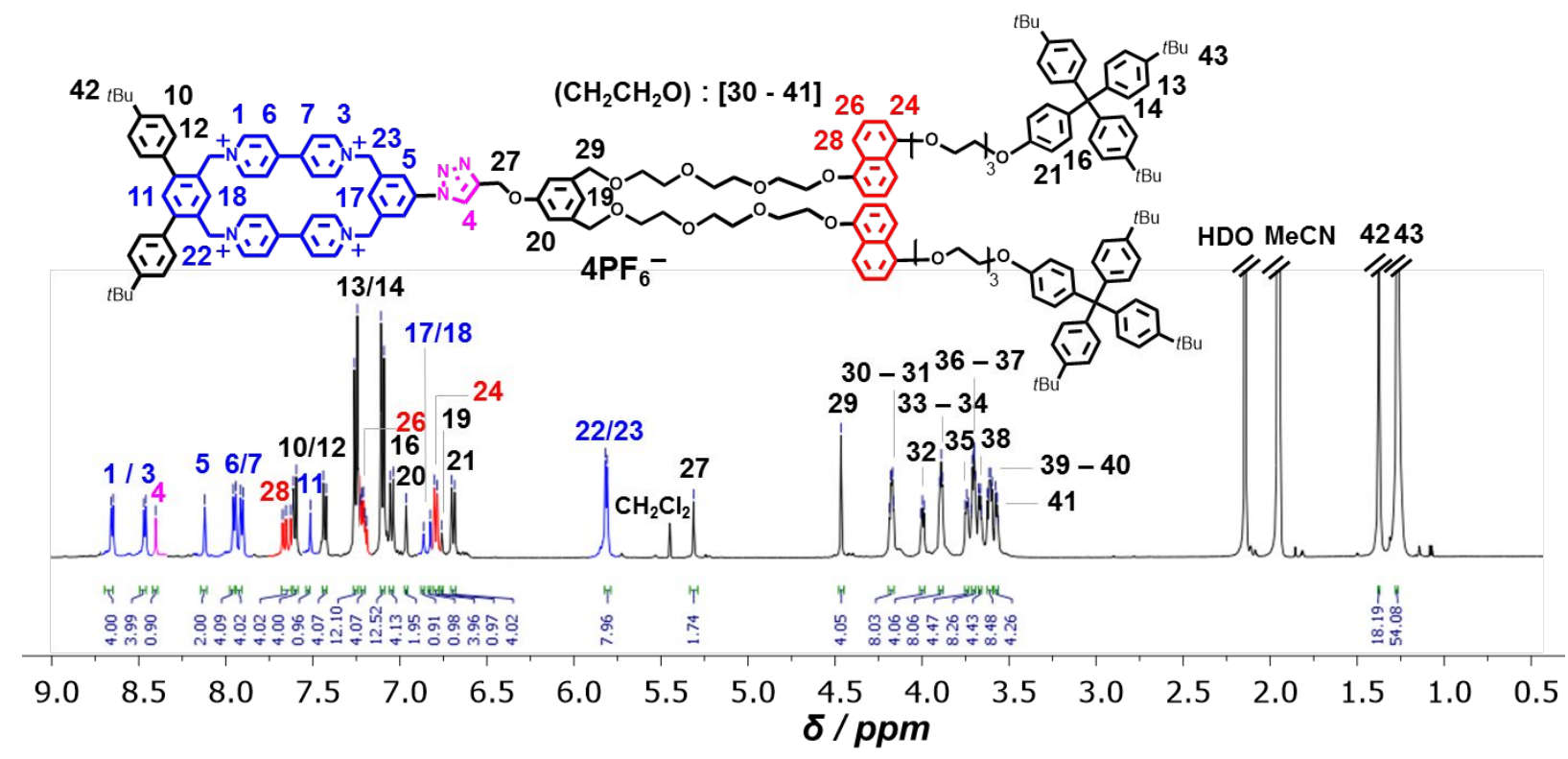

Figure S9. Full ${ }^{1} \mathrm{H}$ NMR spectrum of DB.4PF 6 in $\mathrm{CD}_{3} \mathrm{CN}(3 \mathrm{mM})$ at $298 \mathrm{~K}(500 \mathrm{MHz})$

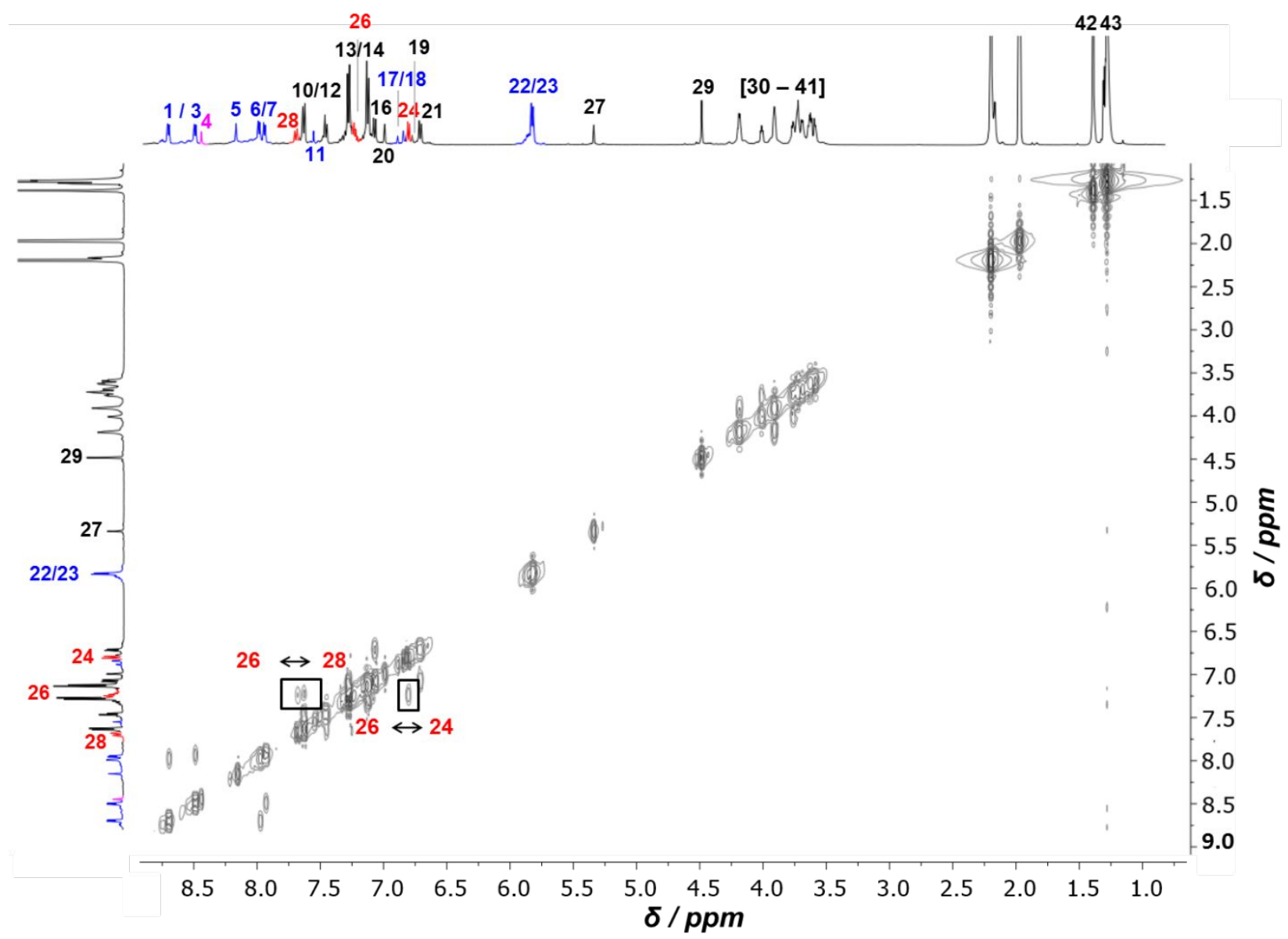

Figure S10. ${ }^{1} \mathrm{H}-{ }^{1} \mathrm{H}$ COSY NMR spectrum of DB· $4 \mathrm{PF}_{6}$ in $\mathrm{CD}_{3} \mathrm{CN}(5 \mathrm{mM})$ at $298 \mathrm{~K}(500 \mathrm{MHz})$ 


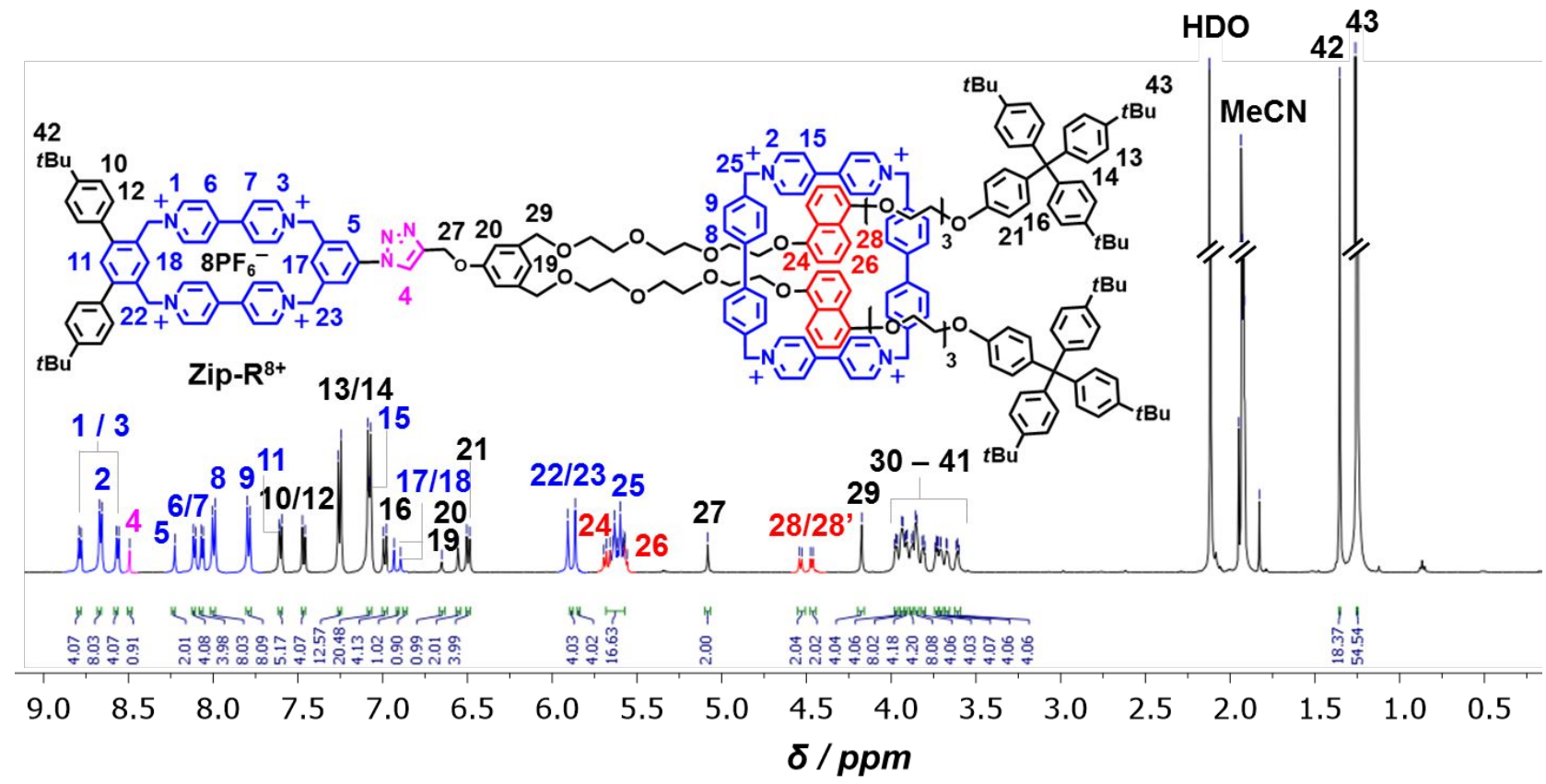

Figure S11. Full ${ }^{1} \mathrm{H}$ NMR spectrum of Zip-R $8 \mathrm{PF}_{6}$ in $\mathrm{CD}_{3} \mathrm{CN}(2.14 \mathrm{mM})$ at $298 \mathrm{~K}(500 \mathrm{MHz})$

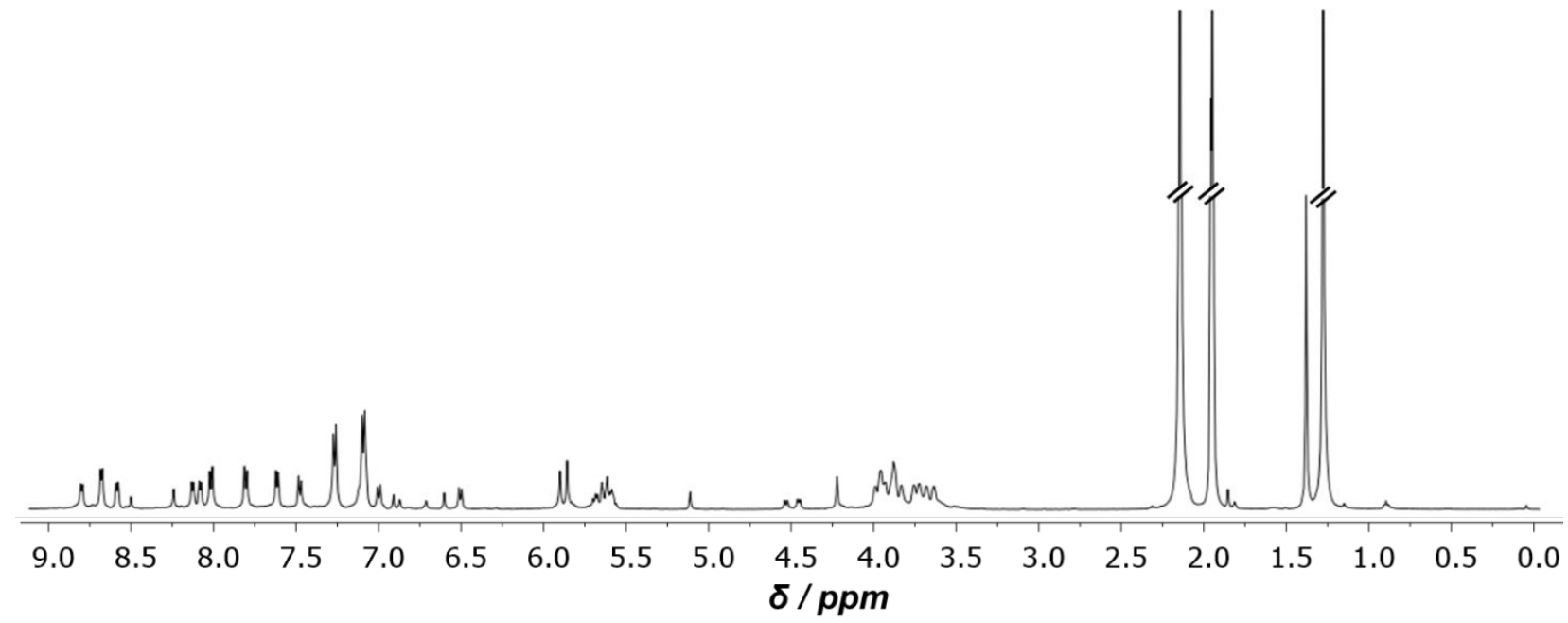

Figure S12. Full ${ }^{1} \mathrm{H}$ NMR spectrum of Zip-R $8 \mathrm{PF}_{6}$ in $\mathrm{CD}_{3} \mathrm{CN}(2 \mathrm{mM})$ at $298 \mathrm{~K}(500 \mathrm{MHz})$ without color code and legend 


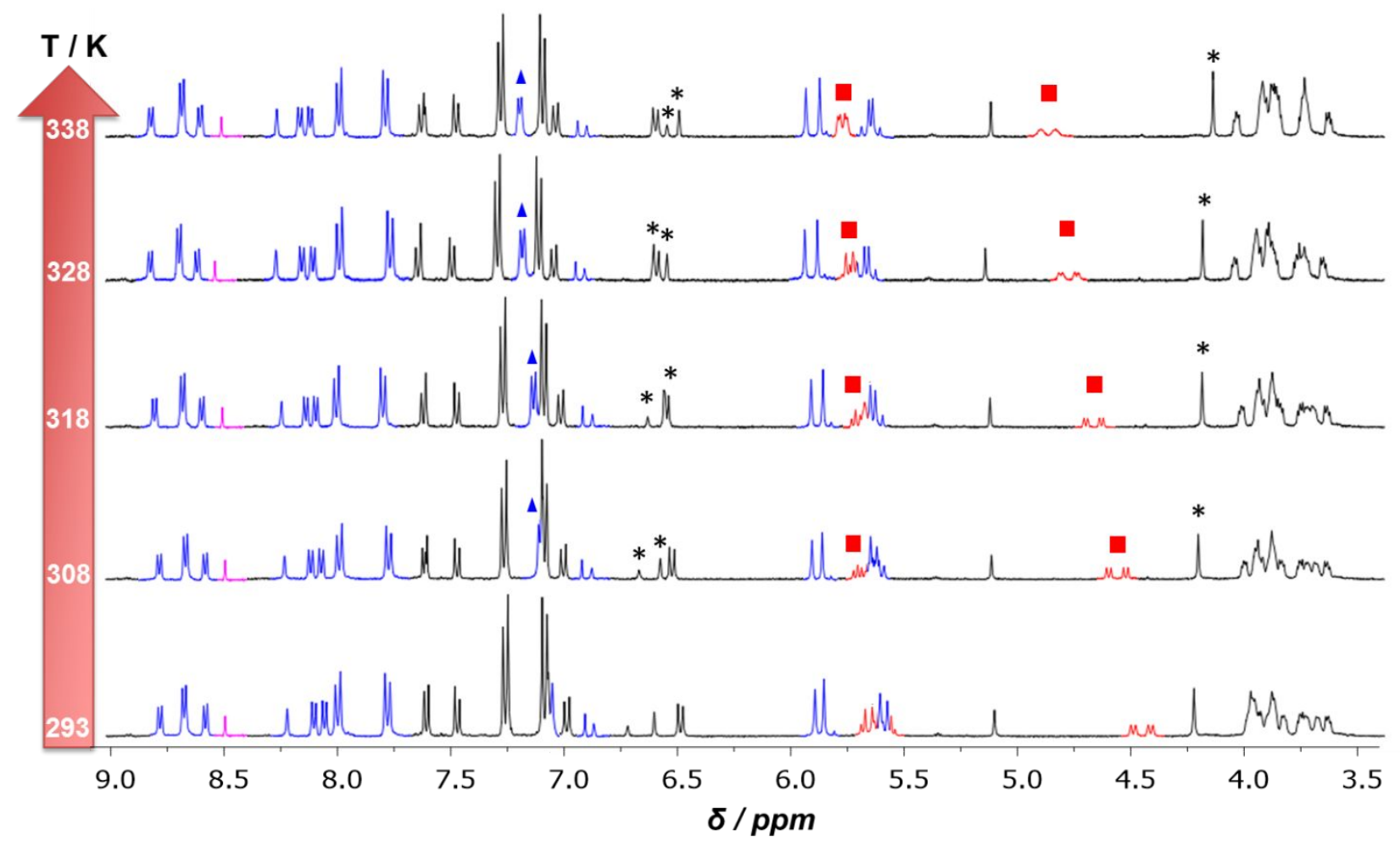

Figure S13. VT ${ }^{1} \mathrm{H}$ NMR spectra of Zip-R·8PF in $\mathrm{CD}_{3} \mathrm{CN}$ (2.14 mM), [293-338] K (600 MHz).

Partial spectra: 9.0-3.4 ppm. Asterisks highlight the shift of $\mathbf{H}_{\mathbf{1 9}}, \mathbf{H}_{\mathbf{2 0}}$ and $\mathbf{H}_{\mathbf{2 9}}$. Squares highlight the shift of $\mathrm{H}_{24}, \mathrm{H}_{26}$ and $\mathrm{H}_{28 / 28}$. Triangles highlight the shift of $\mathrm{H}_{15}$. (See discussion in the main text) 


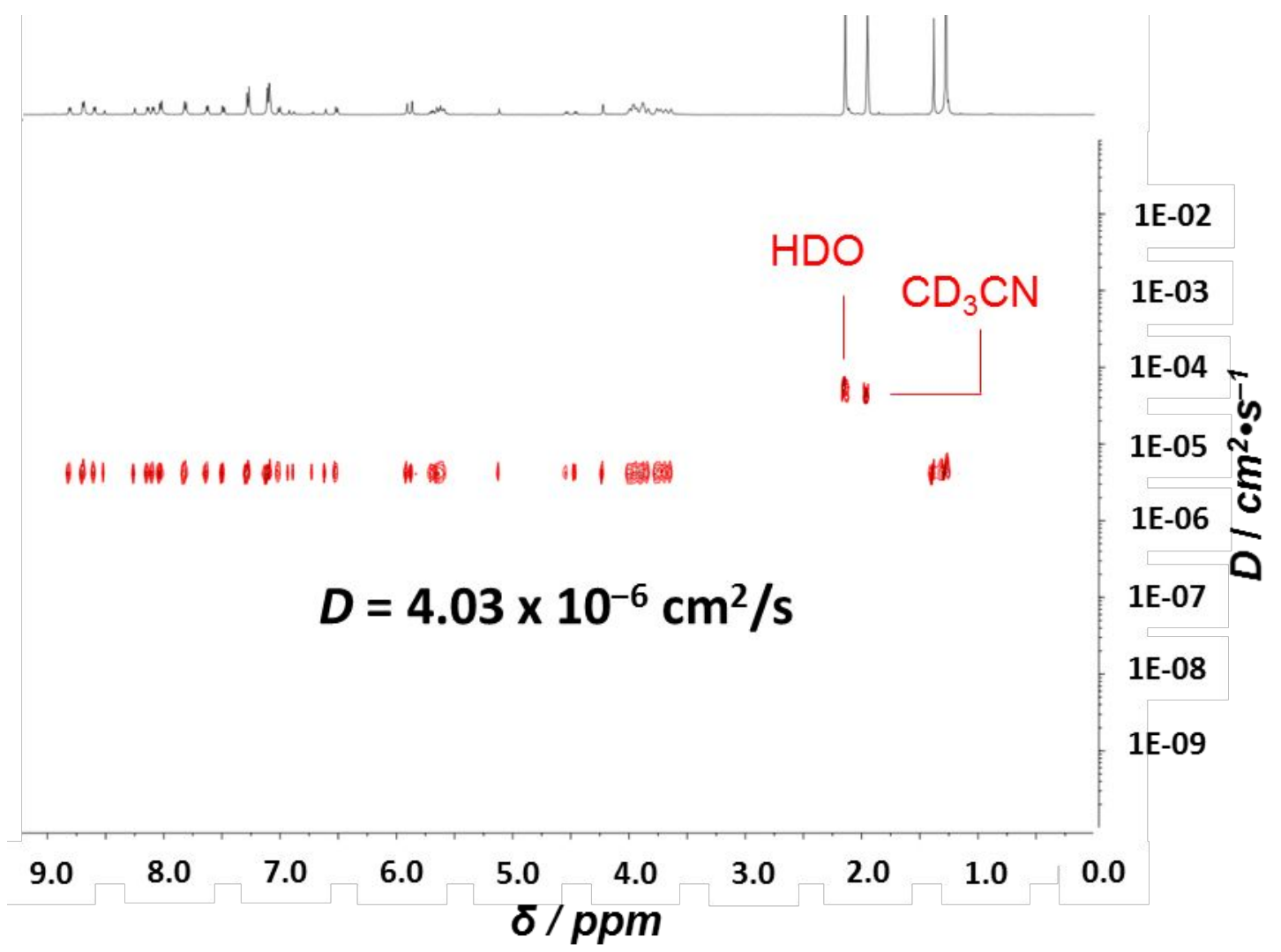

Figure S14. Diffusion ordered (DOSY) ${ }^{1} \mathrm{H}$ NMR spectrum of Zip-R·8PF 6 in $\mathrm{CD}_{3} \mathrm{CN}(2.14 \mathrm{mM})$ at $298 \mathrm{~K}(600 \mathrm{MHz})$

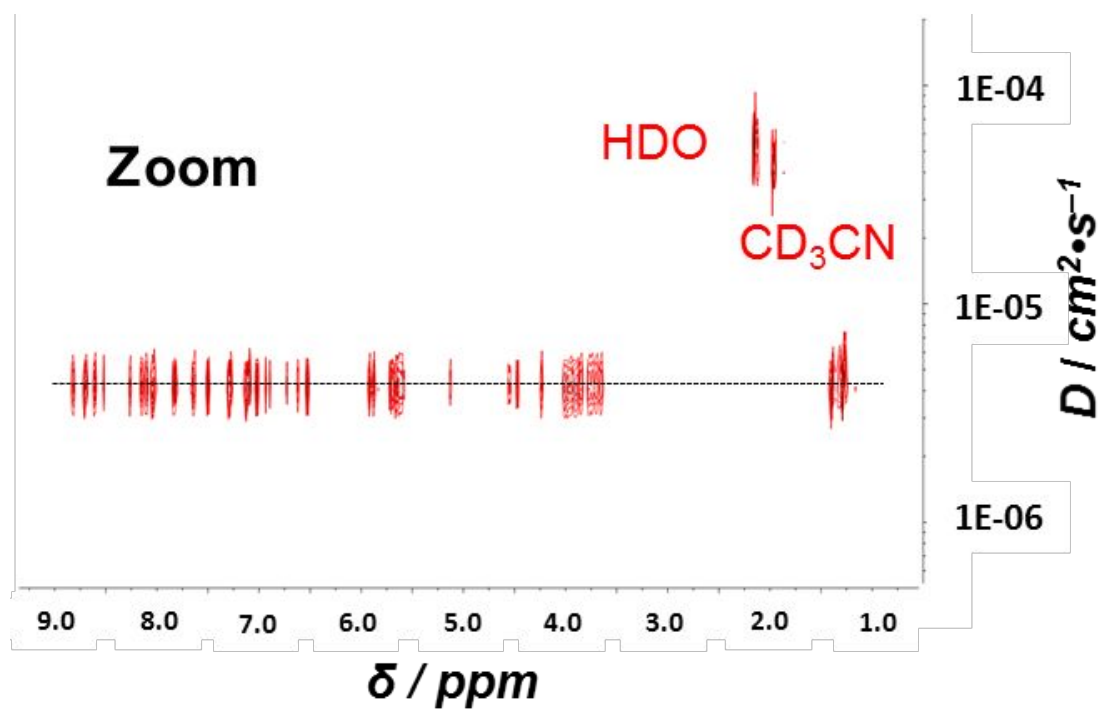

Figure S15. Zoom of the DOSY ${ }^{1} \mathrm{H}$ NMR spectrum of Zip-R·8PF 6 in $\mathrm{CD}_{3} \mathrm{CN}(2.14 \mathrm{mM})$ at 298 $\mathrm{K}(600 \mathrm{MHz})$ 


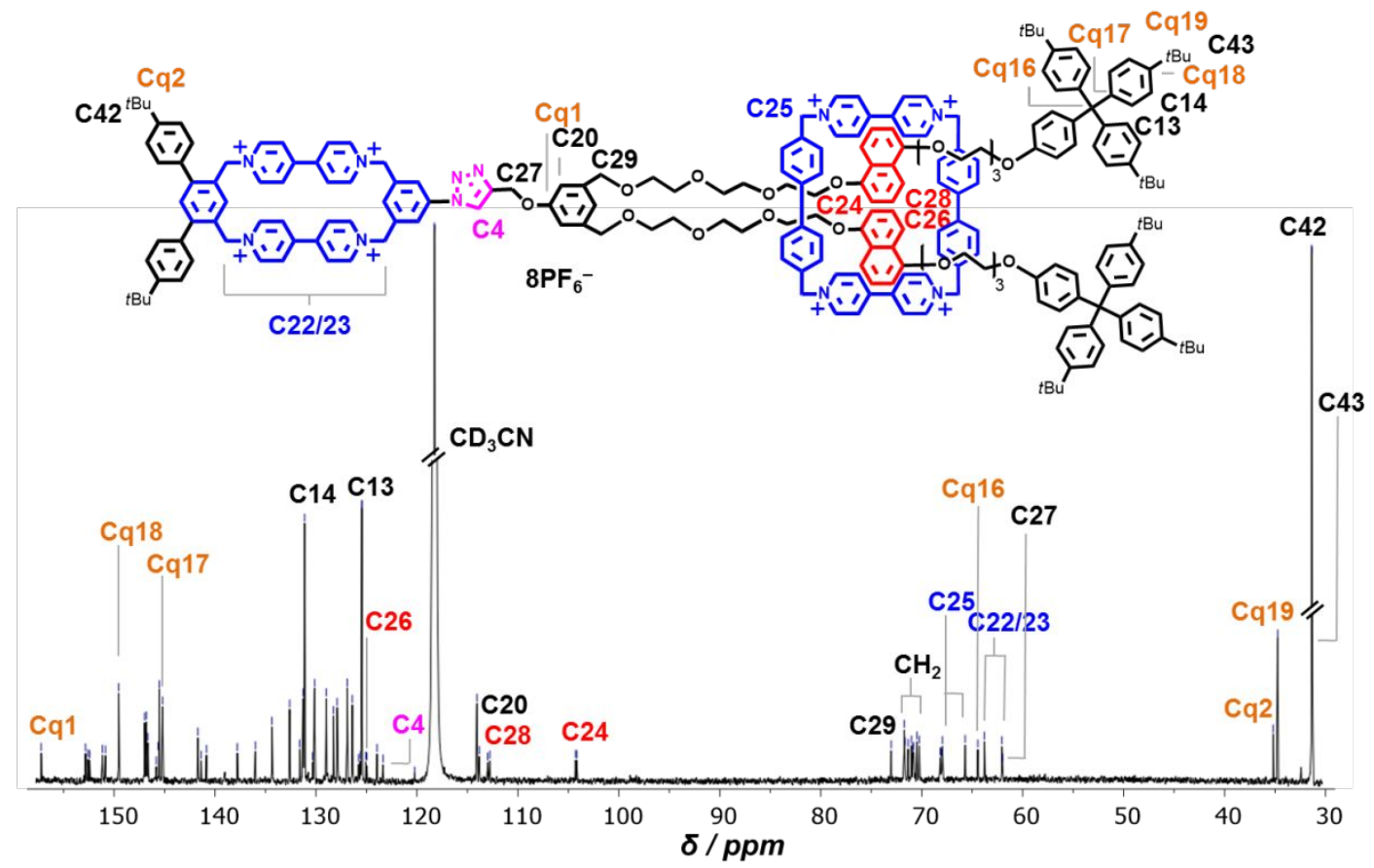

Figure S16. ${ }^{13} \mathrm{C}$ NMR spectrum of Zip-R $8 \mathrm{PF}_{6}$ in $\mathrm{CD}_{3} \mathrm{CN}(5 \mathrm{mM})$ at $298 \mathrm{~K}(500 \mathrm{MHz})$

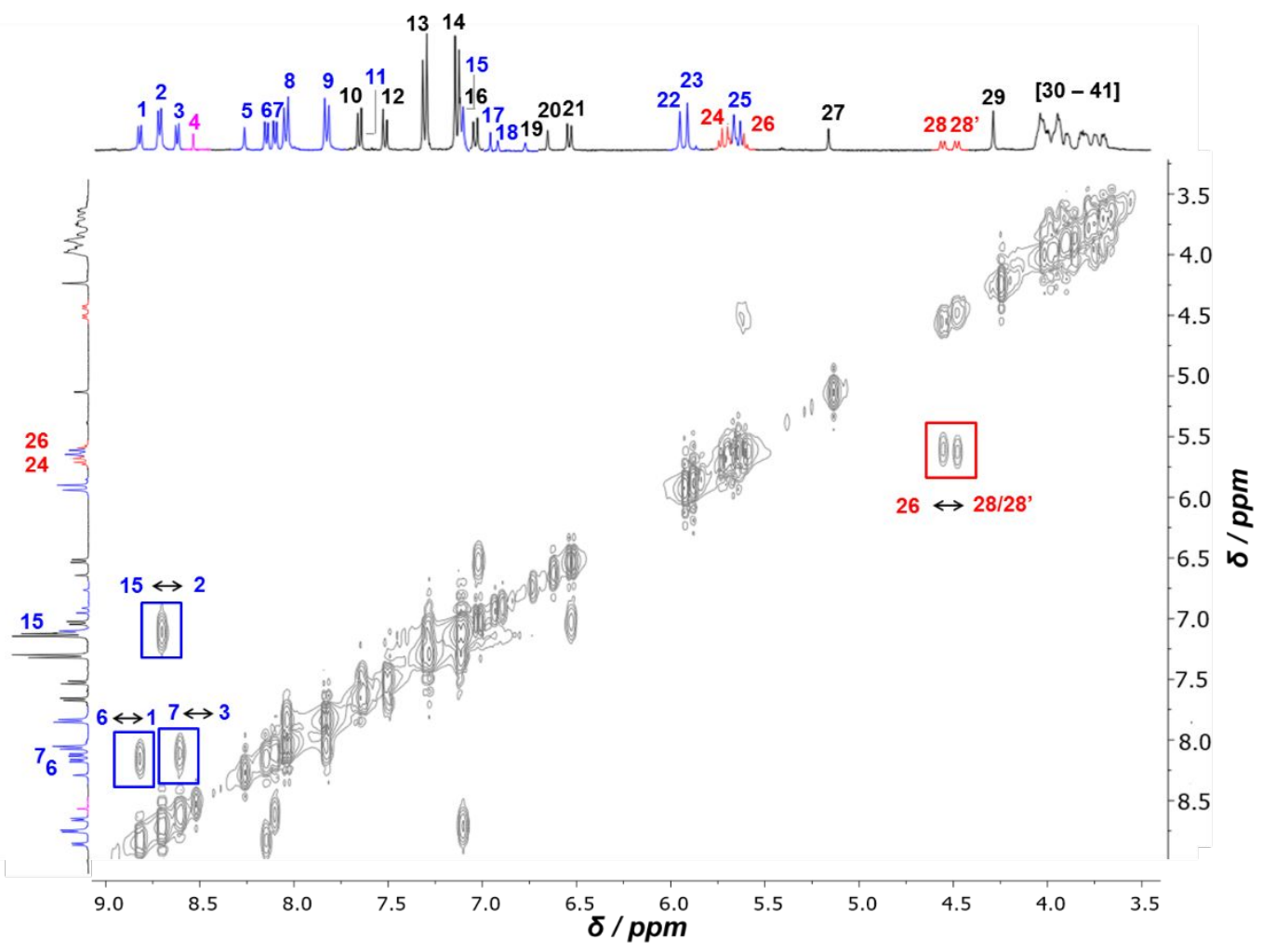

Figure S17. ${ }^{1} \mathrm{H}-{ }^{1} \mathrm{H}$ COSY NMR spectrum of Zip-R $8 \mathrm{PF}_{6}$ in $\mathrm{CD}_{3} \mathrm{CN}(5 \mathrm{mM})$ at $298 \mathrm{~K}(500 \mathrm{MHz})$.

Partial spectrum: 9.0-3.5 ppm 


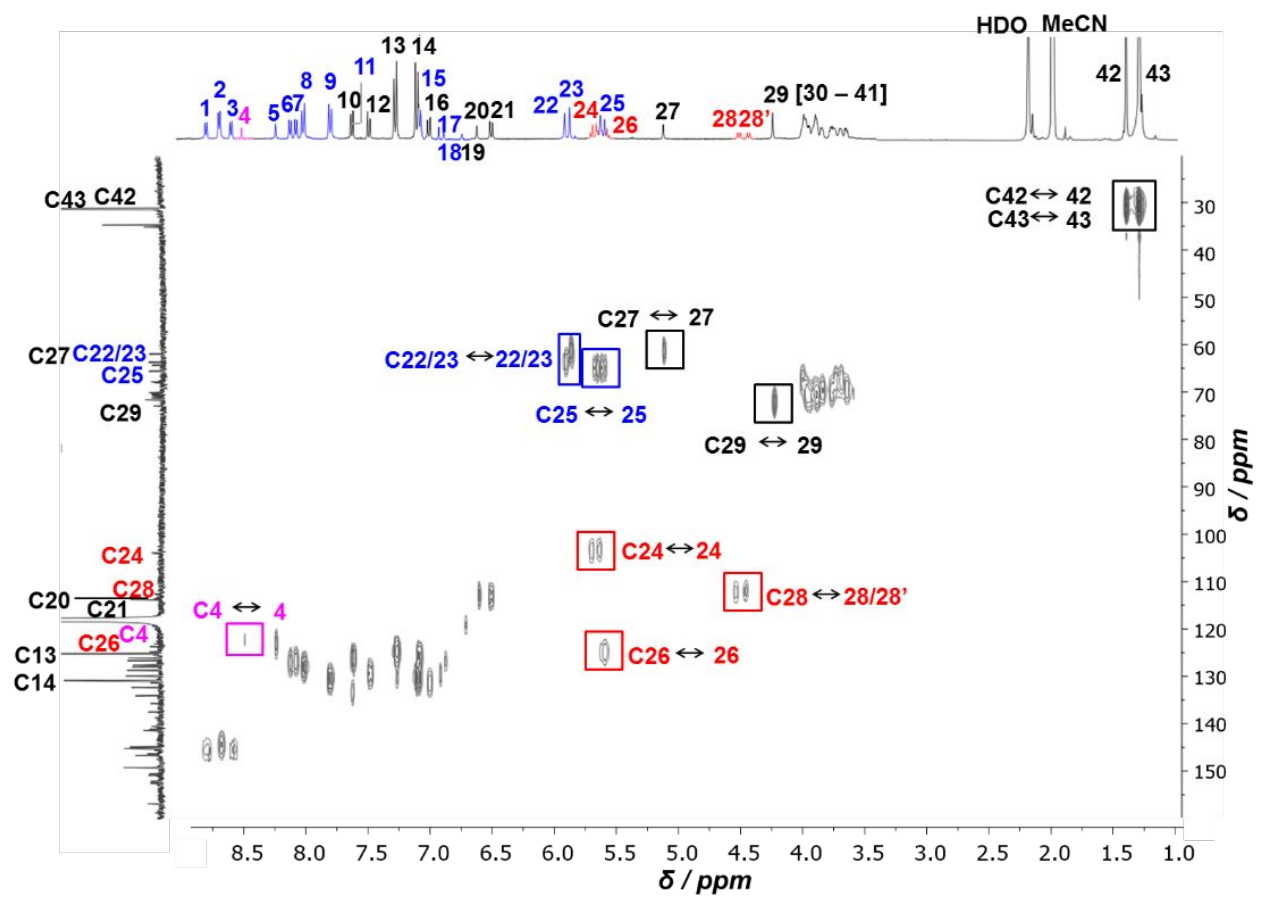

Figure S18. ${ }^{1} \mathrm{H}-{ }^{13} \mathrm{C}$ HSQC NMR spectrum of Zip-R $8 \mathrm{PF}_{6}$ in $\mathrm{CD}_{3} \mathrm{CN}(5 \mathrm{mM})$ at $298 \mathrm{~K}(500 \mathrm{MHz})$.

Partial spectrum: 9.0-1.0 ppm

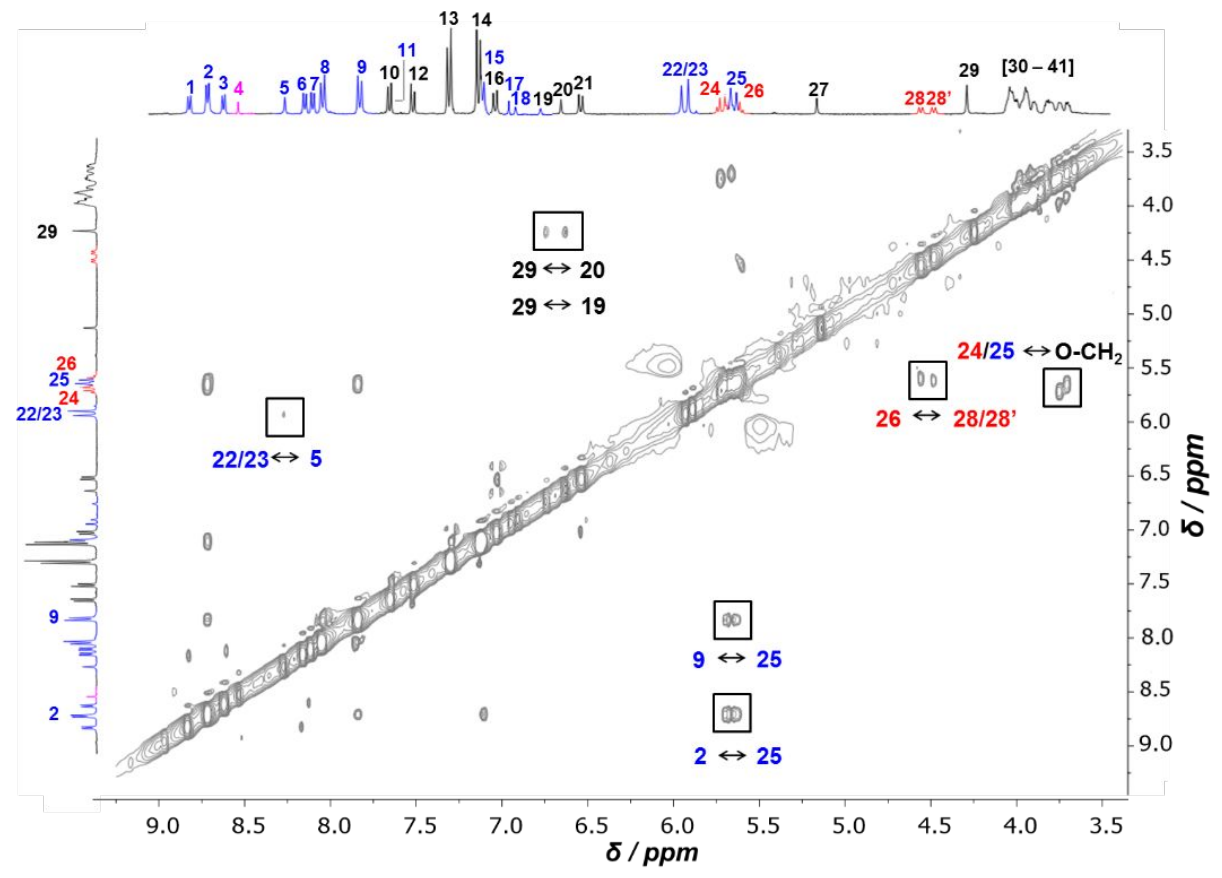

Figure S19. ${ }^{1} \mathrm{H}-{ }^{1} \mathrm{H}$ NOESY NMR spectrum of Zip-R $8 \mathrm{PF}_{6}$ in $\mathrm{CD}_{3} \mathrm{CN}(5 \mathrm{mM})$ at $298 \mathrm{~K}(500$ MHz). Partial spectrum: 9.2-3.5 ppm 


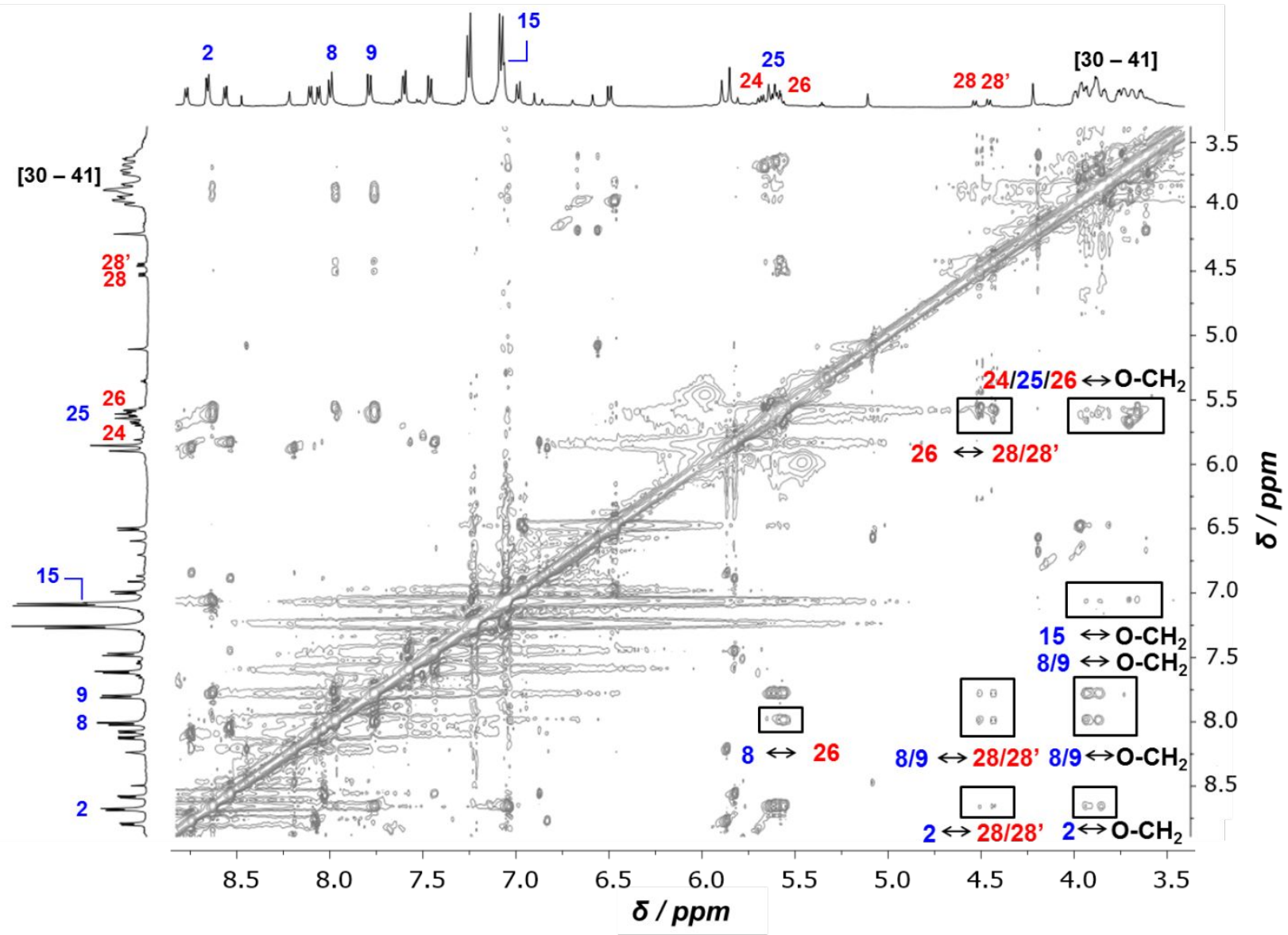

Figure S20. ${ }^{1} \mathrm{H}-{ }^{1} \mathrm{H}$ ROESY NMR spectrum of Zip-R·8PF 6 in $\mathrm{CD}_{3} \mathrm{CN}(2.2 \mathrm{mM})$ at $298 \mathrm{~K}(500$ MHz). Partial spectrum: 9.2-3.5 ppm 


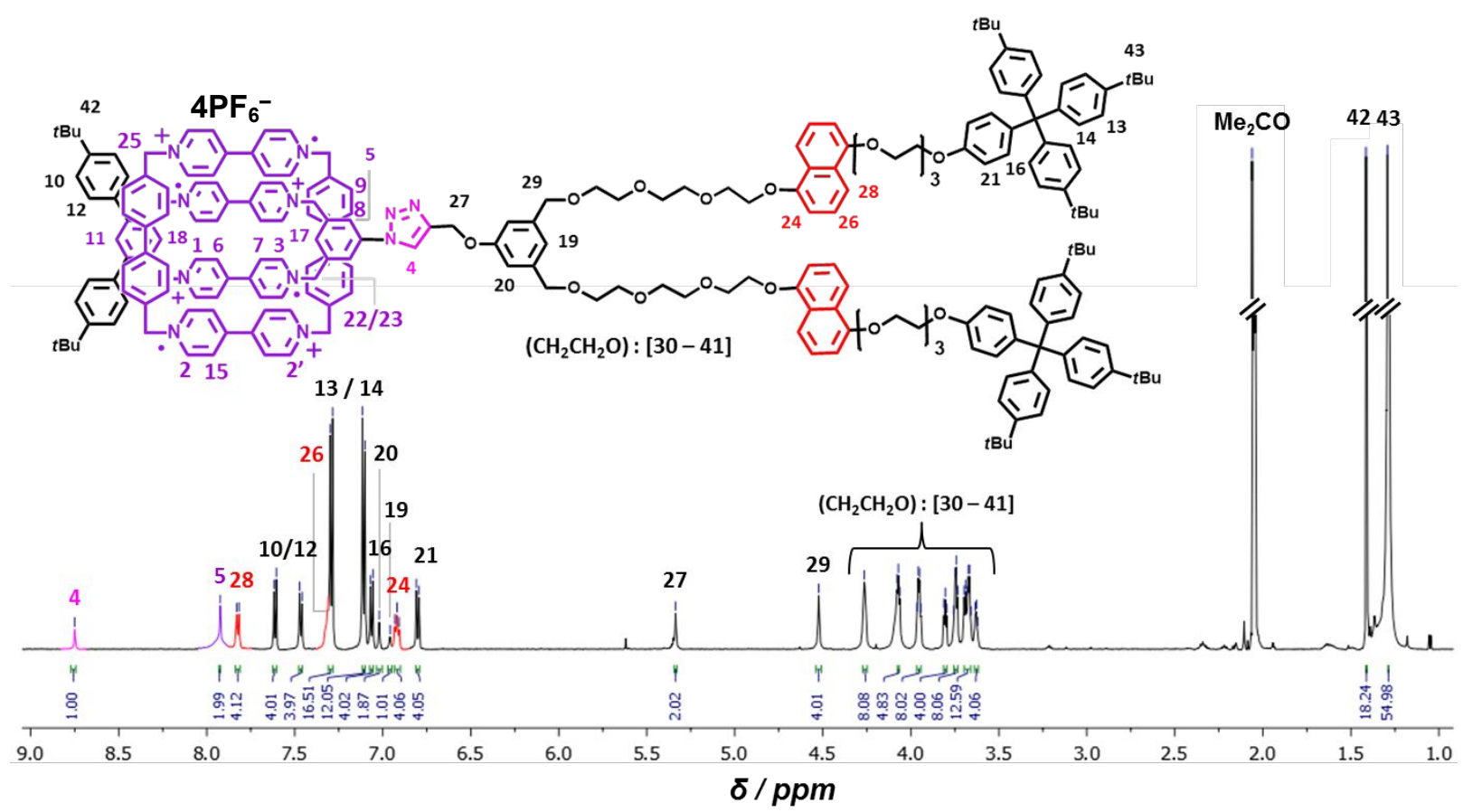

Figure S21. Full ${ }^{1} \mathrm{H}$ NMR spectrum of Zip-R $4 \mathrm{PF}_{6}$ in $\mathrm{CD}_{3} \mathrm{COCD}_{3}(2.2 \mathrm{mM})$ at $298 \mathrm{~K}(600 \mathrm{MHz})$

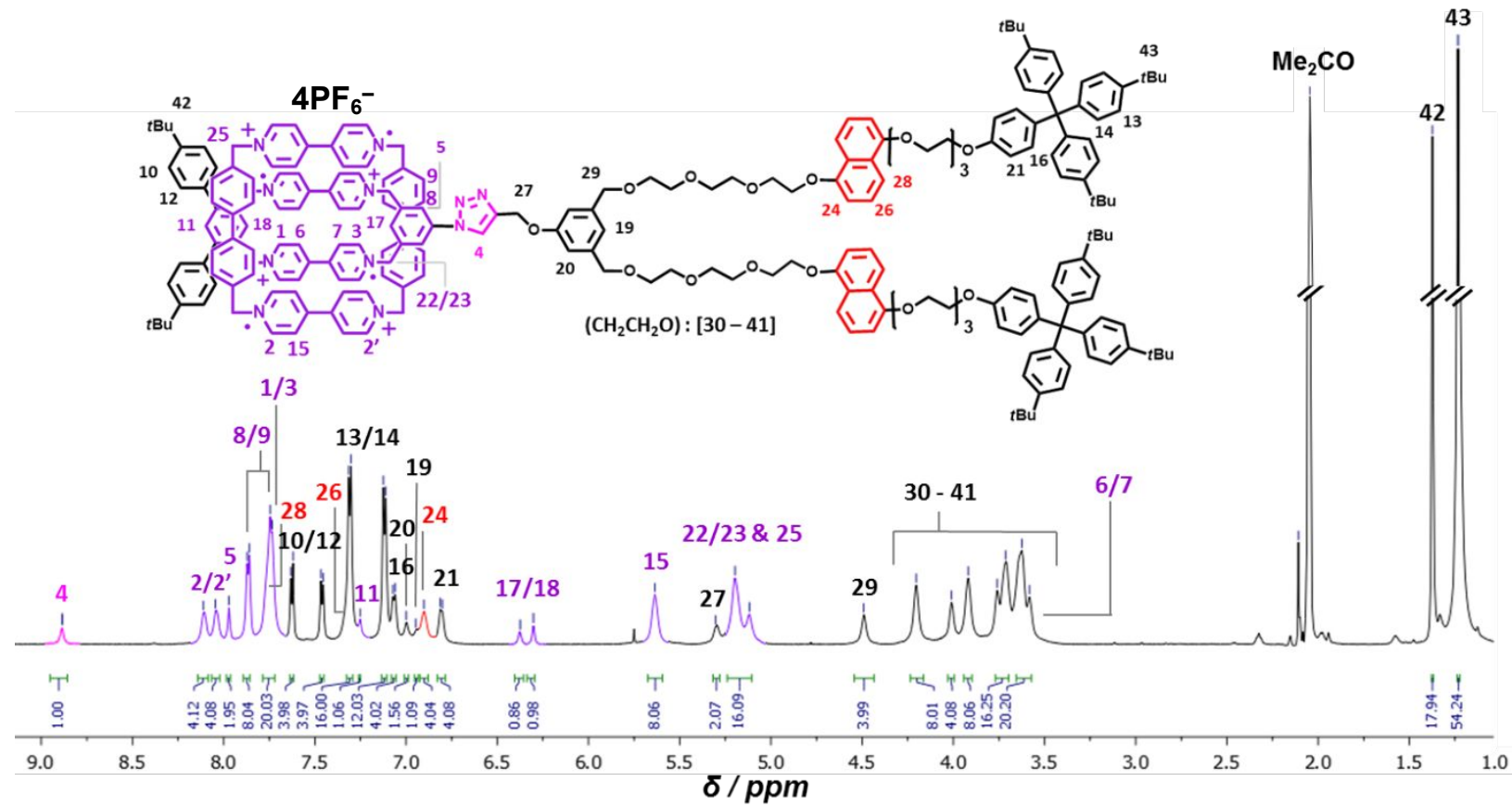

Figure S22. Full ${ }^{1} \mathrm{H}$ NMR spectrum of Zip-R $4 \mathrm{PF}_{6}$ in $\mathrm{CD}_{3} \mathrm{COCD}_{3}(2.2 \mathrm{mM})$ at $218 \mathrm{~K}(600 \mathrm{MHz})$ 


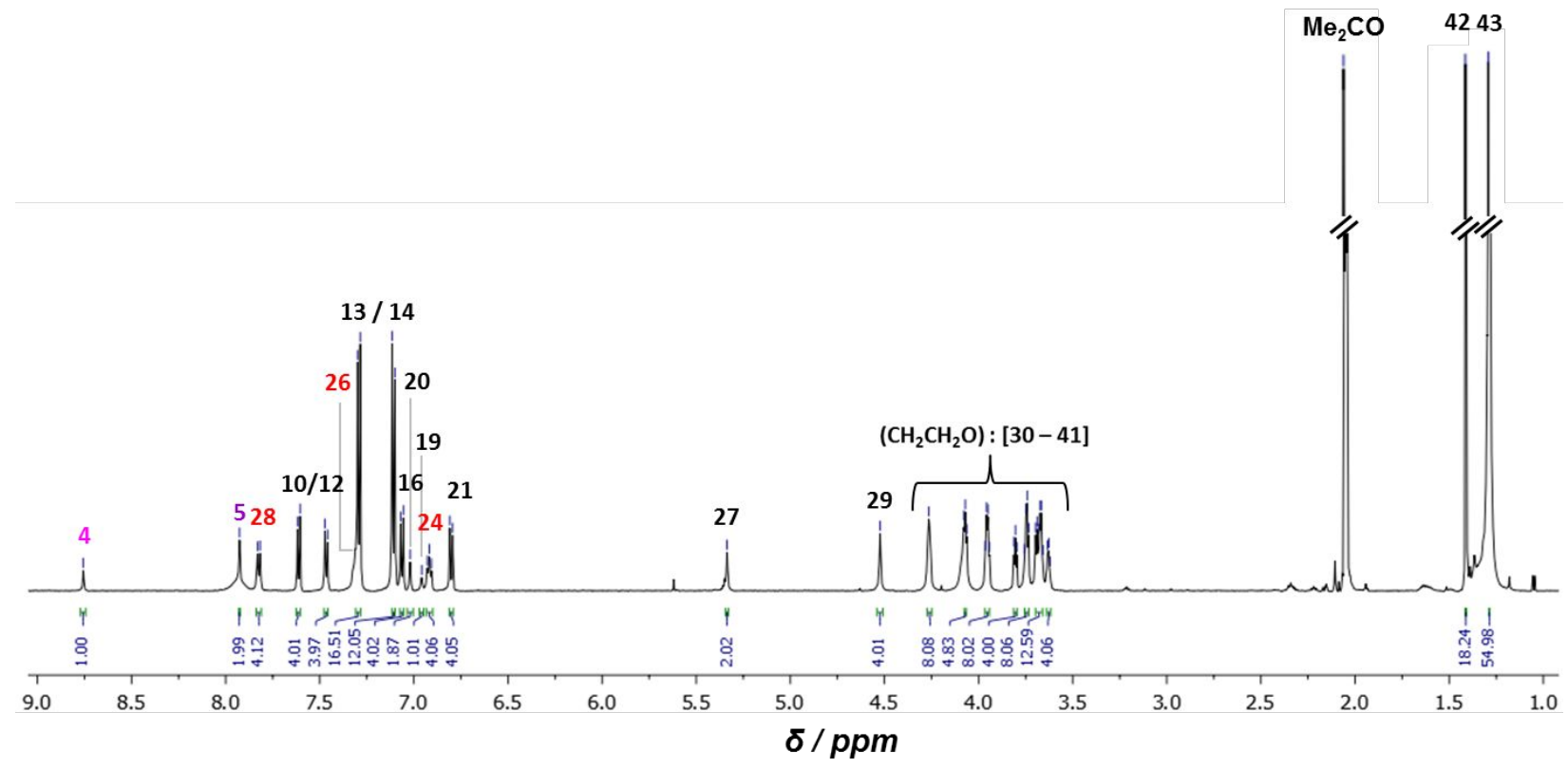

Figure S23. Full ${ }^{1} \mathrm{H}$ NMR spectrum of Zip-R $4 \mathrm{PF}_{6}$ in $\mathrm{CD}_{3} \mathrm{COCD}_{3}(2.2 \mathrm{mM})$ at $298 \mathrm{~K}(600 \mathrm{MHz})$ without color code on the ${ }^{1} \mathrm{H}$ NMR trace

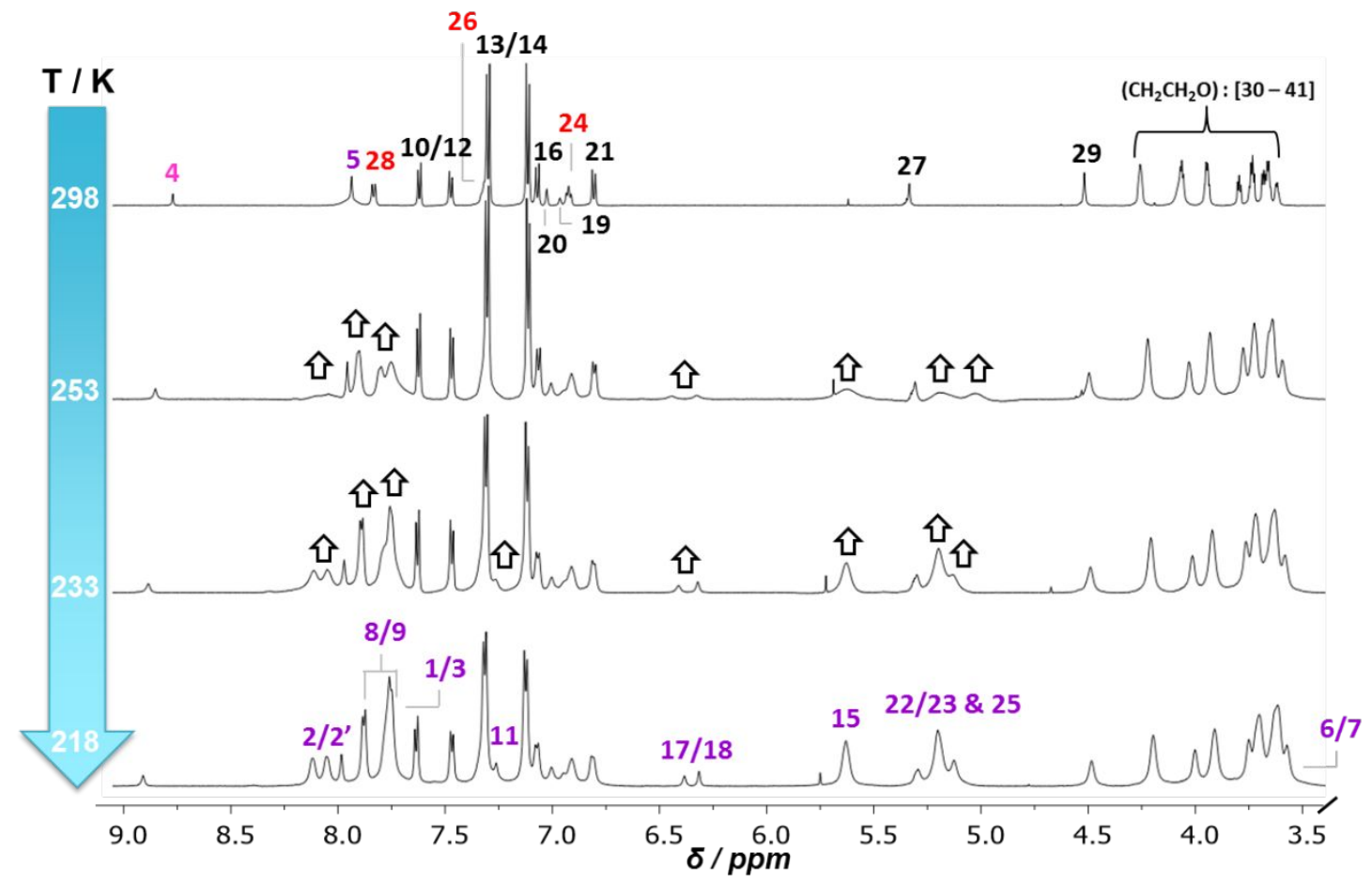

Figure S24. Variable temperature ${ }^{1} \mathrm{H}$ NMR spectra of Zip-R $4 \mathrm{PF}_{6}$ in $\mathrm{CD}_{3} \mathrm{COCD}_{3}(2.2 \mathrm{mM})$ recorded between $298-218 \mathrm{~K}(600 \mathrm{MHz})$ without color code on the ${ }^{1} \mathrm{H}$ NMR trace 


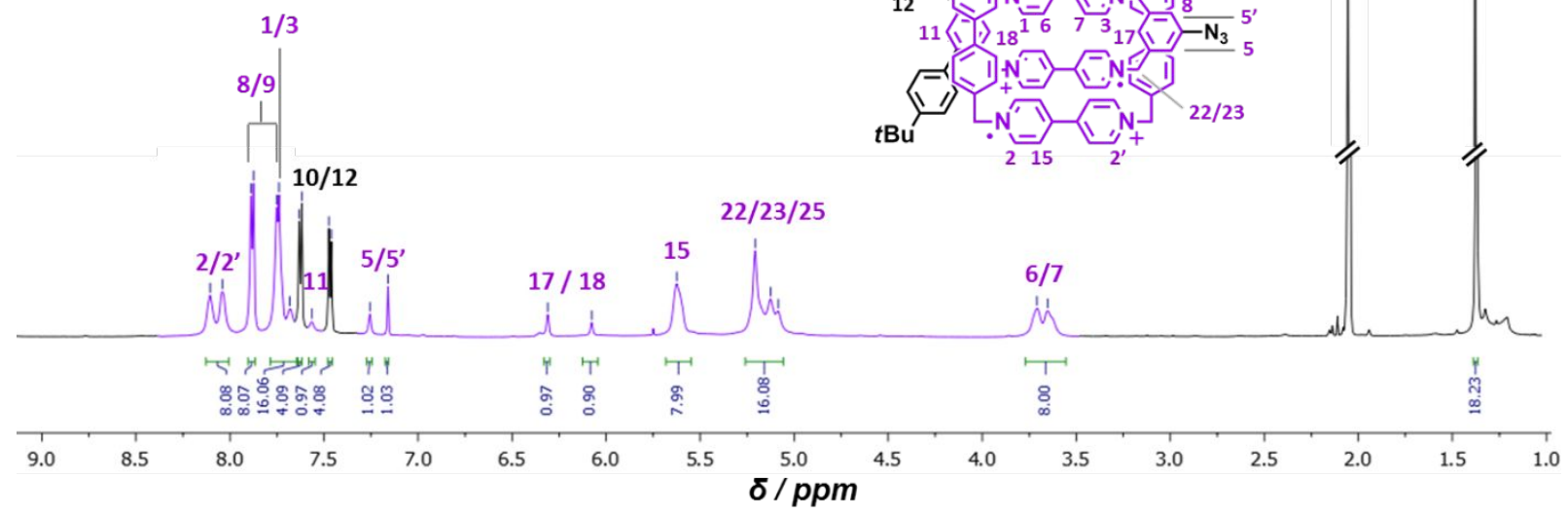

Figure S25. Full ${ }^{1} \mathrm{H}$ NMR spectrum of $\left[\boldsymbol{m}-\mathbf{N}_{\mathbf{3}}-\mathbf{A r}_{2}-\mathbf{C B P Q T} \subset \mathbf{M S}\right]^{\mathbf{4 ( + \bullet}}$ complex (1 equiv. $\boldsymbol{m}-\mathbf{N}_{\mathbf{3}^{-}}$ $\mathbf{A r}_{2}-\mathbf{C B P Q T} \cdot 4 \mathrm{PF}_{6}+1$ equiv. $\mathbf{M S} \cdot 4 \mathrm{PF}_{6}$ reduced using activated $\mathrm{Zn}$ dust $)$ in $\mathrm{CD}_{3} \mathrm{COCD}_{3}(5 \mathrm{mM})$ at $218 \mathrm{~K}(600 \mathrm{MHz})$

(a)

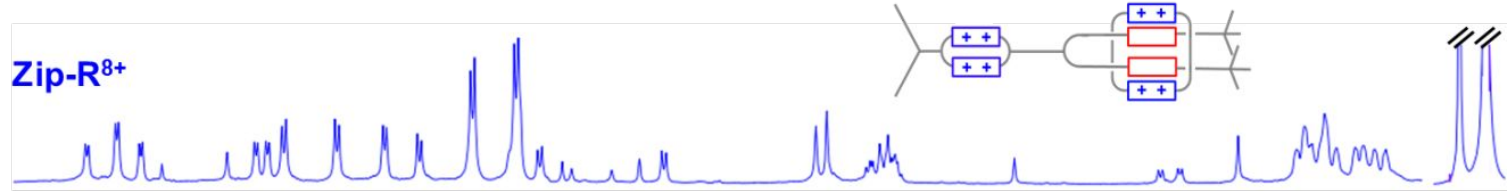

Zn dust / MeCN / $1 \mathrm{~h}$

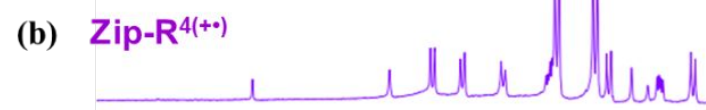

\section{$1 \mathrm{~h}$}

Air $/ \mathrm{NH}_{4} \mathrm{PF}_{6} / 16 \mathrm{~h}$

(c)

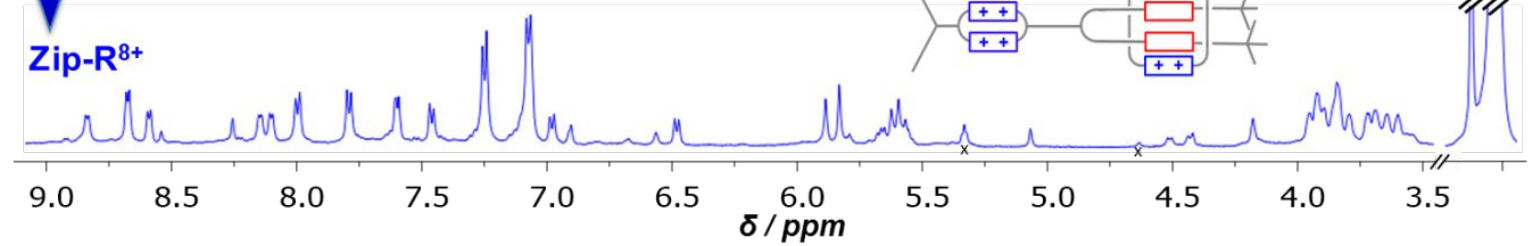

Figure S26. ${ }^{1} \mathrm{H}$ NMR Spectra $\left(\mathrm{CD}_{3} \mathrm{CN}, 298 \mathrm{~K}, 500 \mathrm{MHz}\right)$ of (a) Zip-R· $8 \mathrm{PF}_{6}(0.21 \mathrm{mM})$, (b) Zip$\mathbf{R} \cdot 4 \mathrm{PF}_{6}$ after reduction over $\mathrm{Zn}$ dust and (c) Zip- $\mathbf{R} \cdot 8 \mathrm{PF}_{6}$ after oxidation using air in presence of an excess of $\mathrm{NH}_{4} \mathrm{PF}_{6}$. Spectra (b) and (c) recorded without prior purification (x designate the resonances attributed to impurities). Partial spectra: $9.0-3.5 \mathrm{ppm}$ 


\section{Section G. Cyclic Voltammetry}

The glassy carbon working electrode was polished prior use with a figure-eight motion on a polishing pad in a water-alumina slurry. ${ }^{10}$ The $\mathrm{AgNO}_{3} / \mathrm{Ag}$ reference electrode was prepared using an $\mathrm{Ag}$ wire immersed in a solution of $\mathrm{Bu}_{4} \mathrm{NPF}_{6}(0.1 \mathrm{M})$ and $\mathrm{AgNO}_{3}(0.01 \mathrm{M})$ in $\mathrm{MeCN}$ that was separated from the solution by a porous glass frit. Samples for cyclic voltammetry were prepared using an electrolyte solution of $\operatorname{TBAPF}_{6}(0.1 \mathrm{M})$ in $\mathrm{MeCN}$ that was sparged with $\mathrm{N}_{2}$ to remove $\mathrm{O}_{2}$. The samples were kept under $\mathrm{N}_{2}$ atmosphere and ferrocene was added as an internal redox standard. Currents were normalized between different scan rates by dividing by the square root of the scan rate. Where noted, the background current of the electrochemical cell was recorded at the appropriate scan rate and potential window and then subtracted from the CVs. In these cases, the first cycle of the CVs is presented since the best correction for the background current was achieved for the first cycle at each scan rate. Simulation and fitting of the CV data was performed using $\mathrm{CH}$ Instruments chi630e software based on the mechanism presented in the Figure 6 of the main text but simplifying the electron transfer steps to $1 \mathrm{e}^{-}$rather than $2 \mathrm{e}^{-}$transfers between each oxidation state. 

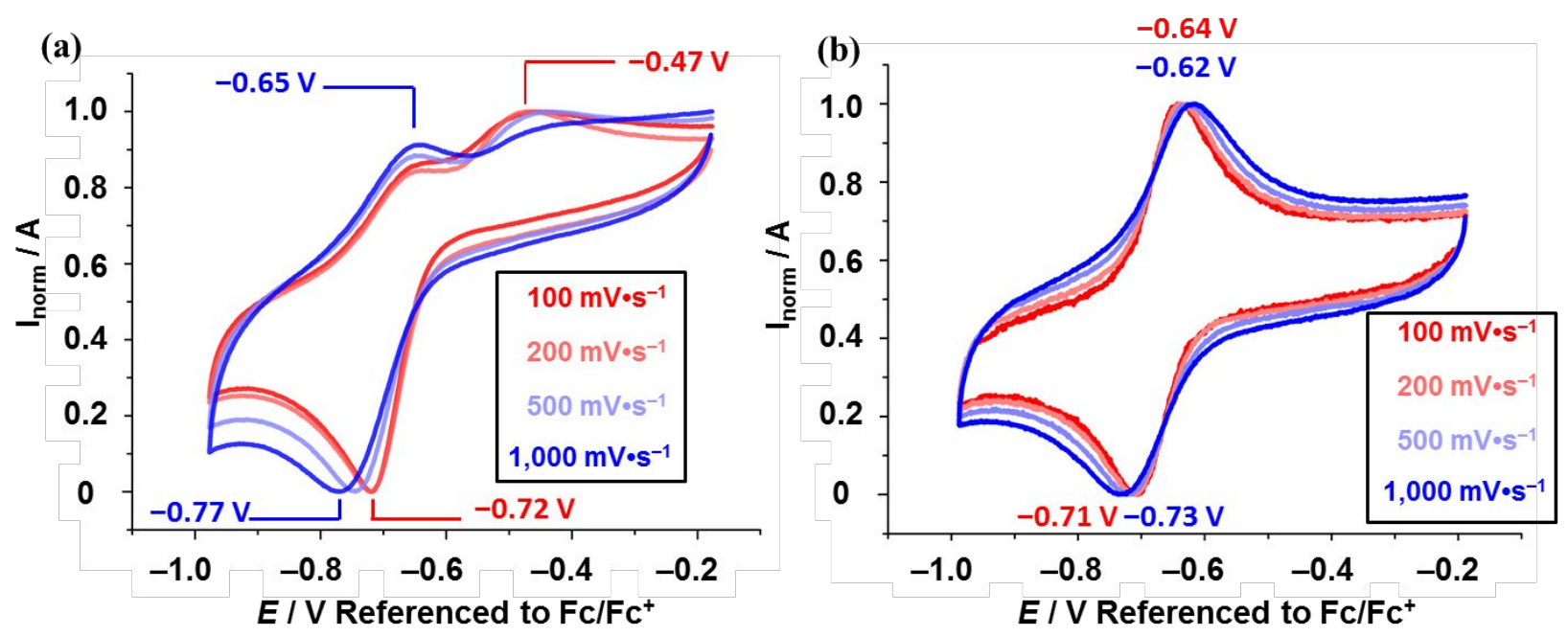

Figure S27. Superimposed CVs of a solution of (a) Zip-R· $8 \mathrm{PF}_{6}(0.13 \mathrm{mM})$ in $\mathrm{MeCN}$ and (b) DB· $4 \mathrm{PF}_{6}$ in $\mathrm{MeCN}(0.13 \mathrm{mM})$ measured at different scan rates: $100-1000 \mathrm{mV} / \mathrm{s}$. Measurements were recorded at $298 \mathrm{~K}$ and at a constant volume. $\mathrm{CVs}$ are referenced to the reversible $\mathrm{Fc} / \mathrm{Fc}^{+}$ couple. Potential window: -1.0 to $-0.2 \mathrm{~V}$
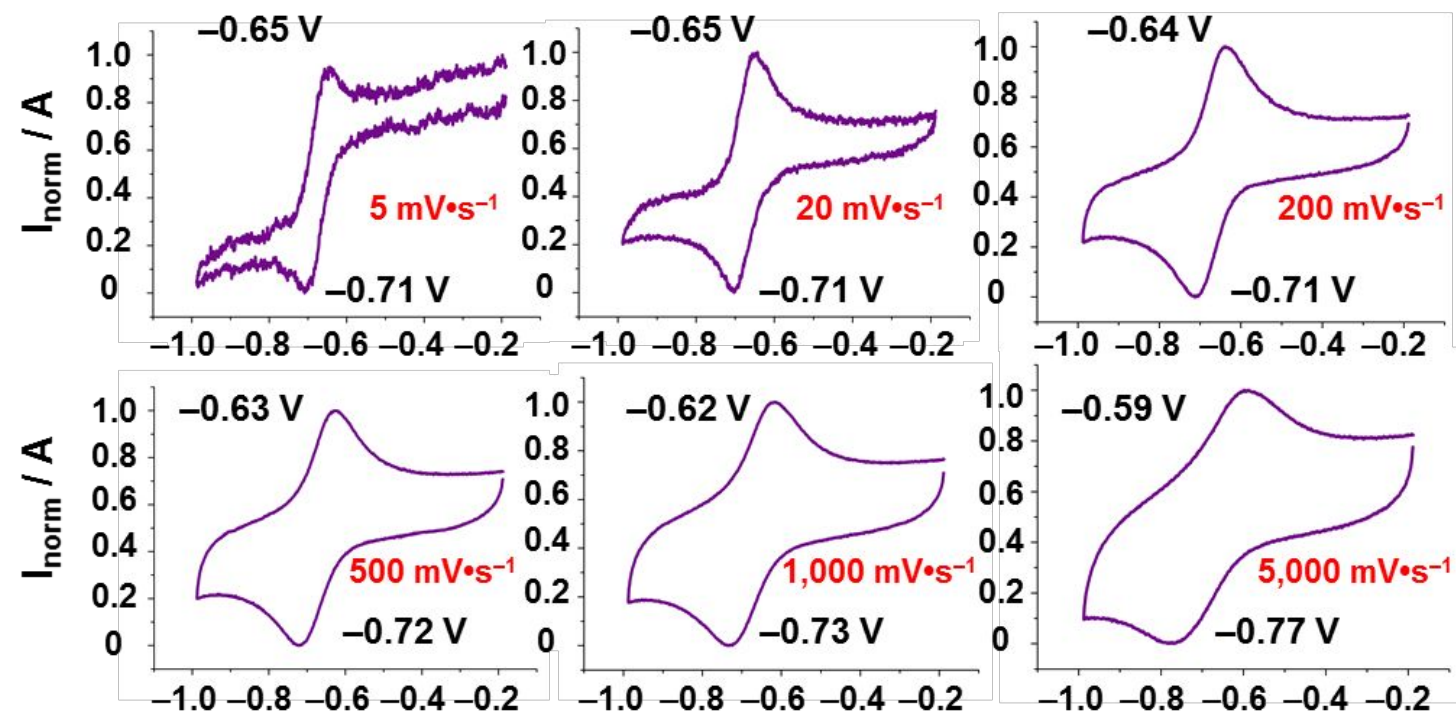

E / V Referenced to Fc/Fc ${ }^{+}$

Figure S28. CVs of a solution of $\mathbf{D B} \cdot 4 \mathrm{PF}_{6}(0.13 \mathrm{mM})$ measured at different scan rates: 5-5000 $\mathrm{mV} / \mathrm{s}$. Measurements were recorded at $298 \mathrm{~K}$ and at a constant volume. CVs are referenced to the reversible $\mathrm{Fc} / \mathrm{Fc}^{+}$couple. Potential window: -1.0 to $-0.2 \mathrm{~V}$ 


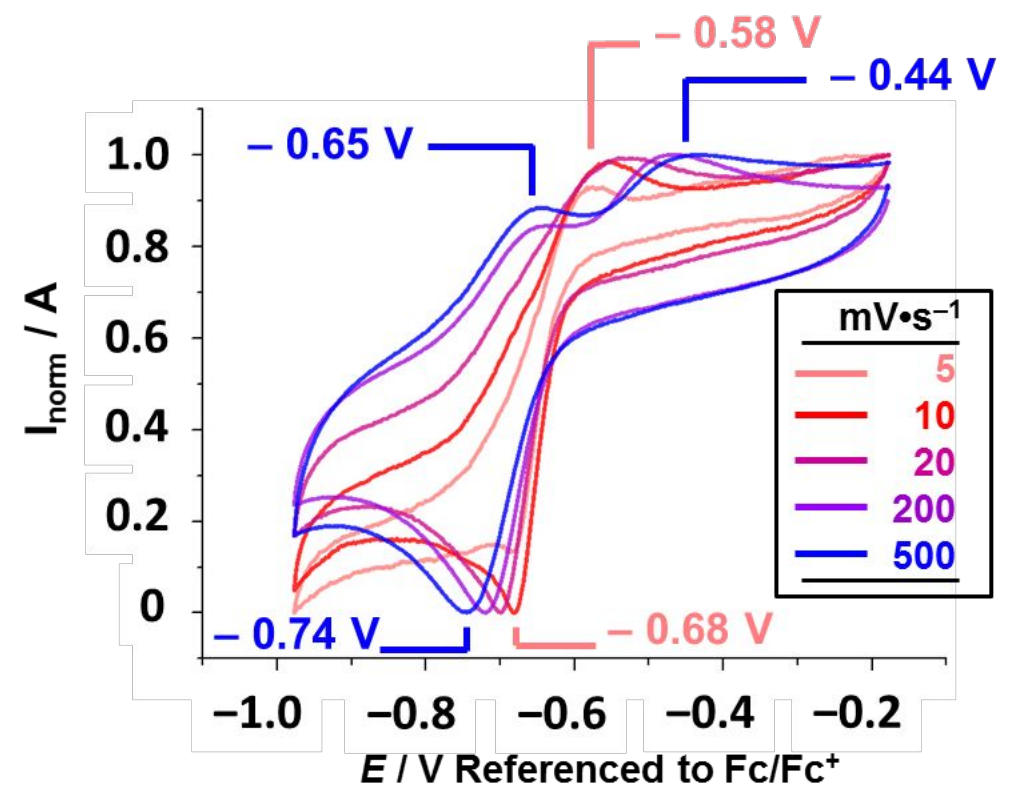

Figure S29. Superimposed CVs of a solution of $\mathbf{Z i p}-\mathbf{R} \cdot 8 \mathrm{PF}_{6}(0.13 \mathrm{mM})$ measured at different scan rates: 5-500 mV/s. Measurements were recorded at $298 \mathrm{~K}$ and at a constant volume. CVs are referenced to the reversible $\mathrm{Fc} / \mathrm{Fc}^{+}$couple. Potential window: -1.0 to $-0.2 \mathrm{~V}$

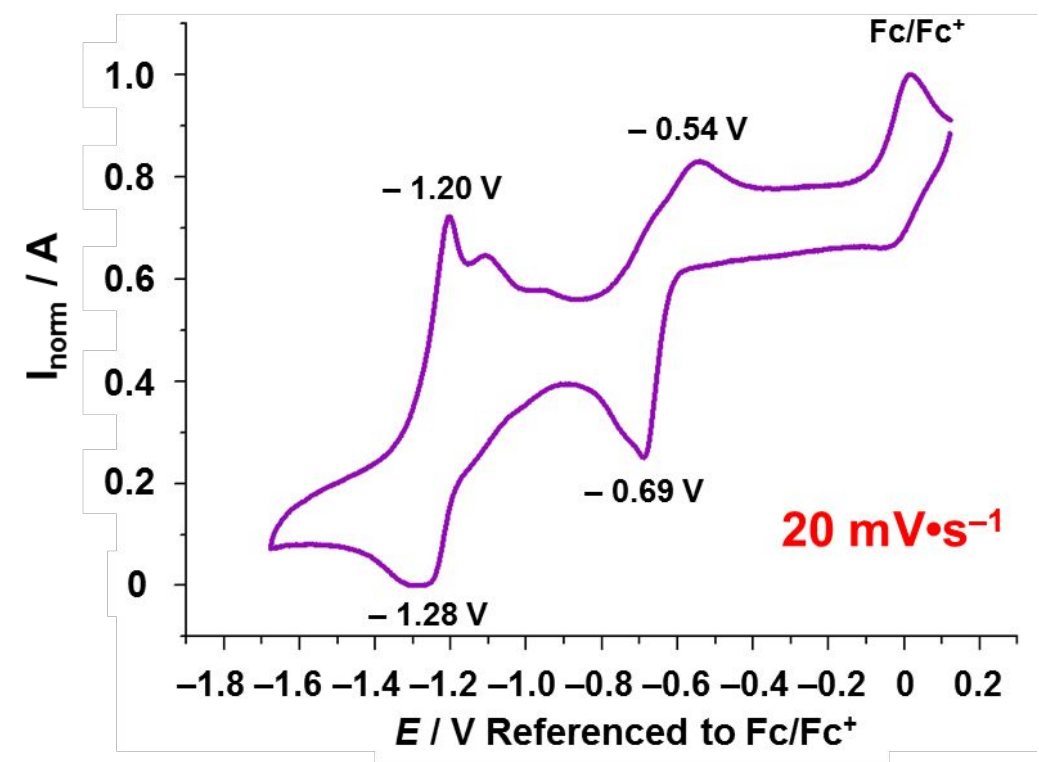

Figure S30. CV of a solution of Zip-R· $8 \mathrm{PF}_{6}$ in $\mathrm{MeCN}(0.13 \mathrm{mM})$ measured at a $20 \mathrm{mV} / \mathrm{s}$ scan rate ( $298 \mathrm{~K})$. CVs are referenced to the reversible $\mathrm{Fc} / \mathrm{Fc}^{+}$couple. Potential window: -1.7 to $0.2 \mathrm{~V}$ 


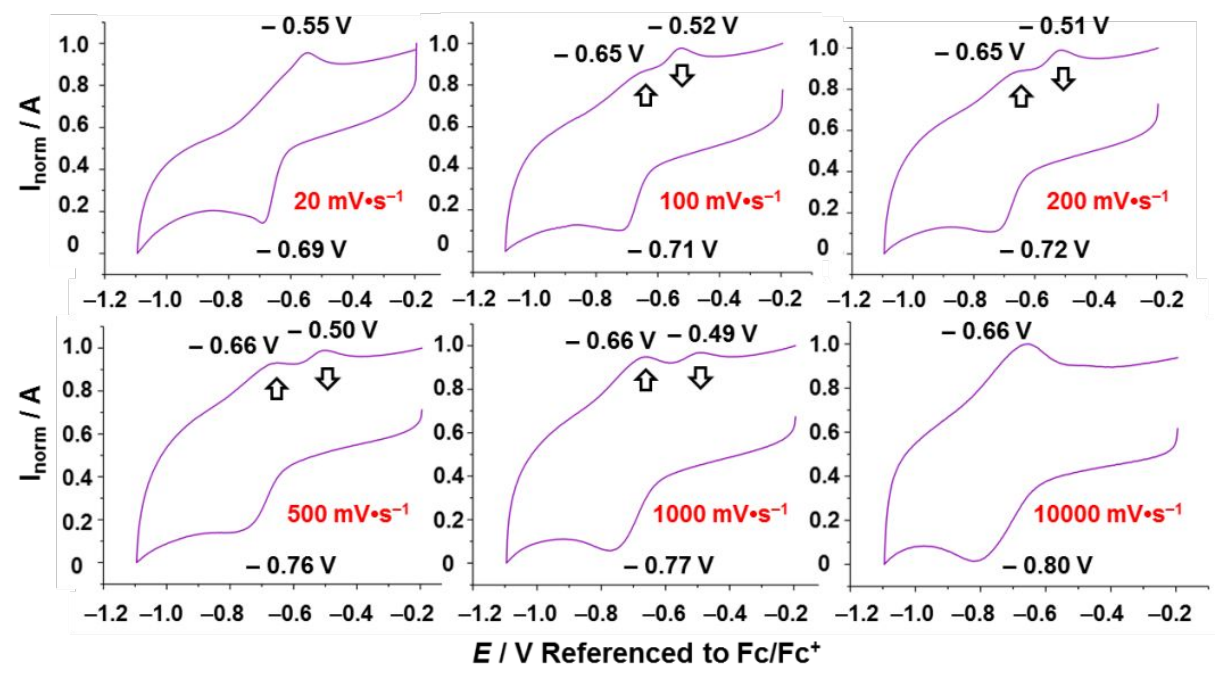

Figure S31. CVs (first cycle, without subtraction of background current) of a solution of Zip$\mathbf{R} \cdot 8 \mathrm{PF}_{6}$ in $\mathrm{MeCN}(0.05 \mathrm{mM})$ measured at different scan rates: $20-10,000 \mathrm{mV} / \mathrm{s}$. Measurements were recorded at $298 \mathrm{~K}$ and at a constant volume. $\mathrm{CVs}$ are referenced to the reversible $\mathrm{Fc} / \mathrm{Fc}^{+}$ couple. Potential window: -1.1 to $-0.2 \mathrm{~V}$
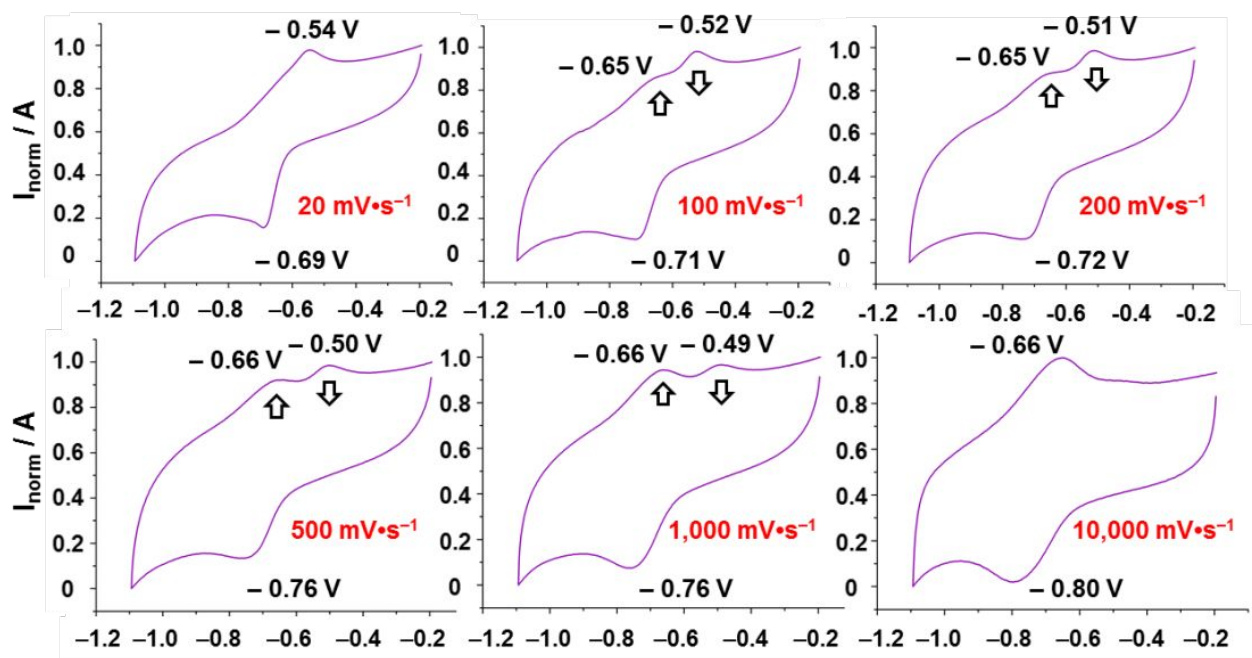

E / V Referenced to Fc/Fc ${ }^{+}$

Figure S32. CVs (second cycle, without subtraction of background current) of a solution of Zip$\mathbf{R} \cdot 8 \mathrm{PF}_{6}$ in $\mathrm{MeCN}(0.05 \mathrm{mM})$ measured at different scan rates: $20-10,000 \mathrm{mV} / \mathrm{s}$. Measurements were recorded at $298 \mathrm{~K}$ and at a constant volume. $\mathrm{CVs}$ are referenced to the reversible $\mathrm{Fc} / \mathrm{Fc}^{+}$ couple. Potential window: -1.1 to $-0.2 \mathrm{~V}$ 


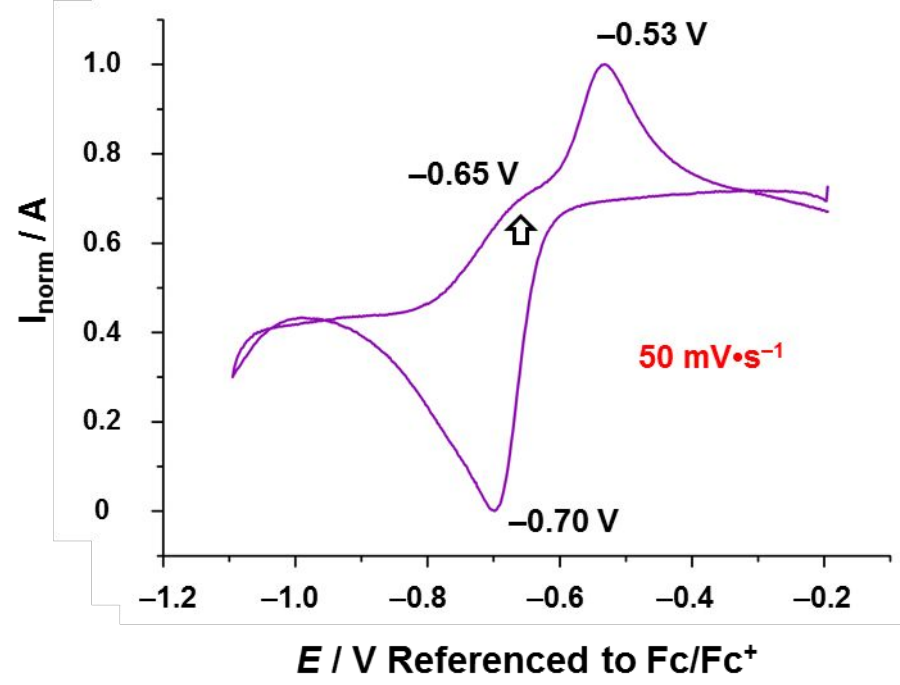

Figure S33. CV (first cycle, with background current subtracted) of a solution of Zip-R $8 \mathrm{PF}_{6}$ in $\mathrm{MeCN}(0.05 \mathrm{mM})$ measured at a scan rate of $50 \mathrm{mV} / \mathrm{s}$. Measurement were recorded at $298 \mathrm{~K}$. CVs are referenced to the reversible $\mathrm{Fc} / \mathrm{Fc}^{+}$couple. Potential window: -1.1 to $-0.2 \mathrm{~V}$

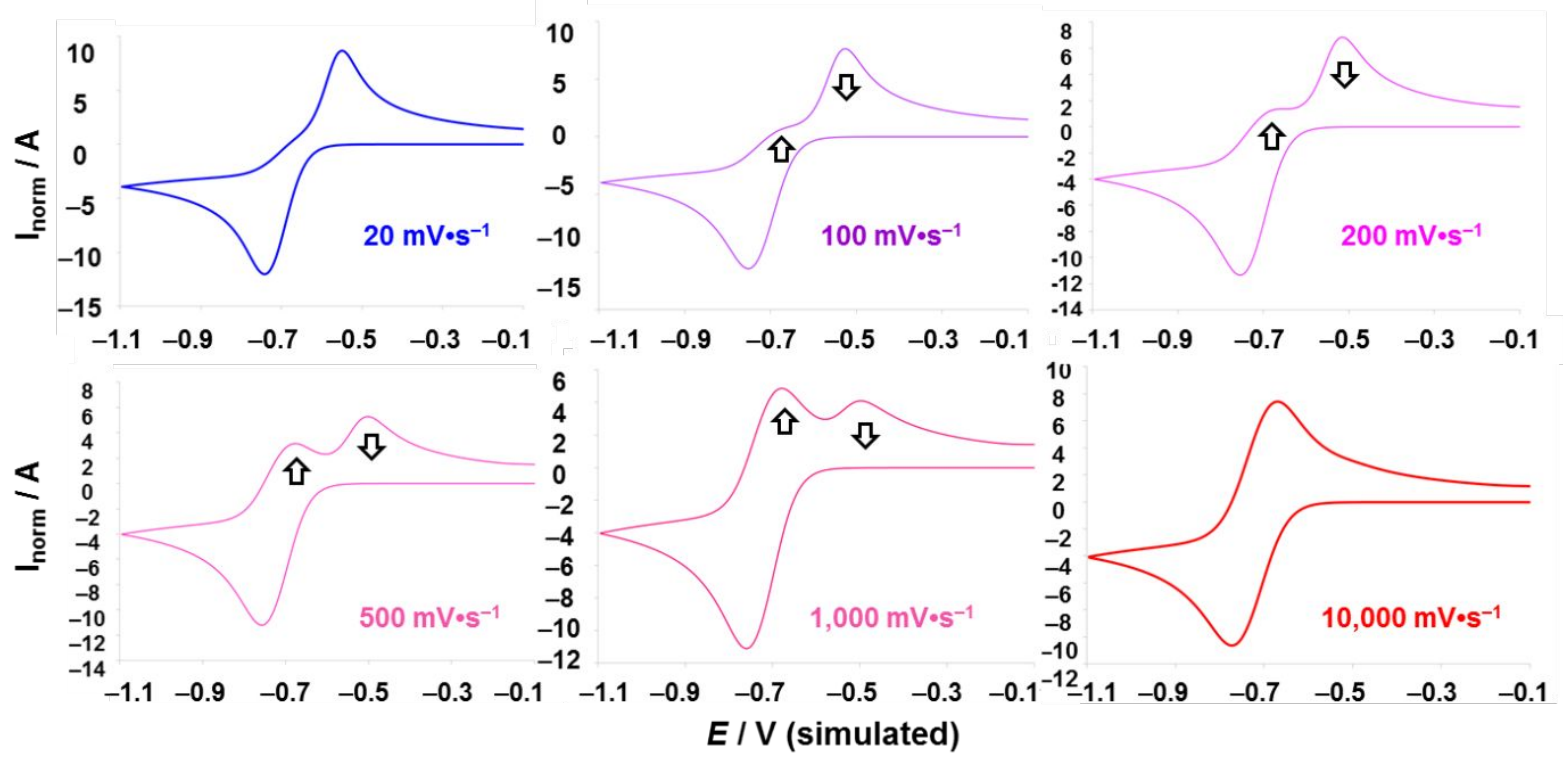

Figure S34. Simulated CVs at different scan rates: $20-10,000 \mathrm{mV} / \mathrm{s}$. Kinetic parameters used for these simulations: $k_{1}=1.2 \mathrm{~s}^{-1}, k_{-1}=0.008 \mathrm{~s}^{-1}, k_{2}=0.825 \mathrm{~s}^{-1}, k_{-2}=35 \mathrm{~s}^{-1}, k_{3}=1.7 \times 10^{-10} \mathrm{~s}^{-1}$, $k_{-3}=100 \mathrm{~s}^{-1}$ 


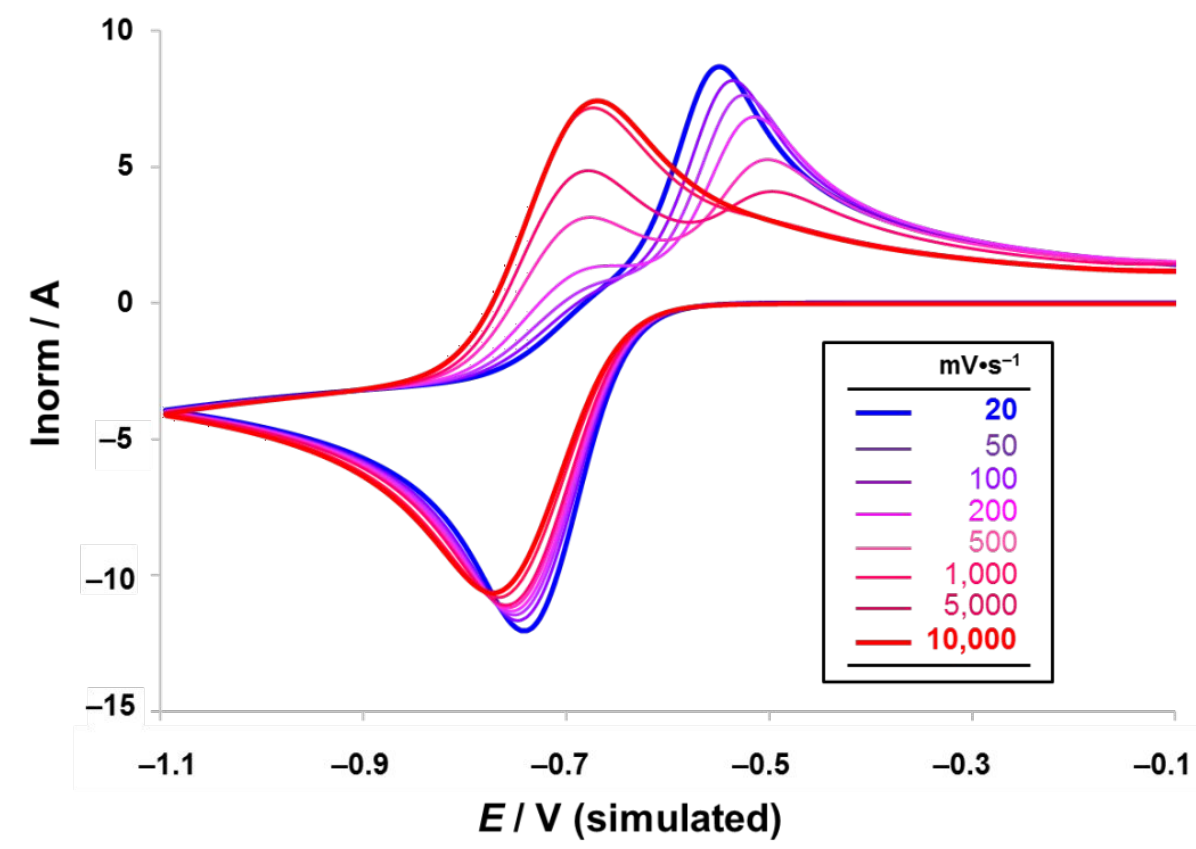

Figure S35. Overlaid simulations from Figure 35

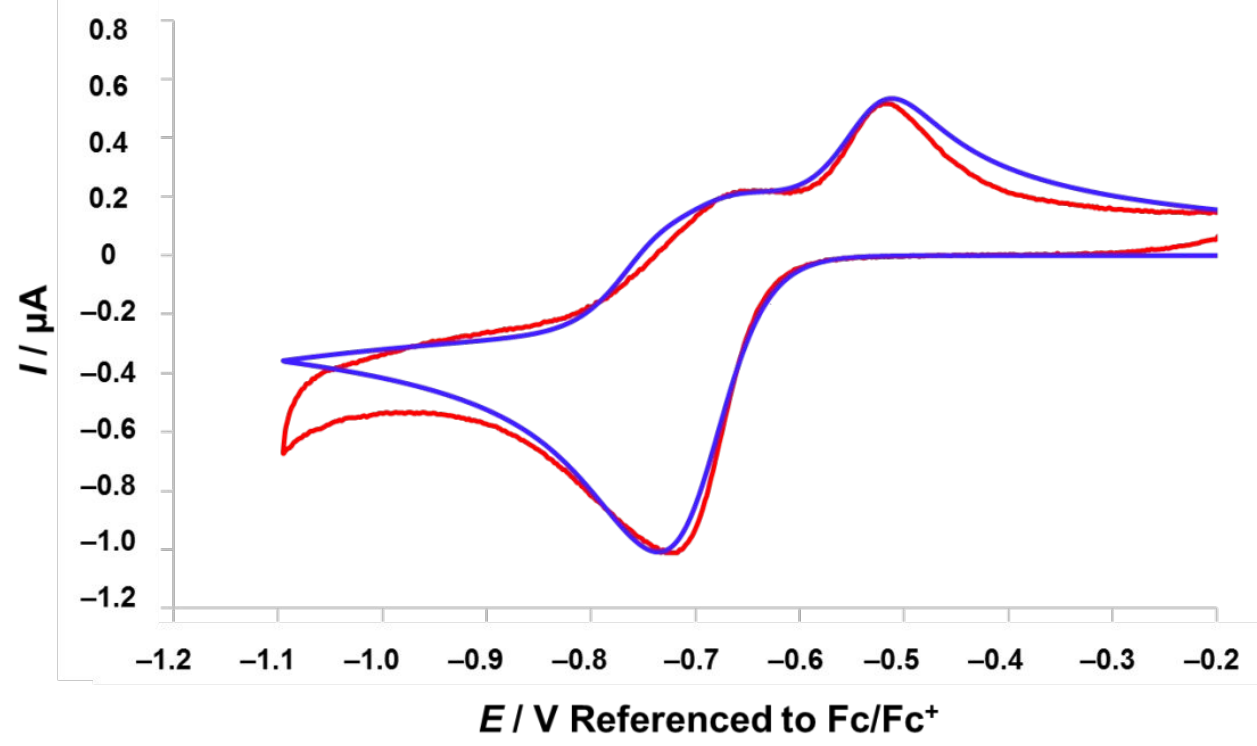

Figure S36. Computational fitting (blue trace) of the $\mathrm{CV}$ (red trace) of Zip-R $\cdot 8 \mathrm{PF}_{6}$ in $\mathrm{MeCN}(0.05$ $\mathrm{mM}$ ) recorded at $200 \mathrm{mV} / \mathrm{s}$ in the potential range -1.1 to $-0.2 \mathrm{~V}$ (background subtracted). The rate constants: $k_{1}=0.228 \mathrm{~s}^{-1}, k_{-1}=9.75 \times 10^{-5} \mathrm{~s}^{-1}, k_{2}=8.181 \mathrm{~s}^{-1}$, and $k_{-2}=22.597 \mathrm{~s}^{-1}$ were determined with a Fit Error of 0.0505 . 


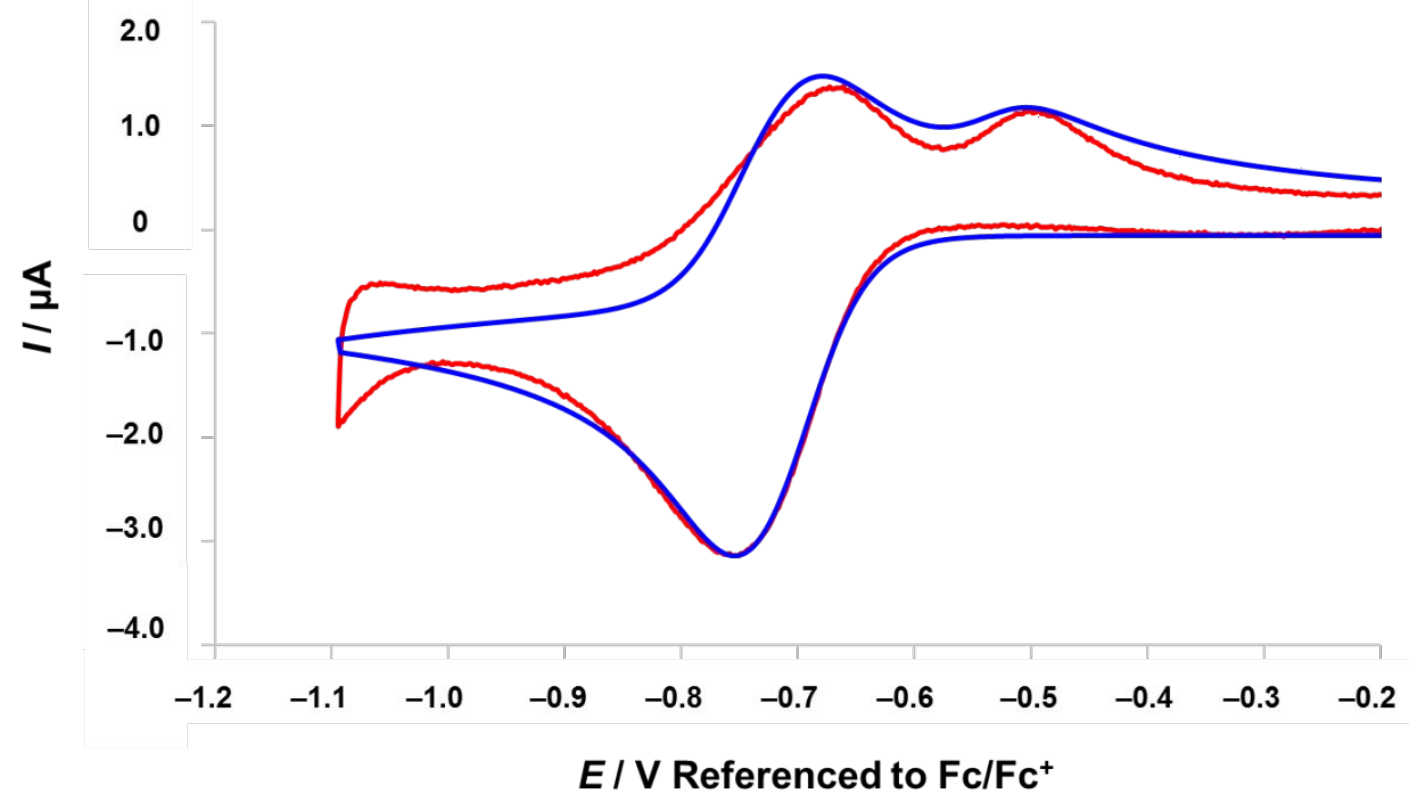

Figure S37. Computational fitting (blue trace) of the CV (red trace) of Zip-R $8 \mathrm{PF}_{6}$ in $\mathrm{MeCN}(0.05$ $\mathrm{mM}$ ) recorded at $1,000 \mathrm{mV} / \mathrm{s}$ in the potential range -1.1 to $-0.2 \mathrm{~V}$ (background subtracted). The rate constants $k_{1}=0.563 \mathrm{~s}^{-1}, k_{-1}=4.55 \times 10^{-4} \mathrm{~s}^{-1}, k_{2}=6.936 \mathrm{~s}^{-1}$, and $k_{-2}=35.6 \mathrm{~s}^{-1}$ were determined with a Fit Error of 0.0356.

\section{Section H. References}

(1) Asakawa, M.; Ashton, P. R.; Menzer, S.; Raymo, F. M.; Stoddart, J. F.; White, A. J. P.; Williams, D. J., Cyclobis(Paraquat-4,4'-Biphenylene) - An Organic Molecular Square. Chem. Eur. J. 1996, 2, 877-893.

(2) Shi, Y.; Suguri, T.; Dohi, C.; Yamada, H.; Kojima, S.; Yamamoto, Y., Highly Active Catalysts for the Transfer Dehydrogenation of Alkanes: Synthesis and Application of Novel 7-6-7 RingBased Pincer Iridium Complexes. Chem. Eur. J. 2013, 19, 10672-10689. 
(3) Lipke, M. C.; Wu, Y.; Roy, I.; Wang, Y.; Wasielewski, M. R.; Stoddart, J. F., Shuttling Rates, Electronic States, and Hysteresis in a Ring-in-Ring Rotaxane. ACS Cent. Sci. 2018, 4, 362-371.

(4) Ashton, P. R.; Ballardini, R.; Balzani, V.; Bělohradský, M.; Gandolfi, M. T.; Philp, D.; Prodi, L.; Raymo, F. M.; Reddington, M. V.; Spencer, N.; Stoddart, J. F.; Venturi, M.; Williams, D., SelfAssembly, Spectroscopic, and Electrochemical Properties of [n]Rotaxanes. J. Am. Chem. Soc. 1996, 118, 4931-4951.

(5) He, C.; Li, L.-W.; He, W.-D.; Jiang, W.-X.; Wu, C., "Click” Long Seesaw-Type A B A Chains Together into Huge Defect-Free Hyperbranched Polymer Chains with Uniform Subchains. Macromolecules 2011, 44, 6233-6236.

(6) Dolomanov, O. V.; Bourhis, L. J.; Gildea, R. J.; Howard, J. A. K.; Puschmann, H., OLEX2: A Complete Structure Solution, Refinement and Analysis Program. J. Appl. Crystallogr. 2009, 42, $339-341$.

(7) Sheldrick, G., SHELXT - Integrated Space-Group and Crystal-Structure Determination. Acta Crystallogr. 2015, Sect. A 71, 3-8.

(8) Sheldrick, G., A Short History of SHELX. Acta Crystallogr. 2008, Sect. A 64, 112-122.

(9) Thorn, A.; Dittrich, B.; Sheldrick, G. M., Enhanced Rigid-Bond Restraints. Acta Crystallogr. 2012, Sect. A $68,448-451$.

(10) Elgrishi, N., Rountree, K.J., McCarthy, B.D., Rountree, E.S., Eisenhart, T.T., Dempsey, J.L., A Practical Beginner's Guide to Cyclic Voltammetry. J. Chem. Educ. 2018, 95, 197-206. 